\title{
AN INVESTIGATION OF THE RIMES AND PHONOLOGY OF THE MIDDLE-SCOTCH ROMANCE CLARIODUS. (Part II.)
}

(For Part I see Anglia, vol. XVI.)

Angl. $\overline{\mathbf{e}}=$ WS $\overline{\mathbf{a}}$, WGme. $\overline{\mathbf{a}}$,

\$ 212. rimes with - a) itself. weid : dreid 2.1498. deid : dreid 3.834 (\&c.) : meid 4.1086. - b) 0E. $\bar{x}$, mut. of $\overline{\mathbf{a}}$. see $\$ 226$ (b). c) $0 \mathrm{E}$. $\overline{\mathrm{ea}}$. feare : eare 1.1370. evine (for eve, OE. äfen, éfen) : leane, sb. 3.102. - d) OE. $\bar{e}$, mut. of $\overline{0}$. see $\$ 155(\mathrm{~h}) .-$ e) OE. $\overline{\mathbf{e o}}$. $\alpha$ ) sleip : diep (for deip) 3.1870. weine, vb. (wēēnan, veènan) : betwine 3.182. weid : zeid 1.1094. meid : zeid 1.1418. $\beta$ ) adreid : fled 3. 1126. - f) OE. e : adred(e) : wed (inf.) 2.622, 3.1874 : wade (for wed) 4.1896. adreid : bed 1. 1068 : wade (for wed) 4.1872. wate (w(êt) : set 5.2338. - g) OE. æ. adred : had, prt. 3.1456. - h) Fr. or Lat. e. dreid : proceid 4. 1900 : poseid 2. 702. streit : repeit 5. 2910, streits (for streit) : repleit 5. 2786. reid $(r \bar{c} \bar{d})$ : remeid $3.752 . \quad$ - i) Fr. a. blast (blōest) : past. ptc. 4.1762. wat (wöt) : plait (Fr. plate) 2. 44.

$\S 213$. This vowel belongs to t. Br.'s Class $\beta$. We have $\beta: \beta$ rimes in (a) and (b), $\beta: \gamma$ rimes in (d), (e) and (h), and $\beta: \alpha$ rimes in (c). When

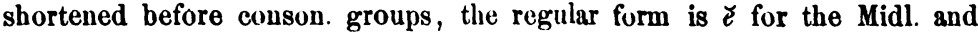
N., and $\breve{a}$ for the SW., ef. Sweet $\$ 675$, t. Br. p. 40 ; we have examples of $\breve{e}$ in (b), (e) adreid : fled, and (g); (the spelling with ei in adreid is false, as is shown by the alteruate spelling with $e$ and corroborated by the rimes in (f)). The reason of the difference is that in the SW. the shortening took place before $\bar{x}$ had becume ME. $\bar{l}$, i. e. $\bar{a}$ became $\bar{a}$, which was developed further like any other $\breve{e}$, while in the Midl. and N. the OE.

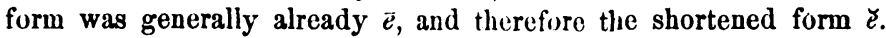

We must assume that shortening took place after OE. $\overline{\boldsymbol{\varepsilon}}$ had become $\vec{c}$ in the case of general OE. $\bar{u}(\bar{\beta} .2)$ and also in those cases where an $\bar{c}$ instead of $\breve{a}$ appears for $\beta .1$. in the S. W., anless we are to explain from the influence of outside diall. For Clar., $e$ must have been the gennine form of the shortened vowel, and the rime in (g) withe $\breve{a}$, if $\breve{a}$ is really meant, is evidence of the mixed dialect of the author; cf. $\S 91$. The other rimes show that adreid is also used by the author with a long vowel; it is another word with an unfixed pronunc.

$\S 214$. The mod. Sc. diall. show a long $i$ for the MSc. unshortened form in most words of this class, the pronunc. generally being uniform throughout, (with the exception that it is sometimes shortened to $Y$ in

Auglia. N. F. V. 
those diall. which are addicted to late shortening; this is especially the case in the more northern diall.); so we find $t$ in read, cheese, speech, deed, needle, sheep, sleep, which are nowhere found with $e$, and even in thread, which in rec. sp. has an $e$-vowel. Forms are found with an $e$-vowel only in bleat, (D. 39), meal (39) (but in other diall. only an $i$-vowel) and breath (in all diall. just as in rec. sp., except that in Sc. it is sometimes long).

The shortened vowel before conson. groups is $\breve{\zeta}$, not $\breve{a}$, (except in the word wat, = wet, see $\S 216$ ), e.g. in read, prt., Ellis gives (ræd) once in 33 , and (rid) in 42 , but otherwise only (red).

$\$ 215$. blast, see (i). This word generally appears only in this form in the N.; bat in Dougl. we have blist : trist, 2. 87. 9, i. e. a short $Z$, which

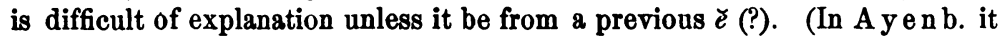
appears with $e$, the regular development of $\bar{x}$ in $\mathrm{Kt}$. and Angl.). The form with $a$ might be considered to be a south-western form which had asserted itself in other diall.; bat this seems an unlikely explanation for the extreme $\mathbf{N}$.; perhaps it wonld be better to connect with $0 \mathrm{~N}$. blästr or the corresponding vb. blāsa, to blow; this seems better than Sweet's suggestion, HoES. \$675, since we should expect, if the verb blawwen influenced the form of the noun, to find blōst, as soon as blawwen became blōwen. But it is not eren necessary to go to Old Norse, for, just as in OE. there was a form mäst in the $\mathrm{N}$. by the side of māest, (cf. Sievers, $\S 312$, note 1), so there seems to have been a form blast, as well as blōst, at any rate we find it in composition, cf. B.-T., where the two forms blopst-belg and blastbelg (= bellows) are given. None of these explanations, however, remove all difficulties; for why did not blast, if this was the early form, develop itself like the exactly similar word mast and produce in mod. rec. sp. blöst and in Sc. blëst? We must either assume that OE. blöst first shortened its $\bar{a}$ to $\breve{a}$, and that then this $\breve{c}$ was later lengthened after becoming ME. $\breve{a}$, just as fast became ME. făst and NE. fäst, or else perhaps in the N., bläst $>$ ME. blăst $>$ NE. bläst. Although "long vowels are generally kept before st" (Sweet $\S 397$ ), e. g. gāst, māst, \&c., yet this rule is not absolute (see Kluge, PG. 1.869), for there was often shortening before st in the 12 th cent. Morsb., p. 20, says this was rare; his citation of mod. Engl. as a proof of this is unsatisfactory, for in many words the long vowel before st is certainly of purely modern growth. In this case the shortening may perhaps have been assisted by the co-existent word bläst (of different meaning, = flame, blöst $=$ a blowing), or it may be simply a case of confusion of the two words, bläst eventually ousting bli st; but this assumption is by no means necessary. In any case we must probably assume the form blčst at some stage or other, for most of the words containing $\bar{a}+8$ in rec. sp. are derived from OE. forms containing $a+8$ e. g. fast, mast, hasp, grass, glass, ghastly, $=0 \mathrm{E}$. faest, maest, haespe, graes, glaes, gaestlic. Moreover the orthography with $a$, not $a i$, in MSc. (cf. maist with a long ai) as well as the rime in (i), point to shortness of vowel.

There are other cases both of $\bar{a}$ and $\bar{a}$ producing NE. $\bar{a}$ before $s$, e. g. ask (= āscian), last (= OE. kist, last, for shoe), last, vb. (= lästan); all of them probably contained $\dot{c}$ at some stage or other of their deve- 
lopment; in fact, $\breve{a}$ can still be heard in some of the mod. diall., and is especially characteristic of the N. ME. had mostly ăsken, not äsken, (Kluge PG. 1. 876); this would be an exactly similar case to bläst $>$ blăst $>$ bläst, unless we have to explain through the form acsian $>$ ăcsen $>$ ăsken $>$ æ̌sk or āsk. In Chauc. we have lăsten for lästan, and yet the later language has läst (t. Br. $\S 16$. $\beta$ ).

Cf. Fick, Engl. Stad. 8. 503.

$\S 216$. weite $=$ wet. This word appears in Clar. in no less than three forms; it rimes with $0 \mathrm{E} . \check{e}, \breve{e}$ and Fr. $a$. It is also spelt in different ways in the MS. weite, wate, and wat. The usual ME. form is wet, the $\bar{e}$, of course, being closed in the nun-Westsaxon districts, hence such rimes as weite : sweit in $\$ 212$ (d). The shortened form of this $\bar{e}$, that is $\bar{e}$, which was quite regular in the compar., was afterwards transferred to the positive and hence the form $w e t$ in rec. sp. and the rime wate : set, $\$ 212$ (f); the $a$ in wate is due to the scribe, and must be altered to $e$, wet : set. The $a$ form is especially Scotch, ef. Satir. P., watt : that 48.39; as we have already seen, there was a tendency in Sc. diall. to change we into $w a$, a tendency which is reflected in the mod. diall.; wat appears in almost all of them; wit, the regular development of ME. wet, appears in D. 20, 21, 22 and 30, 32, i. e. North Midl. and Northern English, but not in Scotch, although wrt is found in D. 33, 38, 39, 40, and 42 . wat seems to be the real Scotch form, it is found in $33,34,35,36,38$ and 39 ; and one of the scribes was evidently accustomed to this form, for he writes $a$ where the rime certainly proves an $\breve{E}$; similarly in other words, e.g. wade (= wed) : adred, see above (f) (still it is possible that this means wad : adrad; cf. $\$ 91$ ). It is noticeable that wet is not found at all in the mod. Sc. diall.; it is therefore all the easier to understand why a Sc. scribe changed wet into wat; the anthor had evidently allowed himself an Anglicism in writing and riming wet. But another explanation of the $a$ in wat is possible; for in (i) we find it riming with an undoubted long $\bar{a}$, in plait; (the orthography wate. with final $e$, proves nothing alone; it might mean wat or $w \bar{a} t)$. We have similar rimes elsewhere, e.g. Dunb. wait : state : lait : debait, 72.133, where the spelling, ai, proves an $\vec{e}<a$. There is no doubt that we have here another case of Norse influence, and we must connect with $\mathrm{ON}$. vätr, for the $\bar{a}$ is in no way to be explained from OE. $\vec{e}$, Angl. $\bar{e}$. So the $\breve{a}$ in mod. Sc. $w a ̆ t$ may be a shortening of the $\bar{a}$ in wăt, though the other explanation of it as a parallelism to wed $>$ wad is just as good. It is strange that the author of Clar. uses all three forms wẹt, wit, wett, from previous wāt, wẹt, wět.

Other Sc. authors use the form wit or wit; Brace, wet, vb. : gret, (inf. = weep) 3.518 , wete, adj. : het (= heat) 11.612 . - K. Q. wete : great (greät). - Roll. C. V. weit : spreit (= spirit) 1.36. - Montg. weet : greet, MM. Ps. 6. 35. weit : Margareit MP. 51. 6; also Sir Tr. wete : mete : grete : sket, 732. 


\section{Angl. $\overline{\mathbf{e}}=$ WS. $\overline{\mathbf{e a}}$ before gutturals.}

$\S 217$. rimes with - a) $0 \mathrm{E}$. $\overline{\text { eO. }}$ eine (ēgan, pl.) : beine, ind. pl. 4. 372 : seine, inf. 2.1550 : betweine 3.1594 : teine (tiēna) 3. 2268 . ey (eāge) : se, inf. 3.2296 : see, indic. 4. 2060. hee $($ hea $h):$ see 1.70 , hie : be

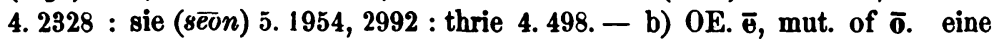
: queine 3.1848. eik(e) : beseike 1.420 (\&c.) : seike 4.790. - c) General OE. e. he $(h \bar{e} a h):$ me 3.644. - d) OE. or ON. i+g. hie $(h \overline{e a} h)$ : worthie 5. 2402 : joyouslie 5.1524. ey : eydentlie 2.1406. - e) ON. øy. he (heah) : die (deyja) 3. 1098. - f) ON. jū. eik(e) : meik(e) 2.1552 (\&c.). g) Fr. e. ey : meinze 2. 912 : quantitie 3. 1394, eyes (for ey) : bewtie 5.298 , eie : royaltie 5.1034 . hee $(h \overline{e a} h):$ degree 1.252 : cuntrie 1.1242 , hie : degrie 5.1796, 1882 : quantitie 5.1604 : solemnitie 5.1630 : royaltie 5. 2004. - h) Fr. i. eeine (ēagan) : Palexine 4.1196.

$\S 218$. In OAngl. $\overline{e a}$ was smoothed to $\bar{e}$ before gatturals, see Sweet $\S 465$; consequently $\bar{e}$ is to be found in ME., but it is not confined to Angl. districts, as we might expect, but is met with in all diall. except Kt. (Sweet $\S \S 677,679$ ).

Hence the word eke has an $\bar{e}$ almost everywhere in ME., though the form with $\bar{e}$ from $\mathrm{OE}$. $\overline{e a} \mathrm{c}$ is also found, e.g. Chauc. has both forms (t. Br. § $24 \gamma$, note 3, Kluge PG. 1. 880). In MSc., as may be expected, it only had $\underline{e}$ and with the change $\bar{e}>\tau$ became $i k$; see above in (b) and (f).

$\S 219$. All the rest of the above rimes concern the two words, OE. $\overline{e a} g e$ and $h \bar{e} \bar{h}$, Angl. $\bar{e} g e$ and $h \bar{c} h$. It is well known that in MSc. in these and other words containing $\mathrm{OE} . \overline{e a}, \overline{e O}+$ gutt. the gatt. disappeared without leaving any trace, and the result was a pure vowel ẹ. The loss of the gutt. was not complete at the time Bruce was written, but it was accomplished by the beginning of the $15^{\text {th }}$ cent., cf. Brandl, Th. Erc. p: 59, Buss p. 497, Wischmann p. 6, \&c. Buss gives a number of rimes from $15^{\text {th }}$ cent. texts. Clar. has pure Sc. rimes and shows none of the Engl. influence which is so apparent in $K$. Q. in these words. The rimes

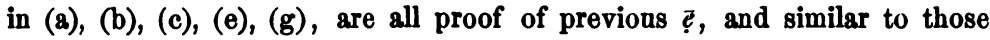
given by Bass.

$\S 220$. Such rimes are, on account of the OAngl. forms with $\bar{C}$ and the ME. forms with $\bar{e}$ in all diall. except $\mathrm{Kt}$., not generally reckoned amongst the $\alpha: \gamma$ rimes; and we have further above taken $e y$, he, eik as $\gamma$-words. But we might look upon this class of words as only the first in which the change $\ddot{e}>\bar{e}$ was effected, and consequently also the only ones in which the $\bar{e}$ obtained a large extension beyond its original home, the Angl. dial. (in $\mathrm{OE}$. the $\vec{e}$ forms were confined to the Angl. dial).

$\S 221$. The rimes in (d) are, as explained in $\S 126$, evidence of the change $\bar{e}>\bar{i}$; so also that in (g) with Fr. $i$; the final syll. of $\mathrm{Palexine}$ cannot have contained an $\bar{e}$, but must have retained its Fr. pronnnciation, as in many other cases, in which the was not changed to a diphthong si, ei.

$\S 222$. The mod. Sc. diall. have and in for rec. sp. eye and eyes, and sometimes $h i$ for rec. sp. high, e.g. D. 34, (always so in the com- 
pound hilands = highlands), sometimes hei, hai, e.g. in 33, 34 and 37 (this probably due to influence of rec.sp., exc. in D. 33 , in which a diphthong generally stands for Central Sc. final $\imath$ ); we also find (heikjh, haikjh) in $33,41,($ hekh) in 34 , (hiikh) in 35,38 . and (hilkh) in 39 ; height appears as (hekht) and (hikht).

$\S 223$. The word neir (= rec. sp. near), nearly always spelt with $e i$; the rime words contain:

a) OE. $\overline{\mathrm{eo}} .-$ : deir 3.1140. - b) Angl. $\overline{\mathrm{e}}, \mathrm{WS} . \overline{\mathrm{x}}$ (or ON. $\overline{\mathrm{a}}$ ?) nar : ware (wäre) 1.474, neir : zeir (zer, zär) 3. 24. - c) 0E. y-. : speir (spyrian) 1. 534, 1255. - d) Angl. $\overline{\mathbf{e}}=$ WS. $\overline{\mathbf{e}}$. - : steir, vb. 2.1524. - e) ON. $\bar{e}$. - : seir 4.9S2. - f) OE. $\bar{e}$, mut. of $\overline{\mathbf{o}}$. - : in feire 4.1232 : feir 3.406. - g) Fr. e, ie. - : cleir 2.260, 1662 : suppeir 2.558 : maneir 2.1394 (\&c.) : mater 3.476 : cheire 5.1400.

$\S 224$. All the rimes prove an $\bar{\imath}<i$, except perhaps the first in (b). $\mathrm{Nar}$ is a form often found in Northern and Sc. texts by the side of ner, e. g. nar : war (adj.) and nere : here, adv. 'Townl. M.; nar : bar : dar : far, Roll. C. V. 1.516; nar : debar : afar : dar Montg. MP. 36. 53; nar : sar, Satir. P. 39.160. But the $a$ seems mostly to be a short $\breve{a}$, and as in all the other rimes we find only $n \bar{i} r<n \bar{e} r$, and $w i r<w \bar{i} r$ is the most usual form for OE. wäron with our author, it is probably better to ascribe nar and ware to the copyist and to change into neir : weir, or were. It has already been noticed above that the copyist prefers the form ware to were.

The form neir must be derived, of course, from Angl. nēr (cf. Law of Alf.) = WS. nièr, nyr; can nar be explained from nēar or nēarra? perhaps from the latter through a form neărra, with shortening. In the mod. Sc. diall. the pronunc. is generally the same as in rec. sp., with i; but $n \vec{a} r$ is found 38 and 39 , and also in Engl. in 25 (South Cheshire), $n \breve{r}$ in 31 (N. Lancs.). J a m. Dict. gives nar for Scotl. and Yorks., also the compound nar-side.

$\$ 225$. aneist (= Angl. anè(h)st, Northumb. aneist, see Sievers $\$ 166,5$.) : breist, 3. 1010. This word, or the shorter neist, is of frequent occurrence in MSc. texts; e. g. Satir. P. neist : breist 30.99 (\&c.). In mod. Sc. diall. we still find (niist), e. g. ill 35̆, 35, 39, 41, 42, and (nist) in 33,36 .

\section{AE' (mut. of OE. $\overline{\mathbf{a}}, \mathrm{Gme}$. ai).}

$\$ 226$. 1. Not followed by $r$ or $w$. - rimes with

(In these lists, forms with a long vowel are given under $\alpha$, those with vowel-shortening under $\beta$.).

a) itself. $\alpha$ ) deill (vb.) : heill $(h(\bar{e} l u) 3.810 . \quad \beta)$ led (prt.) : vncled (ptc., acc. to Skeat from $O N$. kläp $/ d i) 3.2134$. - b) Angl. $\overline{\mathbf{e}}=$ W.S. $\overline{\boldsymbol{B}}$ (Westgmc. $\overline{\boldsymbol{e}})$. $\quad \alpha$ ) breid $(b r(\bar{p} d u)$ : meid 5. Prol. $4 . \quad \beta$ ) led (prt.) : adred 4. 118. - c) OE. ea. $\alpha$ ) leid (vb.) : reid (adj. = red) 1.1128. feid (OE. $f(\bar{c} h \delta):$ reid, adj. 5. \$4, 1190. gleimes, (pl. off OE. glām) : streamis 4.1188. $\beta)$ left (ptc.) : bereft $1.17 \mathrm{~s}$. - d) OE. - (general OE. $\bar{e}$ ). ( $\alpha$ ) sea : me 3.102 : he 3.1142. deale, deill, sb. : weill, adv. 2.104, 934. - e) OE. $\bar{e}$ (mut. of $\overline{\mathbf{o}}$ ). ( $\beta$ ) delt : felt 3. 352. bespred : sped (prt.) 5. 2366 . cled 
(ptc.) : fede (ptc. of fedan) 4.1670. - f) Angl. $\overline{\mathbf{e}}=$ WS. $\overline{\mathbf{1}}$. $\quad(\alpha)$ cleine

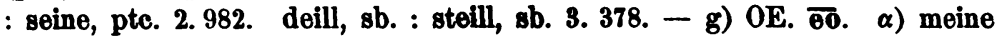
(vb.) : betweine 1.298. cleine : beine, ptc. 3. 2356 . $\beta$ ) led, ptc. : fred (liberatus) 2. 130. spred : fled 3.404. - h) OE. $\overline{\text { a }}$ mone (sb. from $\mathrm{vb} .=$ OE. mēenan? rec. sp. moan) : wo-begone 2.676 : allone 3.710 : stone 3.1598 : gone, ptc. 3. 1834. - i) OE. e: . ( $\beta$ ) lest (léstan) : rest, vb. 2.58 : best 2. 1246 : mirriest 2.1768 : vnrest 3. 526 : rest, sb. 4. 1904, 5. 2180 . les (hēssa, cf. Sievers, § 312; but Grein and B.-T. give lăs8a) : nobilnes 1. 370, 5. 2630 : blythnes 2.1256 : humbilnes 3.1600 , humblenes 4.48 : bissines 3. $1852 .-$ k) OE. $\circledast$, see $\S 80(\mathrm{~h}) .-$ m) Fr. e. $\alpha$ ) leist, least (superl.) : feist 2. 1804 (\&c.). teace (for teache) : fleich (flechir) 2. 291. sea : cheritic 3. 850 : cuntrie 3. 52. deill, sb. : reveill 3.2148. $\beta$ ) ment (prt. of mōenan) : intent 4. 2228. les (compar.) : dres 2.820, 5. 2888 : proces 5. 668: distres 5. 918. lest (lästan) : opprest 2. 664. - n) Fr. a. maist : haist 1.1364. - o) Fr. el. dealle, vb. : leill 3.832. - p) Fr. o. mone, sb. : Palamon 5. 90. - q) ON. ig. sea : trewlie 5. 2746.

For $\bar{a}+h t$, see $\S 99$ (a).

$\S 227$. This vowel belongs to ten Brink's Class $\beta$. As $\bar{\alpha}$ is found in all the OE. diall., we should expect it to rime chiefly with an open $e$ in ME., and it does so in the SW.; but just as Orm's $\bar{a}$ for Gmc. $\bar{a}$, Goth. $\bar{e}$, soon became $e \bar{e}$ in East Anglia (see Morsb. p. 154), so also did the $e$ from general OE. $\bar{a}$, mut. of $\bar{a}$, Gmc. $a i$; hence the $\beta: \beta$ rimes in (a) and (b), and the $\beta: \gamma$ rimes in (d), (f), (g), (m), would be quite in order in any Angl. district. We have also $\beta: \alpha$ rimes in (c) and (o) and one in (m), leist, least : feist. The sound we have to understand in most of the above rimes is $i<e$ (for possible exceptions see $\S 230$ ).

\& 228. The shortened form before conson. groups is chiefly $\check{C}$, see (a), (b), (c), (e), (g), (i) and (m); but perhaps once $\breve{a}$, in mad, see (k); in

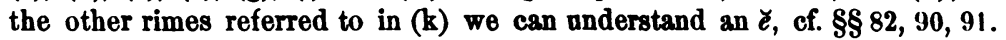
Kluge P.G. 1. 876, note 2, explains some of the $\succ$-forms through the influence of the ME. $\bar{e}$ in non-shortened forms. Since the $\bar{z}$ is more frequent in the Midl. and N., as contrasted with the more usual $\breve{a}$ of the S., we might be inclined to look upon it as evidence of the different treatment of $\bar{a}$, and a further proof that this early produced a closed $\dot{c}$ in the Midl. and N., whose shortened form could not then be $a$. If so, then the $a$-forms in Clar. are further borrowings from Engl. In Bruce we find $a$ written for $e$ in rad (rädde), lad (löedde). \&c., see Buss p. 12. But $ð$ forms are also found in Southern texts as well, (cf. Bülbring p. 108, \&c.) and Kluge's explanation, which is that also given by Bülbring and Morsb. p. 154 , must be correct as far as the $\mathrm{S}$. is concerned, although the same result may have still been arrived at in another way in the $\mathrm{N}$.

$\S 229$. The rime in (q), sea : trewlie, is probably a proof that $\bar{e}$ had already become $i$; cf. $\S 126$.

$\S 230$. The mod. diall. offer many instances here of an e-vowel, where rec. sp. has $i$, far more than in the case of Angl. $\bar{e}=$ WS. $\bar{\alpha}$. Sometimes the $\vec{e}$-vowel is only found in single diall.; in D. 33 it is only found in sea, which, however, has $I$ in all other diall, and in breadth, which 
has also an $e$-vowel in 39 , but $\bar{\imath}$ in 35 and 36 . D. 33 agrees very closely with D. 32 (Northumberland), where $\bar{i}$ is found throughout, just as an $i$ fracture is found in these two diall. for the $\bar{e}$-vowel of the other Sc. diall., which proceeds from MSc. $\bar{a}$. An $\bar{c}$-vowel is found in all diall. beyond 33 (i. e. as far as notified by Ellis) in heal, vb., heathen, deal, sb., (which certainly generally had closed $\bar{c}$ in MSc.), and, in all diall. but 35 , in leave, $\mathrm{vb}$., lead, vb., and heat; and further it is occasionally found in clean (36), wheat ( 37 and 38 , and $a i$ in 39 ), sweat $(38,41,42$, and $a i$ in 39 , where also teach has $a i)$; while mean, vb., has an $e$-vowel in all Sc. diall. The abundance of $e$-forms, which cannot be accounted for by English influence, being contrary to the pronunc. of rec. sp., is very striking, and difficult to be brought into harmony with the evidence of MSc. texts, although traces of such forms are not wanting in MSc., e. g., Satir. P. a greit daill moir, 33. 222, $(a i=\bar{e})$ and above in $\$ 226(0)$, where the spelling dealle certainly points to $\bar{e}$ for the scribe who wrote it, and perhaps also the rime with leill for the author. Perhaps OE. $\ddot{e}(\beta .2)$ should, for some parts of Scotl., be classed with $\alpha .3$, and $\alpha . j(1)$, as an exception to the rules given above. If Ellis's lists were less incomplete than they are, and less open to suspicion than they sometimes appear to be, we might be more easily able to get at the true history of this vowel in Scotl.

$\S 231$. never; the vowel only rimes with Fr. e. - never : dissauer (= dissever, separate, intrans.) 5. 552.

Probably the $a$ in dissauer is a scribal error for $e$, and the $\bar{e}$ from $\bar{c}$ in never has been regularly shortened to $\breve{c}$. (The mod. Sc. diall. have generally an $\tau$ in ever, never, just as in together - iver, niver, togidder). Or does the $a$ perhaps mean a long $i$ in the pronunc. of the scribe? Cf. $\mathrm{S}$ atir P. euer : disseaver 25.52. Montg. has ever : fever p. 35.

$\S 232$. mone, sb. = complaint, lament, see (h) and (p), (the latter proves the $o$-pronunc.) is a Southern form and must be derived from a form with OE. $\bar{a}$, either a sb. *män, or a vb. *manian. Elsewhere we find $\bar{a}$ or its outcome $\ddot{e}$ in Sc., e. g. Sc. Leg. myne, sb. : nane, 24/668, Roll. C. V. mane : ane : tane : grane (= groan) : Montane 2. 382, but mone : begone : stone : anone, 2. 405, mone (sb.) : anone : gone : fone : propone. The verb meine, with different sense $=\mathrm{NE}$. to mean, has the vowel $i<i$, see (g) and (m), and is quite regular; it has $t$ everywhere in NSc. But Roll. C. V. seems certainly to have $i$ also in mene (= moan, complain) : serene : pertene : sene : quene 1. 730, menit (=moaned) : complenit : sustenit : convenit : pertenit : vnrefrenit $1 . \$ 19$.

$\S 233$. maist, see (n), should properly be included under OE. $\bar{a}$, for it must be derived from ONorthmb. mäst; the form mäst would produce ME. messt, (which is found in Chauc. \&c.) and in MSc. mẹst, later mist, but in all early Sc. texts the form is generally mnast, the forerunner of the $m \bar{e} s t$ of all the mod. Sc. diall. exc. D. 33, which has, of course, ( $\left.i^{\prime}\right)$.

$\S 234$. deill. The difference between the sb. with $e$ and the verb with $e_{i}^{i}$, which Buss observes in the Sc. Leg;., we should not expect to find in Clar., yet it might appear to exist, forr the sb. only rimes with a $\gamma$-vowel, whereas the vb., which only appears once in rime, rimes with an $\alpha$-vowel, and that one which generally prodiuces $\bar{e}$ in late MSc. and NSc., 
but from a single appearance of the $\nabla b$. we cannot form any decided conclusions. In Montg. MP. 2. 12, deill, vb. : weill adv., it certainly has an $\tau<\bar{e}$, cf. the corresponding rime-words in the other stanzas, steill, seill, meill, feill. Still it is noticeable that the verb is in Clar. once spelt with $e a, 3.832$, but in 3.810 , it is spelt with $e i$, the symbol for $i<e$, and the sb. is also spelt with ea in 2.104. These irregularities of spelling are due to difference of dial. on the part of the scribes; the ea is an English orthography, which can scarcely be ascribed to the anthor; so also in the rime teache : fleiche.

$\S 235$. feid is the regular Sc. form for the incorrect Engl. form feud; see Skeat, Princ. 1.206. Its vowel is against Bradley's derivation from MLat. faida; it is rather from OE. fōh $\delta$, perhaps with Norse side influence on the conson. (Dan. feide?)

$\S 236$. lest, vb. The form in rec. sp., last, must be explained in the same way as blast, cf. § 215 , viz. 0 E. lästan $>l \check{a ̈ s t a n}>l a ̆ s t>l a ̈ s t$; lest is especially Sc., and here again we must assume that in the extreme $N$. $\bar{c}$ early became $\bar{c}$, or that the shortening did not take place so early as in the $\mathrm{S}$. The rimes prove conclusively the shortness of the vowel; it is a parallel form to the Kentish blest for blast. The same form is found in Bruce (but not in rime), Gol., Lanc. lest : fast 812 (i.e. the author used an Engl. rime, and the scribe altered to lest to suit bis own pronunc.), Dunb. lest : best 24. 15,30, Dougl. lest : drest : rest : vnrest 1. 97. 3, Satir. P. lest : manifest 40.107, 44. 115.

\$ 23i. sweit, sb. = rec. sp. sweat, sppears once in rime with beird 5. 2022, a corrupt orthography which we can almost with certainty alter into beit, prt., OE. beut, he beat. The OE. form of the sb. is swät, but it has been influenced by the $\nabla b$., OE. swōtan, or else we must derive from an alternative $\mathrm{OE}$. form with $i$, mut. of $a,{ }^{*}$ swät, as Ellis does in EEP. 5 ; hence the long $\bar{e}$, later $\bar{\tau}$, of the North, and the $\check{e}$, through shortening from $\vec{\xi}$, of rec. sp.

$\S 238$. The word bedeine."

As usual in northern ME. verse, this word also appears in Clar. The rime-words contsin.

a) 0 E. $\bar{e}$, Angl. $\bar{\oplus}$ (mat. of $\overline{0}$ ) - : queine 3. 536, 4. 1344, 5. 2490. b) Angl. $\overline{\mathbf{e}}=$ WS. $\overline{\mathbf{e}}-$ : seine, ptc. 3.12 ; $\mathbf{i}$ e. its vowel is $\bar{\tau}<\bar{c}$.

$\S 239$. Murray, N. E. D., says it is " of uncertain origin", but "its latter part is almost certainly the early ME. adv. ane, ene, OE. æene, once, at once, in one, together, (cf. the ME. phrases at ene, at once, for ene, for once); but the bid - is difficult of explanstion." According to Skeat it $=b i+d \bar{e} n$ (=done), with mutation, instead of $d \bar{\delta} n$; cf. mididone in Alisaundre. The vowel, whether belonging to the $\alpha, \beta$, or $\gamma$ class, unless it be $\alpha .3$ or $\alpha .5$. (1), would be $?$ and then $t$ in late MSc., so that the rimes in Sc. texts can throw no light on its origin, though it is somewhat striking that it almost everywhere rimes with $\beta$ and $\gamma$ vowels only; we require rimes from Sonthern texts to decide between $\beta$ and $\gamma$, but the word seems to be strange to the southern dial. For further rimes see Kölbing's glossary to Sir Tr., NED. s. v. bidene, and Bruce : queyn 5.144 : fiftene 
15. 108, D un b. bedene : ene F. 422, Roll. C. V. : schene : sene : ene : circumvene 2.598 : schene : clene: Quene : ene 4. 644; Hamp. P. C. : sene, ptc. 7968, Sow done of Bab. : kene 2942. \&c.

\section{$\S 240$. The suffix - heid, - head.}

The suffix which appears in rec. sp. as -head, appears in $\mathrm{Clar}$. only in the form -heid, and cannot, of course, be derived from $0 \mathrm{E}$. $-h \bar{a} d$, which produced the Chanc. form - hood, but either from an alternative mutated form $-h \overline{c e} d,-h \bar{e} d,=0 \mathrm{HG}$-heit, as $i$-stem, as Kluge P.G.1.8i4 explains, or from a Low Germ. form, as explained by t. Br., $\$ 55$ and Skeat, Princ. 57, 218, 219. The former is preferable, especially as it at the same time accounts for the difference of quality of the $\bar{e}$, open in the S., closed in the $\mathrm{N}$.

$\S 241$. In Clar. it has, with every other $\bar{e}$, already become $\bar{i}$; the rime-words all contain earlier $\bar{e}$ from various sources.

a) 0E. $\bar{\oplus}$ : abreid (on brōedu) 4. 2334. - b) Angl. $\overline{\mathrm{e}}=$ WS. $\bar{\oplus}$ : dreid 1.244 (\&c.) : deid 1.1260 (\&c.) : dread 2.384, 454 : weid 5. 1756, 1932. c) OE. $\overline{\mathrm{e}}$ (mut. of $\overline{\mathbf{o}}$ ) : speid 1.404 : gleid (0E. glēd) 3.1554 : steid 4.1750. - d) 0E. $\overline{\text { eo }}:$ zeid 1.1426, 2.80. - e) Fr. $\overline{\mathrm{e}}$ : proceid 1.272, 2.72.

All other Sc. texts show similar rimes in abundance.

\section{2. $\bar{x}$ before $\mathbf{r}$ - rimes with}

§ 242. a) OE. $\overline{\mathrm{e}}$ - leir (lōeran) : heir (adv.) 3. 872. - b) $0 \mathrm{E} . \rightsquigarrow+g$ - aire $(\bar{a} r)$ : faire, adj. 5. 746.

The vowel in (b), aire, is $\vec{e}$ from previous $\vec{a}=$ an $0 \mathrm{E}$. $\vec{a}$, which arose ont of $\bar{c}$ before $r$, as in $p \bar{e} r$, hw $\bar{a} r, p \bar{a} r, h w \bar{a} r$, cf. Morsb. p. 46. This change did not take place in all words, e.g. in lāran, which accordingly developed quite regularly a ME. $\ddot{e}, \bar{e}$, later $i$; we have the latter already in Clariodus, as implied by the spelling ei.

\section{3. $\bar{x}+w$.}

$\S 243$. Only the word OE. slā $w p$, which rimes with $0 \mathrm{E} . \overline{\mathrm{eO}}+\mathbf{w}$ in $\operatorname{tre\overline {e}wp}$. slewth : trewth 4.1098. sleuth : trewth 4. 2342.

Engl. sloth has been affected in its pronunciation by the corresponding adjective slow; the Sc. form slewth $=($ sliuth $)$ is the correct one, OE. $\bar{x}+w>\underline{q}+w, \bar{e} u>\bar{e} u>i u$, just as $0 \mathrm{E} . \overline{e v}+w>\bar{e}+w>\bar{e} u>i u$. Of course at the late date of Clar., when all è's have become $\bar{i}$, the last stage, $i u$, of the diphthong has already been reached in both combinations OE. $\bar{e}+w$ and $\overline{e o}+w$, which coincided at a previous stage, when $\bar{c} u$ became ẹa, just as simple ę became ẹ. We find the same rime as above, as early as the K. Q., sleuth : treuth, 144 ; cf. for a later period, Montg. sleuth : truth, C. 1560, sleuth : treuth D. P. 4.41; Satir P. sleuth: treuth, 12. 27. Montg. also shows the corruption of the $i u$ form through the influence of the adjective, e. g. C. 824 slowthing; but C. 556 slewthing (= lingering). But the form sloth is otherwise almost unknown in MSc.; it does not occur in Dougl. J am. Dict. gives sloth as a verb, by the side of sleuth, and quotes for it King James VI; otherwise he gives sleuth, sb. and vb., sleuthful, (Lyndes. Dreme. \$90i) sileuthan, sleuthun, sb. = 
a lazy person, and sleeth sloven, sluggard, a form found in Aberdeen, in which district earlier (iu) is now generally represented by (ii).

In slow : slewth, we have the same difference of vowel as in broad : breadth, whole : health, \&c., due to mutation in the $\mathrm{sb}$. on account of the following suffix (= Goth. $-i p a)$.

\section{ON. $A E^{\prime}$.}

$\S 244$. rimes with

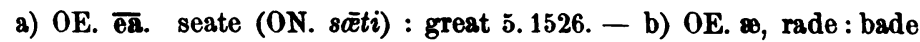
4.116. - c) OE. ea, a, thrall (prōell) : sall 1.390 : all 4.696, 5.808. d) OE. e, cled(e) (ptc. klōepdi, Sweet) : bed 3. 918, 1646 (MS. bedis for bed). - e) $0 \mathrm{E} . \overline{\mathrm{e}}$ (shortened), clede : fede (ptc. of fedan) 4.1670. - f) Fr. ai, seat : retreit, 5. 2082.

$\S 245$. $0 \mathrm{~N}$. $\bar{a}$ belongs to t. Br.'s $\alpha$-class, but like $0 \mathrm{~F}$. $a i, e i$, it does not produce MSc. $\bar{e}$, later $i$, but instead of this a late MSc. $\bar{e}$ which coincides and rimes with $\vec{e}$ from previons $\vec{a}$; cf. $\S 108$. The rimes and spelling in MSc. texts in the word NE. seat, ON. saeti, show this plainly; cf. Satir. P. sait, 39.278 : gait : debait : estait 43.63, Montg. seat : stait : bleat : fleat (prt. of OE. fltan), MP. 3.78, W in zet, sait, 2.35. 19, saitis, 1. 106. 17, and see Jam. Dict. s. v. sait.

In Clar. seat only appears in two rimes, see (s) and (f), which, however, both agree with the $e$-pronunc. For we have seen in $\$ 280$ that great was pronounced by the author with $\bar{e}$ as well as $\bar{\tau}$, and it is also found in the mod. Sc. diall. with $\vec{e}$; and retreit, in spite of the spelling with $e i$, must have contained an $\bar{e}$-vowel, for $0 F r$, ai always gives $\vec{e}$ in late MSc., ef. $\S 108$.

Some rimes between $0 F r$. ei, $a i$ and previous $\bar{a}$ are given in $\$ \S 1$ $(\mathrm{g}, \mathrm{h}), 96$ (i, k); many other similar rimes are to be found in Clar., e. $\mathrm{g}$. consait : debait 3.1466 , deceave : knaue 4.1452. The spelling with ea in seat and great also points to an $e$-pronunc. on the part of the scribe.

In the mod. diall. we find seat with an $\vec{e}$-vowel in 38 and 41 (Ellis does not give its pronunc. in the others) and the corresponding ( $\left.i^{\prime}\right)$ in 33 (Murray DSS.). All the diall. also show $\bar{e}$ for Fr. $e i, a i$, in words in which rec. sp. has $i$, e.g. deceive, conceit, \&c., exc. 33, which has, as usual, (i'); ef. Murray DSS. 145, 146. Bradley gives OE. sōte as the origin of NE. seat, but ON. sāti must have been of influence in Scotl., or why should not OE. $\bar{\alpha}(\beta .1)$ bave produced MSc. $\bar{z}$ and $\bar{i}$ here as in other words?

$\S 246$. Above in (b) we have probably the shortened form $\breve{a}$, of. $\S 89$. For the etymology of rade, see Brate, p. 53, and Stratm. - Bradl., and cf. Sc. Le g. rade : bad, prt. 17/170 : had 19/300, B ruce (see Skeat's glossary), Dougl. rad : had 4.152. 18, raddour $=$ ferr, 3.265.17, radour, 1.94.19, Montg. rad : sad DP. 6.25, rad to reveil S. 45, Yw. Gaw. rad : bad.

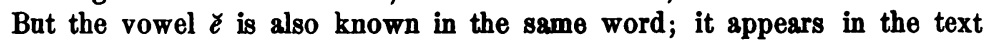
in Clar. in 4. 1417, "Full red scho was that he sould pase hir fro." $\mathrm{J}$ am. Dict. says mod. Sc. of Clydesdale has red, I'se red = I am afraid; cf. Sc. Leg. rad : sted (= placed) $24 / 676$, red : sted $24 / 682$, W e d d e r burn 
(Irving, p. 387) red : fred (= freed, liberatus), D n n b. redour = fear, 2. 11.; John Ga u has reid.

In (c), too, the shortened form of the vowel is $\breve{a}$, but in (e) and (f)

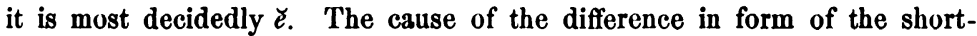
ened vowel is not quite clear; it cannot depend upon the following consonants alone, as $h r \bar{x} d d r$ appears in both forms; perhaps the cause lies in the difference of dial. and of date at which the shortening took place; the words may have been adopted from the Norse at different dates.

\section{ON. EI.}

$\S 247$. rimes with

a) itself. ay : they, thay $1.318,660$. nay : thay 5.1106. - b) $0 \mathrm{E}$. e + g, see $\S 134$ (e). - c) OE. $x+$ g, see $\$ 94$ (i). - 'd) Fr. ei. ay : perfay 1.836 : deray 5. 2272 ; pray, vb. $1.1522,3.2180$. nay : perfey 2.1032. raise : praise 4.1044 , raisit : praisit 4.1104 . they : tornay 2.730 , thay : perfey 4.1312. - e) Fr. ai. bewaill : assaill 3.906. thay : delay 3.1604: aray 4.340 : assay 4.876. - f) Fr. e. thay : livaray 4.1520.

$\S 248$. The rimes in (b), (c), (d), (e) are all with the older diphthong $a i$ or $e i$, and that in (f) with Fr. $e$ is therefore a further proof that the monophthongal form of this diphthong was already $\bar{e}$; perhaps the occasional spelling with ey may be looked upon as an indication of the same.

The mod. Sc. diall. have almost exclusively an $e$-vowel in all words of this class. The word aye, however, appears as a diphthong, only D. 34 has a monophthong (ææ).

$\S 249$. Words of uncertain etymology.

feir(e), effeir(e), fair(e), fayre. These are the forms of two, or perhaps even more, words used in the sense of manner, demeanour, behaviour, carriage, comcliness, \&c.; e.g. with ane knichtlie feir (: speir) 2. 1106, with awfull feir(e) (: speir) 3.44 (: thair) 5. 1176, foure fresch wirginis of effeir (: beir, vb.) 2. 872, smylit, kissit, \&c., with womanlie effeir (: weir, vb.) 3.2212, 4. 296, 1.452, (: deir) 3.1024, (: cheir) 3.2178, 5.342, (: chyre $=$ chair) 1.164, the wonderfill beawtie and the firesch effeir (: eare) 1.336, to the kirk to go all in effeire (: mancir) 3. 2362, I wald gone to Queine Meliades with fiesche effeire (: beire, vb.) 5. 562 , with sorrowfull effeir (: teiris, for teir = tear, sb.) 5. 2524, This noble Count of manlie effeiris (: weiris $=$ wars) 5. 2984, with awfull fair $(:$ mair $=$ more) 3.634 , the manlie faire (: maire) 4. 1046, with courtes faire (: thair) 4. 2034, with glaidsume visage and with faire (: speir) 2.1525 (the sense would also allow this to be taken as = fager, fair, adj., bu.t the rime would then be impossible), the minstrellis playit with ane mirrie fayre (: chyre = chair) 5.1530.

$\S 250$. The rime - words to the forms feir $(e)$, affeir $(e)$, contain $0 \mathrm{E}$. $e-, \bar{a}, \bar{e} \bar{a}, e o$ and Fr. $i e, e, a i$; those to the forms fair $(e)$, fayre, contain OE. $e-\bar{a}, \bar{a}$ and Fr. $a i$.

It is at once evident that these forms cannot all be referred to the same origin. Jam. Dict. gives "fair, feir, feyr $=$ shew, carriage, gest- 
ure $=$ OE. far, (iter) or feorh (vultus)" and says "affer has the same meaning and source." These two derivations would account for the vowels satisfactorily enough, if we take the form OE. faru, instesd of far, though not quite so satisfactorily for the meanings, and it is difficalt to see where the at- in affer comes from. Can we not assume an $0 \mathrm{E}$. sb. *ge-tere or ${ }^{*}$ ge-fêr $=$ Gmc. ${ }^{*}$ gi-fóri? of. OHG. gi-fwori, OFris. fêre, ON. fōeri, OLG. (gi-) fori. This would explain the vowel and the prefix, which latter, however, could be dropped, and so cause confusion with faru or faer, whence the variation in the rimes. There was the OE. gefar, too, and possibly the $v b$. effeir $=$ OFr. aferir, to become, beseem, may have been of influence, and a noun been derived from it. Fr. affaire has scarcely anything to do with it? Anyhow there seems to have been a confusion of forms, words of different origin, whose meanings had come to be almost synonymous, being interchanged with each other at random. The $0 E$. feran, ME.fére = go, travel, also behave, may also have had a share in the development. Small, in his note to Dunb. 26. 36, suggests Icel. atferð; so also Skeat in his Glossary to Bruce, s. v. effer, says "this difficult word is also spelt affeir, probably by confusion with Fr. affaire, and probably when the word means 'business', it is merely French. Jam. hesitates about the etymol., but needlessly. It is clearly Icel. atferd, conduct, from at and fara, to go." But this latter is very improbable. In Bruce, feire, affeir, \&c., rime with deboner, 1, 361, debonar 8, 382, wer(e)

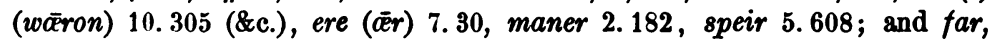
in similar meanings ("behaviour, demeanour, appearance, equipment, make, stature, business, array, pomp", Skeat) rimes with war (wäron) 19. 730, 20.100, thar 16. 46.

$\S 251$. For similar uses and rimes, cf. W all. with manly feyr, 9. 306, The quein com in hyr effer : wer (= war) 9.312; Gol. with felloune affere : were (= war) : here : bere 707, vvith ane fel fair : maire : saire : fair (vvith ane tresch fair) 570, with ane fell fair : schair (prt.) : bair, (prt.) 932 ; Lanc. effere (shew, pomp) 2360, affere (= warlike preparation) 985, (= bearing, aspect) 3043, 3334, 3394; (here Skest says = OFr. afeire, afaire); Rat. Rav. effere (= manner) : gere (= gear) 3. 137; Dunb. discirnyng all thair fassionis and effeiris : speiris : weiris = wars, 49. 128, the pepill so wickit ar of feiris : beiris, 3. sg., 66. 33, Thay micht weill ken be thair effeiris : speiris, 27.65, with sic ane feir : mensweir : weir : beir, 27. 87, feir of weir = accoutrement of war (the same phrase occurs in the Scotch Acts of Parl., James II, 1457, p. 14, c. 78), Ffrawart wes thair affeir : scheir = OE. sceran, 26.39, on syde scho lukit wyth ane fremyt fare : fair, adj. : mare : repaire, 1.125, with lusty effeiris, 3, 49, all is bot trutlese his effeir, 3,401; Satir. P. with fresche effeir: deir 11.83; Sir Gaw. fare (= behaviour, conduct) : ware, adj. 2386.

$\S 252$. weir, sb. $=d o u b t$, in the phrases, but weir(e) (: maneire) 4. 2400, (: heir, adv.) 3.680 , withouttin weir (: cheir) 3.880 , pis is no weir (: maneir) 1. 1320. With regard to the etymol. of this word, Skeat (Bruce) suggests Icel. vari $=$ caution; in $\mathrm{Lanc}$. he gives $\mathrm{OE}$. $w \bar{c}^{-} r$, cautious, wary, elsewhere he gives Du. war, confusion. Morris, Hamp. P. C., gives OE. wär, caution. This last would be the most satisfactory, 
if the form with $\bar{a}$ were found in OE., but our authorities only give us wär, and both this and $\mathrm{ON}$. or $\mathrm{Du}$. forms with $a$ are impossible, for the word rimes in Clar. only with previous $i$, and so in most other texts; e. g. Bruce : heir, adv. 9.637, neir 13.592, 16.110, 17.496: inqueir, vb. 4. 222 : zer (= year) 13. 730 : weir (wëron) 16. $500:$ fer (haill and fer) 9. 231 ; Dunb. in weir (doubt) is : reuerteris (Lat.) 11. 22, but weir : cheiv 25. 70 : appeir : freir $30.50:$ perqueir : speir (= ask) $90.30:$ neir 36.1 : prisoneir 42.102, 110; Roll. C. V. : geir : stranger : deir 3.216, Henryson but weir: heir, vb. (see Roll. C. V. Introd. p. 18); Hamp. P. C. uere : apere, vb. 2296.

Is it possible anyhow to connect with OE. werian, defend?

\section{$\mathbf{E A}$}

\section{After $\mathbf{s c}^{\prime}, \mathbf{g}^{\prime}$.}

\$ 253. In ONthmb., after $8 c^{\prime}$ and $g^{\prime}$, an $e$ is found inserted before $a$, in most cases just as in WS., cf. Hilmer, p. 9. This $8 c$ and $g$, produce, in the $\mathrm{N}$. as well as in the S., sch, sh, and $y$ respectively, except, of course, where Norse influence is at work. After $s c$, the $e$ merely marks the palatal pronunc. of the $c$ (ef. Sievers, $\S 76$, note 5 ); this $e a$, then, is no diphthong, and we must divide $s c e-a$ not $s c-e a$. So that the following words really belong to the section on $a$. The development of the $a$ in sce $-a$ is the same as that of the usual $a$, but the sce produces usually sch in Sc. orthography.

$\$ 254$. The rimes show no exception to the ordinary treatment of $a$.

1. In open syllable not foll. by $g$ - schame : name 2. 1074, 5, 1142 : eschame (vb.) 5. 2038.

The word skaith (: baith, 2. 496) is probably from ON. skaða.

2. Before g, shaw (sceaga) rimes with $\mathrm{OE}$. $\overline{\mathbf{a}}+\mathbf{w}:$ snaw 1.740 : raw (NE. row, sb.) 4.1770. Cf. $\$ \$ 52 \mathrm{ff}$.

$\S 255$. But after $g$, the $e a$ is of a different character from that of $e a$ after $8 c$, see Sievers $\$ 76$. note 5.; in gea we have a real diphthong, as is shown by the later development, which is not that of simple $a$. In Clar. we have only one word in question, OE. geat (porta) which rimes with

a) $0 \mathrm{E}$. e - zet : sete, ptc. 1. 570. - b) OE. $\overline{\mathrm{ea}}$ (shortened) - zet : grit (magnus) 5. 2470. - c) OE. $\overline{\mathrm{e}}$ (shortened) - zet : met, prt. 1.105s.

The spelling in grit is evidently faulty; i. e. for the author's pronunc.; it may have been perhaps correct for the scribe, for the pronunc. with $t$ is still found, e.g. in D. 34 ; but the anthor here more probably wrote and pronounced gret, which is still to be heard in D. 33.

$\$ 256$. The pronunc., then, was yĕt in Clar. For similar rimes ef. Freirs of Berwik (Irving, p. 294) yet : lat (= lett, vb.); Thrie Priests of $\mathrm{Peblis}$ (Irving, p. 303) yet : get; R॥ll. (: V. zet : fret : get : set, 2. 483; Satir. P. yeatt : geatt (= get) 45.652, yeatt : sett, 45. 73, yeattis : debtis 45. 825; Montg. zett : sett, MP. 45. 272; Horn Ch. zete : mete : sete. 
The form yet (= porta) is also found in most of the mod. Sc. diall.; e. g. in 34, 35, 37, 41, (Yæt) in 33, (Jeet) in 34; the forms with initial $g$, (geet) in 35, (gèt) in 37, (git) in 38, (greit) in 39, are not pure disl., but due to the influence of rec. sp. On the other hand get, get, gjet, with $g$ not $y$, are the regular forms found in the sense of via, quite a different word.

$\S 257$. The e-vowel in yet (= porta) is a support of what Sievers says. If the $e$ in geat had merely been a sign of the palatal nature of the $g$, then the $a$ would have been treated like any other $a$, (as it is after sc, cf. $\S \S 253,254)$ and we should have had the form yat in MSc., a form which is not found. But the ea was treated like any other diphthong ea,

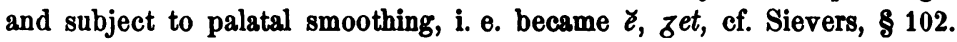

$\S 258$. On the other hand the rime above in (b) might be understood as proving a long vowel, for great generally rimes in Clar. with a previous long $\bar{e}$; but this $\bar{e}$ had already become $\tau$, and, if the vowel is long, we must therefore understand $y i t$, which is scarcely possible, while the form grět is not unknown.

There is, however, another form found in MSc. as well as ME., viz. $z$ ate with a long $\bar{a}$, the forerunner of the yet, still found in dial. e.g. D. 34; cf. Gol. yate : estate, 181, K. Q. zate: vnquestionate, 125, Freiris of B. (Irving. p. 295) yet : lait (= late, adj.), Deb. zate : late, 329, Hav. zate : late (lietan) $6781 ; 0 \mathrm{rm}$. and Townl. M. have both zate and gate. The rime may mean, therefore, yet : gret, bat yet : grett is more probable.

$\S 259$. The right explanation of the fluctuation in the form of the initial conson. in this word is given by Sweet, $\S 748$, where he remarks that "Chauc. has gate and North. yate, thus reversing the usual relation." OE. geat and pl. gatu, produce regularly ME. yet or yat and gate respectively; in the $S$. the latter became fixed; in the $N$. it assumed by analogy the conson. of the former, and thus produced a mixed form yate, which existed and still exists side by side with yet in Sc.

$\S 260$. The explanation of the $g$ in gate (= porta) from Norse influence can hardly be correct, from the fact that it is specially a Southern form; if due to Norse influence, it would certainly have been most firmly settled in the $\mathrm{N}$. On the other hand, gate = road, is especially Northern English and is rightly derived from $0 N$. For the difference between the two words ef. D unb. ऊettis (= portae) 5.19 (\&c.) but gait (= via) 5. 29.

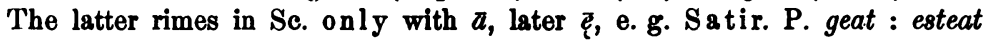
(= estate) 45.640 (the ea is merely Engl. orthography, which in the second half of this particular poem is extensively used for Sc. $a i=\bar{e}$ ). gait : Dissait 33.298, gait : sait ( seat) : debait ; estait 43.63.

For gave, prt., see $\S 88$, and for care, $\S 1$ (c), (d).

$\S 261$. WS. ea $+\mathbf{r}+$ cons. $=$ generally Northmb. $\bar{u} \mathbf{r}+$ cons. a) Before a palatal cons. - rimes with

ON. e - marke (mearcian. $\nabla b$.$) : sarke 3. 484$.

Before a palat. cons. the $e a$ was sometimes smoothed to $\breve{c}$ or $\breve{a}$ in ONthmb., see Sweet, $\S 438$. The above being the only rime, we cannot 
tell from it alone whether the vowel-sound is $a$ or $e$, but as we have accepted $a$ for sarke in $\S 180$, we must also accept it for marke; cf. $\S 318$, \&c., where the treatment of $e r+c o n s$. and $a r+c o n s$. is fully discussed. In $\S 3304 \mathrm{f}$. instances of the form merk in other Sc. texts will be found.

$\S 262$. $\beta$ ) Before other consonants. - rimes with

a) OE. e - geir (gearve. f. pl. ?) : speir 1.500, 2.1516 : weir, vb. 4. 318, 436. - b) OE. eo, see $§ 302$ (b). - c) Fr. a. efterwart : part. 3. 470.

$\S 263$. The rimes in (b) and (c) will be found discussed below in $\S \S 303 \mathrm{ff}$.

There are no examples in rime of ear + voiced cons., unless we reckon the word geir, which is generally derived from $0 \mathrm{E}$. gearwe. It has everywhere $\bar{e}$ in ME. and MSc., so also here $\bar{\imath}<\bar{e}$, see above (a). Sweet, p. 281, explains the $\bar{e}$-vowel from the cognate $\mathbf{v b}$ gerwan, prt. gerede, and the $g$ (guttural) from $0 \mathrm{~N}$. gervi or gervi. This is certsinly the right explanation of the $g$, for the $\mathrm{OE}$. conson. would produce a ME. and NE. $y$, as it does in the adj. yare from OE. gearu, the sing. form of gearwe; cf. also NE. yard, \&c. And we cannot simply derive altogether from $0 \mathrm{~N}$. gervi, on account of the $v i$, and the we of the $0 \mathrm{E}$. word presents the same difficulty, for from it we should expect the NE. form yarrow. The derivation from $0 \mathrm{~N}$. geirr, given by Noltemeier p. 30, is impossible, for $\mathrm{ON}$. ei gives a ME. diphthong $e i$, MSc. $\overrightarrow{\text {, }}$, ef. the pronunc. they, their, \&c. Dannenberg, p. 16, gives Swed. gere as the derivation.

It seems clear that there has been a confusion of forms in this word. It would not be the only example (if we derive the vowel from gearwe) of $\mathrm{OE}$. ear producing ME. or MSc. $\bar{e} r$, later $t r$; we have only to think of NE. beard, and in ME. we meet with such forms as erme (= earmian), fern (also in mod. rec. sp. but with a short $〕$ ), yerd, \&c., (cf. t. Br. $§ 48$, Morsb. p. 50, Noltemeier p. 23, Zielke, p. 20, Knigge, p. 20, Menze pp. 24, 25, Carstens p. 9). The $e$ in these words, where long in ME., is due to the lengthening in OE. before $v 0$ wel-like + cons., beard $>$ bēard; the new $\overrightarrow{e a}$ was treated like original $\bar{e} \vec{a}$, and produced ME. $\vec{e}$, later $\bar{e}$, NE. $i$, except in fern, earn, \&c., in which, in the ME. period, or at any rate before $\ddot{e}$ became $i$, shortening again took place. Chanc. has fẹrn, ycrd, $b \vec{e} r d$, cf. Kluge, P. G. 1.866, s80. 'This $\bar{e}$, found in Midl. and Southn texts, arose at quite a different time and in a different way from the $\ddot{e}$ in Sc. airm $=$ arm, \&c., see below $\$ \S 310,317$, \&c. Zielke localises them in the $\mathrm{SW}$. and $\mathrm{Kt}$. and says they made their way frow these into other diall. Menze shows that they are met with (though only in particular words) in E. Midl. (except the Northern and Southern parts of it in which only $a$ is found) and in the whole of W. Midl. Could we, therefore, satisfactorily account for the disappearance of the $w$ (perhaps from the $\mathrm{OE}$. nom. form gearu, only with the vowel of the oblique cases ?) it would be possible to do without Sweet's explanation from the verbal form; but then the word would stand alone over against such simular words as $\mathrm{OE}$. arwe, spearwa, nearu, bearve, gearice, sg., which produce ME. arwe, sparwe, narwe, barove, zarwe, = NE. arrow, sparrow, narrow, barrow, yarrow. 
So Sweet's explanation of the vowel remains the best, unless a Norse word such as Swed. gere (?) was the origin.

$\S 264$. WS. eal + cons.

$=$ Northmb. $\bar{a} l+$ cons. (acc. to Sievers $\S 158), \not a l+$ cons. (acc. to Hilmer p. 9.)

a) eal or eall - rimes with

a) itself. fall : wall 1.92 : all 5.1186. all : sall, vb. 1.226 (\&c.) : befall 2.620, 3. 446 : wall 2.890 : hall 2.1682 (\&c.). - b) $0 N$. all. all : call 1.1054 (\&c.). hall : call 1.1126 . wallit : callit $1.1350,3.1446$. c) 0 E. æl. all : small 2.648 (\&c.). hall : small 2.1716, 3.1238. - d) $O N$. $\overline{\bar{m}} 1 \mathrm{l}$, see $\$ 244$ (c). - e) ON. $\overline{\mathrm{a}}+\mathrm{g}$. faw (feallan) : law (adj. ON. lag ) 2.1076. - f) Fr. al or Lat al? all : royall 1.1162 (\&c.) : angellicall 2.916 : liberall 2.972 : imperiall 3.988, 4.1114 : speciall 4.592 : universall 4.1976. hall : royall 1.1568 (\&c.) : collaterall 2.1630 : triumphall 4. 2452 . sall : mortall 3.1698. call : royall 1.1044. - g) Fr. ai. all : apparrell 5. 1944.

$\$ 265$. The rimes in (f) show that $a l$ is the regular representative of WS. eal in Clar., and herein there is perfect agreement with most ME. and MSc. texts; whether ONthmb. had $a l$ or $\breve{a l}$, it is plain that in the ME. period the vowel was short. The long vowel of mod. rec. sp. and diall. is of later origin; cf. Köllmann, p. 36. The rimes in (a), (b), (c), (d) are all in accordance with this, that in $(\mathrm{g})$ is not a correct rime, and is due to the unstressedness and consequent uncertainty in pronunc. of the final syll. in apparrell; for the scribe, too, it was not a pure rime.

$\S 266$. In (e) we have the only instance in rime of the vocalisation of $l$ after $a$, which is also found in other MSc. texts; the result of this vocalisation was either a diphthong au, or else the $l$ quite disappeared in $a l$ and the $u$ in the diphthong au (with which it rimes), leaving in both a broad open monophthong $\vec{a}$ or $\bar{a}$, Ellis's (AA) or (2a). Cf. Buss, pp. 509, 510, where a number of examples from $W$ all. are given. Bruce and the Sc. Leg. have not yet this vocalisation of $l$, but it is proved once by rime in the Troj. War; cf. further 'Th. Erc. Fawkirk (= Falkirk) 360, Dunb. fawd (= fold) : frawd : hawd (= hold) 49. 37, Satir. P. faa (= fall) : saw 45.690, wawis (= walls) : cause 24.32. Hence the confusion between $a l$ and $a$, the former being often used where there was originally no $l$, e. g. in K. Q. walking = waking, st. 173, Lyndes. Mon. walk = wake 4.5551, Roll. C. V. awvalk 1. 672, Montg. aualk MP. 43. 1. Cf. Murray, DSS. p. 123.

$\S 267$. Whether the development was $\bar{a} l>\bar{a}$ direct, or $\bar{a} l>\bar{a} u>\bar{a}$, this last is the well-known characteristic of the mod. Sc. diall. The words all, hall, fall, wall, call, \&c., are all to be found everywhere without any sign of the $l$, but with Ellis's (AA), (aa) or (O0). Burns' and other Sc. poems offer numerous examples of this. The form with $l$, when found in dial., is probably borrowed from rec. sp.

$\S 268$. $\beta$ ) WS. ea before ld (ONthmb. āld) - rimes with

a) itself. behold : tauld 1.966 : told 2.40 : fold, inf. 1.10 i0 : old : 2.754 : zold (prt. WS. zeald) 2.896 : zold, ptc. 2.1496 : bold 2.10110 : bauld 5. 2010 : wold (prt. North. walde, WS. wolde) 3. 1596. behanld : bald, adj. 1.864 : hald, inf. 5. 942 . behald : fold, inf. 4.306 : cauld, adj. 4.2456. 
hald, inf. : wold, prt. 5. 2678. houshold : moniefold 2.1772 : bold 4.724. old : bold 1. 1032 : wald, prt. 4. 2366. told : moniefold 4. 1320 : wold, prt. 4.1518 : hold, ptc. 5.220 : bold 5.1310. taulde : hauld, inf. 5.610. b) 0E. o. zold, prt. : gold 1.450. behold : gold 1. 804 (\&c., 10 times in all). bold : gold 4.1360. told : gold 5. 2440.

$\S 269$. WS. -eald, ONorth. - $\bar{a} l d$, produces in ME. no less than three different forms, -ald, -old, -eld, or four, if Morsb. (p. 154) is right in distinguishing between - eld and -êld. ME. -ald and -old both come from the OAngl. form -äld; -ọld is the form predominant in the Midl. and S. (where every $\vec{a}$ became $\bar{g}$ ) and is the origin of the form in mod. rec. sp.; - $\bar{a} l d$ (spelt also -auld in later Northern texts, esp. Scotch) is the Northern form. According to Kölbing (A m. p. 34) and Wilda (p. 13, \&c.) -eld is peculiar to Kt. and the N.; it is also found in the adjacent districts of the Midl. dial., though not frequent, according to Menze. Morsb., p. 154, says -eld, the shortness of whose vowel is proved by rime, is a form taken by Chauc. from the S., where $e a$ was not leugthened before $l d$, and often became $\breve{e}$; while -eld is the form known in the $\mathrm{N}$. of Engl., which has only a long vowel, $\bar{e}$, mut. of $\bar{a}$, having been transferred by analogy from the 2 and 3 sg. pres. indic. into the infin. Forms with $e$, short or long, are, then, liable to be found in all texts, except in the dial. of the S. W. We might also expect to find -old encroaching on the Northern territory just in the same measure as $o$ from general OE. $\bar{a}$ replaced the correct Northern form $a$ or $a i$; but as a matter of fact the combination -old was somewhat slower in forcing its way into the language of Sc. writers. It first appears in the N. of Engl. in the Surt. Ps., i. e. in the $2^{\text {nd }}$ half of the $13^{\text {th }}$ cent. (cf. Zielke, p. 20, Wende, p. 16, Dannenberg, p. 16; the last mentioned shows how far $o$ occurs in other Northern texts). It will probably be found that only those Sc. writers who are strongly influenced by Engl., e. g. James I (ct. Wischmann, p. 6), employ the $o$-form, which can only be explained as a direct copying of Engl. models, not as evidence of the spo k e $n$ language being influenced by a more Southern dial., for -ald was the correct Sc. form, as is shown by the mod. Sc. diall., and by its predominance (if not sole existence) in some even of the latest MSe. texts, written ald and auld, and the complete absence of -old from the earlier ones. Brace has only a, e. g. vald (prt.) : hall, inf. 16. 54, ald : suld, prt. 19. 178. As far as present materials go, there is no trace of 0 in Sc. writers before James I (behold : gold : cold, hold : wold : rold, \&c.); $o$ is also found in Gol., behold : gold, bold : gold (Noltemeier p. 23) and we have it in Clar., see above (b). Dunb. has $a$, $a u$ and $o$, according to Kanfmann, p. 50, who, however, only gives one example of $o$, and no rimes at all; Dougl. $a$, au, aw, ef. withhald : wald, prt. 2.26. 2, cauld : hald 2.27.18, tawld : hauld 2. 41. 8. \&c.; also o, e.g. behold : mold : yold 1.69.12, mony fold : gold 1. 70. 13, behold : gold, 1. \$!. 7.; Wynt. bald : cald (= named). In the later texts. such as Satir. P. and Montg., which have on the whole pure Sc., I can find no rimes with $o$, as far as examined; words of this class rime chiefly only with themselves, and only $a$ or $a u$ is written. For a sketch of the treatment of WS. eald in the rarious diall. of Engl. see Menze, p. 23 and ef. t. Br., $\$ 4$, Mursb., pp. $\$ 9$ and 154, Kölbing, Sir Tr.

Anglia. N. F. V. 
pp. 62, 69, A m. p. 25, Ip o m. pp. 159, 173, Dannenberg, p. 16, Zielke, p. 20, Danker, p. 7, Carstens, p. 8, Köllmann, p. 36.

We have no rimes in Clar. to prove definitely an $a$-pronunc., e. $g$. with such words as called, prt. (cf. bold : ytold : old : cald, Am. 1636), and it is difficult to say how far the anthor is responsible for the spelling with $a$, au; perhaps he, like James I, used only 0 -forms, and the scribe here, as in K. Q., is answerable for the $a$ and $a u$, which are also more frequent inside the verse than $o$, although the latter is not rare. In the absence of rimes of proof, the question mast be left unsettled; we only know that the author certainly used $o$-forms. The rimes with wold, wald, prt. prove nothing, as both forms, with $a$ and $o$, are proved by rime in Northern texts.

$\S 270$. There are two rimes which at first sight might lead us to suspect an $\bar{e}$-form; but very slight and probable emendations remove the necessity of interpreting in this way. For the one, see $\$ 173$; the other is in Bk. 3. 1. 1890, where the MS. has: "That pitie it had beine for to behold Ane efter vther he in his armes fold And kissit them bot micht no wirdis say", \&c. It is evident that fold is intended as a prt. and the correct strong form for the pret. of $\mathrm{OE}$. fealdan, feold, wonld be in $\mathrm{ME}$. and MSc. fẹld, on the analogy of hệld from hēld. This form is found, too, in ME., e. g. Fer. felde : schelde (= shield) 841 . The question is, whether it is really found anywhere in any Sc. text; if so, the rime here may prove an $e$-pronunc. in the infin. behold, which should then be written beheld, or beheild. But instead of armes fold (3 syll.) we can read arm(e)s did fold or can fold; for the ending -es, generally written -is, is a very convenient instrument in the hands of the author, who treats it as a full syll. or suppresses it altogether, just as it pleases him, according as it suits the metre or not. We have to make a similar emendation in another case, viz. 5. 2677-8, "And in fyve dayis as Dame Fortoun wold Toward the land lustilie thay hald". All the surrounding verbs are preterites, so it is probable that the verb in the second line of the couplet should also be a pret., and the correct form for this would be held; if this is so, then wold should be weld, an impossible form; therefore we mast read, "Towárd the lánd thay lústilié did hóld", or can hold, especially as this redeems the metre of the line, which is imperfect as it stands in the MS. Piper's emendation, insertion of full before lustilie, sets the metre right, but then, if the rime is to be saved, hald must be taken as a historic present, in the midst of a lot of preterites; this, it is true, is not impossible with MSc. writers, but we need not accept it, where we are not compelled to do so; some change from the MS. is necessary, and the above emendation removes all difficulties; in either case, the nature of the rime here remains the same.

$\S 271$. There is no proof, then, of an $\bar{e}$-form in Clar.; such are, in fact, rare in Sc., though frequently found in N. Engl. The fact that they do not occur solely in verbal forms of the hold-class, is against Morsbach's explanation of the length of the $\bar{e}$. J am. Dict. gives the form beild, adj. = bold, quoting from Houlate; it also gives eild, as an adj. = old, in Dougl. Virg. (but in Small's edit. this is altered to the nowm 
eld = old-age); we also find in Dougl. eldfader, eldmoderis. Zielke, p. 20, quotes from Sir Egl. the rime elde (eald) : felde; Wilda, p. 33, from Bone Flor. welde: behelde : schylde : belde, and welde : felde : helde : belde. Such preterites as zeld, teld, seld, \&c., quoted by Kölbing, Sir Tr., p. 62, cannot always be explained (as by Dannenberg, p. 16, note) as new-formed preterites from the pres. forms zeld, tell, sell, \&c.; this is satisfactory only when the vowel is short, and is undoubtedly the correct explanation of the forms in the mod. diall. with short $\zeta$, see below, $\S 273$. But they are also found with long vowel in Northern ME. texts, e.g. Sir Tr. teld, prt. : feld : zeld, inf. : beheld, inf. 3252 , teld : zeld, prt. : queld : scheld : feld : biheld (biheold) \&c.; Bone Flor. (Wilda, p. 33) welde : schylde (for schelde) : selde, welde : felde : helde : belde. Similarly apparently in the S. E., where according to Morsb. we should expect a short vowel, e. g. Lyb. Disc. (Wilda, p. 13) telde : scheld, G a y W. (Wilda, p. 51) teld : feld, helde : felde : yelde; although here, too, the scort vowel is found, to judge from a similar rime in $\mathrm{Lyb}$. $\mathrm{D}$ is c., beld : dwellde : held; otherwise we must suppose that in the preterite dwellde, the vowel has undergone a secondary lengthening. It seems better, then, to leave the $e$ in -eld<-eald as a kind of "schwebender vokal" (see t. Br., p. 26, and below $\S 362)$, for the explanation of -eld and -eld from different origins does not always suffice. Kölbing, Sir Tr., pp. 69, 70, has shown that all three forms, with $a, o$ and $e$ are met with in N. Engl. in the middle of the $14^{\text {th }}$ cent. (cf. also Ellinger, p. 12, Zielke, p. 20). Besides Sir Tr., Sir Perc. and Sir Egl. and the works previously quoted, the $e$-form is found in Sir. Torr. (Adam, p. 11), Lyric Poems (Schliiter, p. 16), Ip om. (Kölbing p. 159) and Sir Gaw. (Knigge, p. 19).

$\S 272$. The form wield in rec. sp. is generally derived from $\mathrm{OE}$. -weldan; in $\mathrm{Kt}$. and the N., however, OE. wealdan might have produced the same form, ME. welden, NE. wild; and perhaps this coincidence of the two verbs assisted the final supremacy of the form $w e i d>$ wild instead ${ }^{*} w \bar{a}^{\prime} d>^{*} w \overline{o l} d$. We have a similar form (in pronunc.) in the Weald (in Kent and Sussex); this is certainly a Kentish form and derived from OE. weald $=$ Germ. wald. In the Wolds of Yorks. we have the corresponding Midl. form, wäld $>w \bar{y} \cdot d>w o$ ld. The orthography of Weald would point to a ME. wẹld, while that of wield would rather indicate a ME. wẹld; so that, if any weight can be laid on this difference, wield, if derived from wealclan, can only be a Northern form. But still, OE. -weldan satisfacturily explains the mod. form.

$\S 273$. The mod. Sc. diall. have only the broad (AA) sound, or something near it; sometimes the $d$ has disappeared, so in bold, old, cold, fold, to'd, which all appear with (AAl). Sometimes the $l$ has been vocalised and disappeared; so always in hold, and occasionally in old, fold, cold, sold, told - (haad, aad, fAAd, kAAd, sat, taad). The two last mentioned are often found in the forms selt, telt, corresponding to the ME. forms mentioned above, new-formed from the pres. tell, sell. Forns with ld are also given by Ellis, e.g. (AAld, baAld, kAAld, faAld, saAld, taald) but wever (haAld) only (hAAd, haad) or (had). 
Probably in this combination the $l$ disappeared directly, without first producing a diphthong au, ef. Satir. P. call thame : forbade thame 45.114.

\section{EA'}

§ 274. 1. = Gmc. an

a. Not followed by w or gutt. - rimes with

a) itself. heid (hê̈fod) : deid (mortuns) $3.374: \operatorname{reid}(e)$, adj. 4.938 (\&c.). heade : reide 4.536. deid (mors) : breid (panis) 3.744. - b) OE.

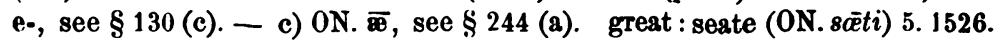

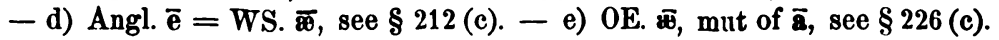
- f) OE. a. clave (prt. clēefan) : drave, draue 1. 48, 730. - g) OE. e: dreidles : gentilnes 1.1530 : worthines $2.778:$ nobilnes 5. 1008. saikles : hevines 3. 662, and others. - h) OE. ea: grit (grëät) : zet (porta) 5. 2470. bereft : beft (= beaten, ptc.) 3. 732, ef. below $\$ 279 . \quad$ i) OE. i. leaue, sb. : give 3.1014, leave : geine 4.146. - k) Fr. e ( $\alpha$-class). eist : feist 5. 606. eare : weir (bellum) 3.1194. doubtles : maistres 3. 800. - l) Fr. e ( $\gamma$-class). reid (adj.) : remeid 1.442, 3.1590. deid (mortaus) : remeid 4. 122 (\&c.). deid, dead (mors) : remeid 3.1696, 2270. great : repeit 1.1146, 5. 2568 : quyet 2. 330, grite : repeit 5. 1360. leave, sb. : greine 1. 878 : mischeve (vb. meschever) 1.1258. eare : cleire 5. 814. - m) OFr. ai. great : treite, vb. 5.1348. - n) Du. i (?). doubtles : ges, vb. (= MLG. gissen, Bradley) 3. 2406.

$\S 275$. OE. $\overline{e a}$ belongs to t. Br.'s $\alpha$-class, but as shown above, in $\S 122$ \&c., it produces $\bar{e}$ in Sc. in most positions, and not only in a special class of words in which the ea was followed by $c, g$ or $h$, and became $e$ already in the OE. period, for which cf. above $\$ \$ 217-225$. Hence we have $\alpha: \gamma$ rimes in (l). There can be no doubt about these rimes, they clearly prove that $\overline{e a}$ had, at any rate in some words, become $\bar{e}$ in Scotl.; the rime-words rime frequently with other recognised $\gamma$-vowels.

$\S 276$. The beginnings of this are apparent in the ONthmb. dial., where $\bar{e}$ is found for WS. $\bar{e} a$ before other consonants than $c, g, h$, e.g. in ned, neten (pecus), $\bar{e} \delta o r$ (facilins), \&c., (Hilmer, p. 26). And there was much confusion between the symbols $e a$ and $e o$; for instance, the following forms are found, with $\overline{e o}$ for WS. $\overline{e a}$ : rēfia (diripere), rēof (spolinm),

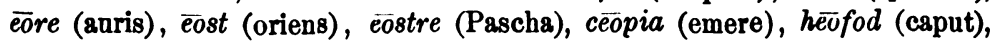
lēof (folium); see Hilmer, p. 31. (The $\overline{e a}$ form is found as well; it is not to be understood that these words are only found with $\bar{e} 0$ ). These peculiarities of the $0 \mathrm{Nthmb}$. dial. are sufficient to explain the early existence of $\bar{e}$ for $\mathrm{OE} . \overline{e a}$ in the N.; most probably it was $\bar{e}$ from the very beginning of the ME. period, at least in some words.

$\S 277$. With regard to the orthography in Clar., we notice that in these words $e a$ is occasionally written, whereas it is rarely, if at all, used for the $\bar{e}$ from $\mathrm{OE} . \overline{e \bar{u}}$, \&c. (Class $\gamma$ ). This difference is probably only due to a scribe, for whom there was an appreciable difference between the two sets of vowels; the author scarcely wrote such imperfect eyerimes as leave : greine, eare : weir : cleir, great : repeit. But it is very difficult to distinguish between the orthographies of author and scribe; 
there is no approach to consistency on the part of the latter, and we do not know, in fact, through how many hands the copying has gone, before arriving at the form of our MS.

$\S 278$. We have $\alpha: \alpha$ rimes in (a), (b), (c), (k) and (m); those in (c) and (m) have a different meaning, however, from the others, ef. $\S \S 245$, $108 ; \alpha: \beta$ rimes in (d) and (e).

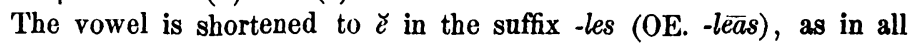

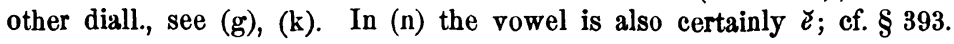

$\S 279$. Also when shortened in verbal contracted forms the vowel seems to have been $\breve{\iota}$, not $\breve{a}$, e. g. bereft, see (e) and (h). The rime-word in (h), beft, is given by Murray, NED. s. v. beft, as only found in the N. as prt. and ptc.; "it is uncertain whether the pres. would be beff, of the same origin as baff, sb., or beft, = 0North. *beafta or *beaftia for *behaftian, from be- + OE. haftian, to clap, strike with the flat of the hand". Jam. Dict. gives pres. beff or baff, but quotes no examples for this. Cf. Dunb. beft prt. : heft 26. 40, beft 33. 78 .

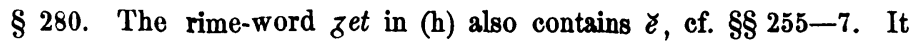
seems that the author knew three forms for the word great, viz. gret, see (c) and (m), gř̌t, see (h), and grīt, see (b) and (l), and the scribe yet another, $g r y t$, for he often spells the word so to the detriment of the outward appearance of the rime, e. g. grite : eit, grite : repeit, grit : zet. The word is also irregular in the mod. Sc. diall., appearing, as will be seen below, in three different forms, chiefly in the furm gret, as in rec. sp., but, strange to say, never as grit; it seems, therefore, to be an exception to our rules made above, and rather to agree with t. Br.'s rules: i. e. if Ellis EEP. V. is correct.

$\S 281$. The rimes in (i) are a farther proof of the closed nature of the earlier $\bar{e}$, cf. $\S 120$. Here again the rimes were not pure for the scribe.

$\S 282$. 'The form clave, see (f), with undoubted $\bar{c}<\bar{a}$, cannot be anyhow explained as regularly developed from OE. cleâf. It is no exceptional form, for it is found in all Sc. texts and also in Engl.; it is, in fact, not yet entirely extinct in Engl., still retaining an artificial existence from its occurrence in the Bible (Ps. 76. 15). It is a parallel form to chase (cf. t. Br. Chauc. pp. 38,40), and sinilar forms may be found of the preterites of one or two other verbs of Class II in ME. 'The following examples are given by Wackerzapp, pp. 3 i \&c. - Curs. M., E. claue : draue; Curs. M., A., raf, chas : was, claue : draf, claif : draif, claf : raf; Metr. Engl. Hom., raf; Y ork P. chaas: grace, raffe; H. Les. raf; Yw. Gaw. rafe; Bruce, claf : gaf, clave : gave, claff : gaff, (clafe : drafe), flaw; Townl. M. rafe : grave, rofe, clofe : grafe; Alex. rofe; Rel. P. chose, raue; Thornt. Rom. chese : was, rafe; Sc. Leg. crape, rafe: strafe: late : clafe, grate, rayf, flaw : saw, rawe, clawe; Gol. flaw, claif (also grat 1141); Dunb. claif, raif (also crap, see Kaufmann, p. 101); Lanc. flaw; Dougl. crap : hap, raif : cave, flaw : law; Ly ndes. raue : graue, raif, flaw : law : raw. To these we can add - Montg. crap : mishap : trap, S. 38, : lap : urap : mishap, S. 47, : hap, MP. 4. 41 : shap : lap, 
MP. 32. 53. From the last it seems that the vowel was later liable to shortening.

$\S 283$. Similar forms are found in the S. (but not to such an extent as in the N.), with an $\bar{a}$, which, according to t. Br. p. 38, never became $\bar{q}$; the $\bar{o}$-forms, which also appear, are explained by $\mathrm{t}$. Br. as resulting from assimilation to the forms of the prt. plur. and pp.; bat is it not possible to explain this $\bar{\sigma}$ as arising out of the $\bar{a}$ which is found so frequently in the N.? (If so, then Bulbring's suggestion, p. 89, that forbode in Trev. and $\mathrm{Sh}$. is a Northern form, may be justified). Or, if not, we can explain the $\delta$ as arising independently in the $S$. similarly to the $a$-forms in the $N$., see $\S 284$. Perhaps, too, we can explain in this way the few $\bar{a}$-forms which appear in the Midl. and S., e.g. chas, Chauc., see t. Br. $\S 35$; this is better than changing chās into chēs (cf. Bülbring, p. 90, and t. Br.'s note thereto); the rarity of the examples with $\bar{a}$, would be, of course, due to the Midl. and Southn tendency to change $\bar{a}$ to $\bar{q}$. There can be no doubt as to the $\bar{a}$ being proved in Southern texts, whether they were regularly developed there as in the $N$., or simply taken from the $N$., and a possible explanation of the later 0 -forms is, that they arose from these $\bar{a}$-forms, perhaps helped by plural forms with $o$, as t. Br., p. 38 , explains for chose, from ME. chōsen. The forms with short $\breve{a}$ in Kt., ssat $(<s c \overline{e a} t)$, lhapp, Ayenb., \&c., are different in nature; see Konrath in Herrig's Archiv, 88. 1. p. 58, \&c.

$\S 284$. The $\bar{a}$-forms in the $\mathrm{N}$. were most probably due to the influence of other classes of strong verbs which had $\bar{a}$ in ME. in the pret. sg., viz. Classes I, IV and V, especially Class IV. The strong verbs of Class II were very few in number in ME., as most of those which existed in $0 E$. had either died out, or become weak; at the same time, the few remaining verbs would in the $N$., in their regular development, have the same vowel $\ddot{e}$ both in pres. and prt.sg., for here $\bar{e} \dot{e}>\bar{e}$ and $\bar{e} 0>\bar{e}$; hence we should have the forms, prs. crệp, prt. crệp, cropen, ptc. crōpen, clẹv, clệv, clōven, clōven, \&c, or, after the plur. prt. had been assimilated to the sg., clẹv, clẹv, clẹven or clẹv, cloven or clōv; \&c. These verbs would then stand quite alone in having no distinction between the vowel-sounds of pres. and prt., and it was, therefore, an easy change to adopt for the pret. the vowel of another class, and an $a$-vowel being the sign of the pret. in Classes I, III, IV, V (in three of them long $\bar{a}$ ), $a$ had the most chance of being adopted, especially as in Class IV the vowels corresponded with those of Class II in pres. and pptc.; e.g. bẹrr, barr, born; hence crẹ̣p, crẹp $p$, cropen became crẹp, crā $\bar{p}$, crōpen.

That this change should have taken place chiefly, if not only (i. e. in the first instance) in the $N$., is easily understood; for in the $S$. there was no coincidence of the vowels of the prs. and prt., prs. cręp, prt. crẹp; and that it was an easy matter for $\bar{q}$ to assert itself later in the $\mathbf{S}$., is also easily understood, because the prt. pl. and ptc. had already $o$, and there was a tendency to make prt. and ptc. alike in other verbs. Bülbring, p. 90, rewarks that the forms found in Lay. se em to be formed from analogy with Class IV (Class I in his scheme), but he rejects this explanation and prefers to understand the $a$ as being $=e$, which is not so satisfactory in 
the face of undoubted $a$-rimes, and even if this were the right explanation for the $S$., the numerous Northern forms would still require explanation.

It is possible that in the $\mathrm{N}$. there were other influences at work, e. g. confusion with similar forms from the Norse. This was certainly the case with the verb reofan, which was confused with $0 \mathrm{~N}$. rifa; in ME. the verb has gone completely over to Class I, rīv, rāu, rtven. Or are we to consider that $0 \mathrm{E}$. reufan died out altogether and that the ME. rive has nothing whatever to do with it? Against this is the fact that the form ref is found for the prt., e.g. in Curs. M.

$\S 285$. The $a$-forms still exist in Scotl., but chiefly with a short vowel; cf. grat, prt. of grit, OE. grētan, e. g. in Banffshire, also crap in Gentle Shepherd, v. 1. (Murray DSS. p. 204). Mr. Low gives me the forms grat and crap for Forfarshire, but says the latter is mostly replaced by the weak form crepit (kriipit). See also Jam. Dict. s. v. greit, grat : sat, Border Minst. 2. 120, grat: gat, Ramsay's Poems 2. 143; also the forms crap and craup as prt. of creep. The verb OE. cēesan became generally weak in Sc., chesit is the most usual form of the prt.

$\S 286$. The mod. Sc. diall. are not at all uniform in their representation of $0 \mathrm{E} . \overline{e a}$; from the MSc. rimes we should expect to find $\bar{l}$ in all words; this is so in most of them, but other forms with $\nearrow, \bar{e}, \bar{e}$ are found as well, thongh far less frequent. How far these are pure vernacular forms and how far they are affected by rec. sp. is difficult to say. The can be interpreted in two ways, either as shortened from $\tau$ or as a devel-

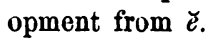

$\overline{1}$ is found in head (in $34,35,38,41)$, dead $(34,35,36,38,41)$, lead, plumbum $(35,41)$, red $(35,36,41)$, bread $(35,38,41)$, deaf $(34,35,36)$, leaf (35), team (35), bean $(35,38)$, death (41).

$I$ is found in head $(33,36,37,39,41)$, dead $(33,36,39)$, lead, plumbum, $(33,39)$, red $(33,34,35,36,37,39)$, bread $(33,35,39)$, sheaf $(33)$, deaf $(33,36)$, leat $(33)$, team $(33)$, bean $(33,39)$, cheap $(33)$, great $(34)$, threat (33), death $(33,37)$, heap (33). It is to be remembered here, however, that many of the vowels marked short by Murray in D. 33, were really medial, and this applies to some of the pronunciations given by Ellis in 34 and 35, so that the (i) of the words in the list just given may correctly reflect perhaps a MSc. è.

$\check{\mathbf{e}}$ is found in head $(37,39)$, dead (39), leal = plumbum $(38,39)$, red (37, 38, 39), bread (35), sheaf $(38,39)$, deaf $(37,38,39)$, leaf $(38,39)$, cheap $(38,39)$, great $(33)$, threat $(34,38,39)$; death $(35,37,38,39)$, beat $(34)$. In D. 38. the $e$ is of a very close nature. It will be noticed that the $\check{e}$ is found chiefly in 37,38 and 39 , and mostly in such words as have $\breve{e}$ in rec. sp. This arouses at once suspicion that Ellis perhaps did not obtain pure dial. here.

$\overline{\mathbf{e}}$ is found in head (36), bread (39), sheaf $(35,41)$, cheap (35), great $(33,35,39,40)$, threat $(35)$, death $(34,35,36,39)$. This is all the more remarkable as it occurs even in words which in rec. sp. have $i$, e. g. sheaf, cheap. 


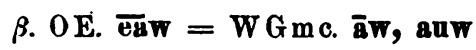

$\S 287$. rimes with

a) OE. $\overline{\mathrm{a}}+$ w. shaw : know 1.1298 (\&c.), schawin : unknawin 3.1410. - b) OE. $\overline{\mathbf{a}}+$ g. show : throw (OE. prag, sb. = time) 3.1028, shew (inf.): throw 3.1346. - c) Lat. au. shawid : land, sb. 1. 786.

$\S 288$. OE. $\overline{e u} w$ appears in ME. in various torms, the variety being partly due to difference of dial, and partly to the difference in development of -eaw- (medial) and -eaw (final); $\bar{e}, a, q u, a u, o u$ are all found, and at least three of these $e u, a u$, ou, are represented in mod. rec. sp., e. g. in dew, straw, show, the latter also spelt shew from ME. sheu). Acc. to t. Br. -eaw (final) can produce $\bar{e}$ or $a u$, and -ếw- (medial) $e u$, ou or $a u$ (see his note to Bülbring, p. 105, and Chanc. pp. 30, 39). The regular development in Engl. is without doubt eaw > ME. ëu, i. e. ëu > ME. ę, as usual under ordinary circumstances; so in the words NE. dew, feev, hew, shrew, thew and ME. shew, i. e. in the majority of words of this class.

$\S 289$. ME. $\bar{q}$ for $O E$. $\bar{e} a w$ is explained from the early loss of final $w$ (see t. Br. $\$ 44$, note). ME. $a$ might be explained in a similar way, if we could only find forms with $\bar{a} w$ instead of $\overline{\epsilon a} w$ in OE., a possibility in which one is at first inclined to believe, as it would not only explain ME. $\bar{a}$ but also ME. au and ou more simply than is otherwise possible, and put the forms straw, \&c., on a level with knaw (OE. cnäwan) \&c. We might perhaps compare the OFris. forms hãwa, skāwia, dāw, unless the $\bar{a} w$ here is nothing more than an orthographical variety for auw, which is sometimes found in the same words. But such forms are not to be found in ONthmb.; bleâwa appears occasionally for bläwa (Hilmer p. 33), but as yet we have no evidence of the reverse interchange, $\bar{a} w$ for $\bar{e} w w$.

$\S 290$. But we can explain satisfactorily from internal processes and Norse influence. The only word which is as yet found with $\bar{a}$ in MSe. (and represented in NSc. correctly by $e$ or $i$, see below, $\S 296$ ) is the word straw, OE. strëav; (the form fo, Gen. Ex., see below, makes a previous form ${ }^{*} f \bar{a}$ necessary). The $\bar{a}$-form is not mentioned by t. Br. as it does not occur in Chauc., but it is well-known in Sc., e.g. Bruce, stra : sa 3. 320 : ta 3. 506, Dunb. stray, strae (Kaufmann p. 59), Dougl. stray : way (see J a m. Dict. s. v. stra, strae, stray), Roll. C. V. strayis : fais : slayis : gais 4. 391, Satir. P. strais : hais (= has) 16. 78, Montg. strais, MP. 3. 36; (Compl. Sc. has strey, which probably means strę); also in the NMidl., e. g. Hav. stra : $g a$ (vb.) : wa, see Sweet p. $35 \%$.

We shall probably be right in ascribing this form stra $a$ to Norse influence, 0N. strá. This then ousted the form strę < streâw and probably forced its way into the forms of the oblique cases, i. e. instead of strę, stręwes came the forms stră, sträwes, whence the form straw, which must be looked upon as a specially Northern form, if the above be correct.

A similar explanation can be applied to the word raw (the only other word in this class with $a w$ in rec. sp.), viz. influence of $0 \mathrm{~N}$. hrar.

$\S 291$. The only other Scotch words I can find with aw are schaw and fawely. The latter is given by Jam. Dict. as an adv. = fewly, few in number, and can also be explained from Norse influence, $0 \mathrm{~N}$. fär. fowe, 
vawe $=$ few, are also found in Rob. Gl., also fo: wo in Gen. Ex., fo : to : go, in Rob. Br., fone, North. (Sweet, p. 352) and Cooper (1685) gives (fo) as a "barbarous" pronunciation of few. Jam. Dict. gives schrow for schrew, schrowis : plowis, Maitl. Po ems, and the verb to schro (= to curse); the $o$ is very remarkable here (perhaps for $a$ through the imitation of Southern forms again?).

\$ 292. Schaw is fund in all MSc. texts, so also in Clar., see the rimes above, all of which contain only au. (The rime in S c. L eg. schaw : Androw, $5 / 151$, is remarkable). Sweet, $\$ 680$, says "the $e$ seems to have been absorbed by the preceding front cons., the length being shifted on to the $a$, our present show pointing to schäwen, although Ancr. R.'s schawen points to short $a$ ". This is better than Morsb.'s explanation (p. 74), " "ē $>\bar{a}$ through influence of $w$ ". If the latter were correct, we should expect to find aw oftener, but the words hew, few, dew, thew, never appear with aw, even in the N., and sceavian, being the only word of this class beginning with $s c$, can very well have had a special development of its own. The show of rec. sp. must also be derived from a form shaw; the two forms shaw and show stand in the same relation to one another as knaw and know, or blaw and blow; the one is Sc., the other Engl.

§ 293. There is yet another explanation, which, it is true, explains all the other au forms as well, without the help of Norse influence, but it is not so simple, although it is possible and can be in part supported by analogous evidence. It is as follows - éäw $>\bar{a} w>\check{e} w>\check{a} u>\check{a} u$, and then further $\breve{a} u>\bar{a} u>\bar{q} u$ for the Sonthern ow, or $\breve{a} u>\bar{a} u>\bar{a}$, for MSc. strä, \&c. For the first step, $\bar{e} \omega w>\bar{e} w$ : Orm mostly writes $a w$, shcewenn, hawenn, faewe, \&c., and $\bar{a}$ is found for $\overline{e a}$ in ONthmb., e.g. $\bar{e} w i a$ (manifestare) for WS. éawian (Hilmer, p. 26). For the $\breve{a} w$ and $\breve{a} w$ stages: there are other traces to be found of $a$ or $\breve{a}$ as the shortened form of OE. $e a$ (cf. Menze p. 72; Peterb. Chron. has fou) and these have been explained through an older $\bar{c}$ for $e \bar{a}$; the words NE. lather, chaffer, chapman, for instance, contain $a$ from $\mathrm{OE}$. e $a$; the suffix -līus appears as -las as well as -les in MSc.; the word near appears as ner and nar; Orm has the forms drah and lafe for $\mathrm{OE}$. drcag and geleafa.

$\$ 2$ 2!4. $\Lambda_{\mathrm{n}}$ au from OE. ecur is therefore not impossible, though it is difficult to see why it is not found in more words than it is; and why, if schaw is to be explained in the same way, it is the only word (besides fowe, fo, for $f(c w)$ which appears in Southern Engl. with ou. Sclkaw must have an explanation of its own, as given by Sweet, and so probably straw, raw, and fawe, fowe, to (from Norse influence) although the latter may have had the development traced above, with a Norse side-influence working in favour of the establishment of the $a$-forns. One thing is particularly worthy of notice, viz. that the SE. shows here again its similarity to the N. (fo in Ge n. Ex. \&c.).

$\S 295$. The $e$, $a$ furms, with loss of $w$, in ME., can only be developed from final $e(i w$, if they are of pure native growth. They are never found in verbal forms; this is because the $w$ could not, except in the imperat., a comparatively seldom used form, appear in final position, whereas in nouns and adjectives the num. case, generally the most important, ended, 
of course, in $w$. But it is difficult to see why t. Br., while recognising au as a possible form from final ea $a w$, should not allow eu from final as well as medial $\overline{e a} w$.

The author of Clar. only knew, as far as the rimes in $\$ 287$ show, the form schaw for OE. sceawian, whether the au had already become $\overline{8}$ cannot be decided from the rimes; (the final $u$ of the diphthong au had disappeared in the second half of the 16 th cent. in some parts of Scotl., cf. Satir P. saa (= saw, prt.) : Spaa 45. 520). The scribes knew also the forms with eu and ou, schew, schow, and perhaps the $o$ form may also have been known to the author, as in the word know, cf. $\$ 55$.

$\S 296$. Show is not included in Ellis's lists of the mod. Sc. diall. (it is a rare word in the Sc. vernacular, and, when found, has the pronunc. of rec. sp., according to Mr. Low's information). But know, where used, has $\bar{a}$, like the words blow, throw, \&c. Slow has $\bar{a}$ in 33 , in the other diall. $\bar{o}$ is given. Raw always $\bar{a}$ or $\bar{a}(\mathrm{AA})$. Straw has $\left(i^{\prime}\right)$ in 33 , and $\bar{e}$ in most of the other diall. (both the equivalent of ME. $\bar{a}$ ), in 41 it has also and in $42, \vec{a}$, (the latter, the equivalent of MSc. $a u$ ). Few has (iu) or (iuu) in 33 . 35,36 and 42 , but (iau) in $37,38,39$, also (ǐu) in 39 , (iəu) in 40 , and $\left(\partial^{1} \mathrm{u}\right)$ as well as (iuu) in 33.

2. $\overline{e a}$ through contraction from a $+\mathbf{a}, \mathbf{a}+\mathbf{0}, \& \mathbf{c}$.

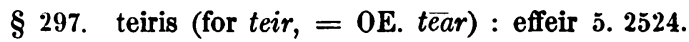

There is no difference in the treatment of this $\overline{e a}$ and that of $\overline{e a}<$ Gmc. $\overline{a u}$. For the rime cf. $\S 250$; the vowel is here $\bar{\imath}<\bar{e}$.

\section{EO -}

§ 298. Only four examples. - a) hevin and sevin rime together, 5. 1928. - b) bent (OE. beonet?) : went, 3.1900 (OE. e). - c) swyre (OE. sweora, neck) : desyre, 4.1776 (Fr. i).

$\$ 299$. Whether the vowel in hevin, sevin, is short or long in the dial. of Clar. cannot be decided, but the spelling with $e$ (not $e i$ ), indicates shortness of vowel for the scribe. That long $\bar{e}$ also existed in MSc., just as in ME., is proved by the long $i$ still found in some of the mod. diall.; both words appear with $\tau$ in 35,37 and 41 . Forms with $\tau$ and also $z$ are found as well.

$\S 300$. bent is included here, according to the etymology usually given to it, which must remain till a more satisfactory one is found; ef. Murray NE. Dict. It always rimes with short $\breve{e}$ everywhere.

$\S 301$. swyre would perhaps be more correctly placed under $i$ or $y$, for the word is found in OE. with $i$ or $y$ (see Koch, Ztsfdph. V. 38, \&c.), which is here lengthened in open syll., but rimes, contrary to the usage of $i$ and $y$ when lengthened (see below $\$ 364 \mathrm{ff}$.), with Fr. $i$. Similar rimes are found in Dougl. swire : fire : desire : conspire 1.12.28, Satir P. swyre : myre : fyre, 39. 350; Hav. swire : sire, 311 . The rime in Do ugl. swair : euirmair, 2. 26. 18, is difficult of explanation. As used in Clar. the word means a neck between two hills, or mountain hollow, "the buks go bak them in the swyre"; so also in Bruce "redis swyre" 
17.13 (cf. Skeat's note thereto). Jam. Dict. says the word is confined to the S. of Scotl. in secondary senses.

\section{EO:}

$\S 302$. 1. Before $\mathbf{r}+$ cons. - rimes with

a) itself. hart (heorte) : smart 1.122, heart : smert 3. 152, hearts : smarts 3.626. - b) OE. ca = Angl. a (before $r+$ cons.). heart : inwart 2. 242,1391 : invart 3.1472 : efterwarte 4.2188. - c) OE. (with metathesis). hearts : carts (crcet) 3.1644. - d) OE. or ON. e. heart : start (prt. ON. sterta) 1.160. warke (weork) : sarke (OE. serce $=$ ON. serkr) 2. 1404. - e) Fr. or Lat. e. heart : advert 1.526 : revert 3. 1534, 4. 2758. smart : expert 5. 1492. sterve : serve 1. 290, 4. 2270 : proterve 1.1038 : conserve 2. 386. - f) Fr. a. heart : dairt, 1.168 : dairte 5.1334 : deart 5.1038 : part 2. 178 : depairt 1. 1380 : pairt (sb.) 4. 386, 702 : escart (escarter $=$ discard) 2.1500, hart : depairt 1. 1514, 5. 2526.

$\S 303$. OE. eo became ME. $e$ through $\propto$ (Sweet $\S 658$ ); but before $r$ there was a tendency in some diall. to change $e$ to $a$, which according to Sweet (see Brandl, p. 57, Kluge PG. 1. 8i7) began earliest in the $N$. and came into full operation in the 15 th cent., but traces of it are to be found in the Midl. dial. of the $14^{\text {th }}$ cent., e. g. in Cha u c. (see t. Br. $\S 48$. V) and Rob. of Br. (Menze p. 30), though not proved by rime. The statements of Sweet and Brandl concerning the $N$. are based on rimes in some of the earliest known Northn specimens of ME. Brandl, l. c., remarks on the frequency of $a$ for earlier $e$ in the Mss. of Brace and Townl. M., but can find no rime to prove an $a$-pronunc.; $e: a$ rimes are, however, to be found, e. g. starnys : tharnys (ON. parna, parnask, see Stratm.-Bradl. s. v. and Brate, p. 6(1), hart : quart in Townl. M. (Sweet HoES., pp. 306, $308)$ and there is at least one such in Bruce, viz. Jarne (adv. = diligently, OE. georne) : farne (ptc. $=$ fared, OE. faren) 3.548 ; and for a still older date we have charre (vb. formed from $\mathrm{sb} .=\mathrm{OE}$. cerr) : waire (OE. war, adj.) in Metr. Hom. (Sweet, p. 306), which were written according to Sweet, $\S 584$, early in the $13^{\text {th }}$ cent. (? Is this a mistake for $14^{\text {th }}$ ?). Perhaps we should read ar for er in some of the other rimes in Bruce and the $a$ in the texts is not perhaps always due to the copyist; in fact, the change might have been made by the copyist in the contrary direction, if he belonged to another dial. in which er had not become ar. The rarity of rimes of proof (perhaps the above is the only one which proves $a$ ) is not to be wondered at so much, seeing that the author seems altogether to have avoided rimes with words ending in vowellike + cons.; we shall see further below that not a single rime in -ind is to be found; the proportion of rimes ending in vowel-like + cons. to the total number is very small indeed, only particular combinations seem to be ased at all; the saine is to be noticed in other carly Sc. texts.

$\S 304$. The spelling with $a$ is found in Sc. texts from Bruce on, and in most of them it is apparently corroborated occasionally by rime; e.g. Sc. Leg. zarne : barne (= child) 32,82 (and again seven times in Vol. 1) and perhaps in the following - wark : mark (vb. = direct, wend; 
march) 134/784, vark : merk 65/204, bark (vb.) : marik, sb. 188/778, ware (= worse) : skere (? = scare) 218,36 , merrys (vb. 3. sg. merran) : skaris (MS. sakiris, prob. = scares?) 226/596. In the rime hard (heard) : ferd (= fared, behaved, went), which appears so often, the form ferd can be derived frum OE. féran (instead of faran) and so is not a good example; some of the other rimes, too, may admit of an e-pronunc., e.g. merk, and others are not certain as to meaning. - K. Q. hart : art (2. sg. = es) 114 . - Wall. hart : part 1. 386 : Eduuart 11.850 : Stwart 10.170. - Gol. has no rimes proving $a$ according to Noltemeier p. 24 ; although $a$ is generally written in the MS. in the word hart (heorte), yet the rimes rather prove $e$ even in this word, and $e$ is written in most other words, and occasionally in hert itself. The $a$ is either dae to the pronunc. at the time of printing (as Nolt. says); or else to a more Southern copyist; ef. mer (= mar) : wer (= worse, often found in Sc. as war) : ner (= near) : fer (= far) 1019. - Lan c. asstart : depart 1138, hart : dart 1228, hard (= NE. heard, ptc.) : hard (= OE. heard, adj.) 1654, hart : part 1796, \&c. Rat. Rav. hart : efterwart 2. 18. - Dunb. bark : clerk : merk : sark, p. 18, clerkis : warkis : markis, sb., p. 81, far : bar, sb., p. 169, far : ar : war, adj. : dar p. 177. - Dougl. hart : depart, 2. 217, 6, marrit (= marred) : charrit (OE. cerran) : skanvit (= skared) : misharrit (OE. mis. + OE. heorra or $\mathrm{ON}$. hiarri?) 1. 13.17, hart : expert : art, sb. : ouir brouderit 1. 21.22, outwart : hart 2.34. 24, hart : part 2. 50.31, covart : hart : apirsmart 1. 73. 2, \&c. Cf. from the $16^{\text {th }}$ cent. Lyndes expart : art Sq. M. 1158, Roll. C. V. Hart : inwart : smart : conuart (= converted) 1. 180, hart : reuert : aduert : smart : part 1.692; Satir P. pairt : desert 35. 9, clerks : barks, 8. 45, departit : harlit 10. 394, partis : peruertis : startis : hartis 12. 50, \&c. - Montg. dairt : heart C. 164, clarkis : markis C. 406, hard (= heard, prt.) : debard C. 674, carte : expert : art : harte M. P. 40. 28; but compare with these, waird : gaird MP. 7. 11, sterv : suerv : deserv MP. 34. 42, fearce : peirce : reheirce MP. 40.61.

$\$ 305$. Such rimes, then, cannot serve as a date test, until we know more of the history of the several diall.; and what is more, they admit of two interpretations, one the reverse of the other; they may prove that ar has become er just as well as that er has become $a r$; for, as the mod. diall. show, all parts of Scotl. did not go in the same course. It will be as well, therefore, first to look at the mod. diall.

$\$ 306$. There seems to be a sharp distinction between D. 33 and the remaining diall. of Scotl. In D. 33 we have three classes of er-words, i. e. of words which in early MSc. contained the vowel $e$. First, we have the sound $\boldsymbol{a}$ (or a) in the following - native or Norse words, work (a), heart, smart, starve, far, star, hearth, dark, carve, farm, start, darn, bark, farthing, sark, hark; French words, certain, deter, mercy, prefer, nerve, merle (= blackbird), concern, serpent, err, divert, serve, stern. Secondly, in a very few words (of French origin) we have e, arbour, clerk, firm, alert, (these are perhaps not purely developed but possibly influenced by some outside dial.). Thirdly, we have i' (a fracture not very distinct from Ellis's $\left(i i_{1}\right)$ and $\left(e e^{1}\right)$, see EEP. Vol. 5, p. $710(3)$, and probably arising from a previous $\bar{e}$ ) in pearl, hearse, herb, perch, search, 
partridge, sergeant, desert, insert, insertion, assert, disconcert, term, terse, verse, pert, exert (i. e. only in words not of native origin). With the exception, then, of a few words with $e$, the mod. forms are of two kinds, either ar or $i^{\prime} r$, arising apparently from previous $\ddot{e r}$ and $\bar{e}$.

$\S 307$. In the same way there are two sets of ar-words, i. e. words derived either from the French, and originally certainly containing $a r$, or from OE. ear. First, we have $\mathbf{a}$ in farce, barrel, warrant, bar, par, marl, bargain (these words are also probably not of genuine dialectal development, but to be explained in some other way, perhaps direct French influence, or more likely from rec. sp., and must, like the second set above, be set aside). Secondly, in the great majority of words we have the regular development $e$ in part, large, charge, carry, army, scarce, garter, arch, garden, dart, merchant, market, Charley, alarm, harmony, parish, narrative, card, art, charter, Martinmas, marry; also in cart, yard, arm, harm, warn, yarn, ward, swarm, fern, sharp, warp, park; but $a$ in warm, hard, and $\alpha$ in mark and spark. Most of these pronunciations will be found in Murray's DSS. pp. 144, 145.

§ 308. We have, then, chiefly three different developments to explain. 1. hert $>$ hart, serv $>$ sarv; here the $e$ of MSc. was not lengthened and was changed direct to $a$ as explained by Sweet and Brandl, the same as in the N. of Engl.; it is noticeable, however, that the change occurs before voiced as well as voiceless consonants.

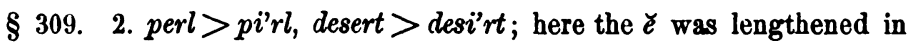
MSc. to $\bar{e}$, which became $\bar{t}$ like any other $\bar{e}$ (probably in the 16 th cent. or earlier); the $i$, given by Ellis and Murray, is of a different nature from the $i$ in (sti'n) (= stone, OE. stān), which comes, throngh $16^{\text {th }}$ century $\bar{e}$, from early MSc. $\bar{a}$; the glide ' in pi'rl is only due to the following $r$. That the mod. (i'r) comes from MSc. er, $16^{\text {th }}$ cent. $i r$, and not direct from $\mathrm{er}$, is shown by occasional spelling with $e i$ in later MSc. texts, e.g. Dougl. peirle, 1.22.6, peirlis (= pearls) 4. 84.14, seirching, 1.25.22; Compl. Sc. eirb (= herb), Sa tir. P. reheirs, 4.135 (\&c.), peirle, 7. 71 (\&c.), peirtly (= pertly) 13. 210 (\&c.), veirs : reheirs, 20.1, 24. 104, seirche 26. 72, peirtryks (= partridges) 33.396 , peirs (= pierce) 42.291 , leirning 28.49 , leirnit 42. 66, Montg. peirce : veheirce MP. 40.61. We have the same development occasionally in rec. sp., e. g. pierce, fierce, tierce.

We might think of another possibility', viz. that every er became uniformly ar in MSc. in this dial., and that for the nod. $i$ 'r the development was $e r>a r r>a r>\bar{a} r>\bar{e} r>i^{\prime} r$, for which the fact, that $i$ ' is also the resulting mod. sound of undoubted MSc. $\bar{a}$, might seem to speak; but then it is difficult to understand why part, large, \&c., which were in the $\bar{a}$ stage before perl, \&c., should since have fallen behind and never reached the last stage $i$, and the MSc. spelling with $e i$ points tou clearly the other way; therefore it is better to explain the $i^{\prime}$ in $p i^{\prime} r l$, desi'rt, as above, from $\ddot{e} r$ which arose direct from $\breve{e r}$, but before $\overline{\bar{a}} r$ had become $\overline{e r}$, otherwise the latter would have gone further together with it. Here again there is no difference between $\mathbf{r}+$ voiced cons. and $\mathbf{r}+$ voiceless cons. 


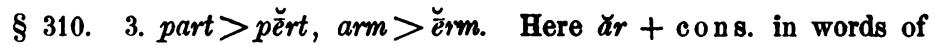
Fr. origin became $\bar{a} r+\mathrm{cons}$, and this $\bar{a}$ followed the course of general MSc. $\pi$ and became $\bar{e}$, i. e. produced $\overline{e r}+$ cons. which might then in mod. times undergo a shortening to err + cons. in some words (or a half-shortening, the vowels given as short by Murray for D. 33 are all really halflong). That the $\bar{e}$ did not become $i$ ' as in sti'n<stẽn $<$ stān is due perhaps to the later date of the change $\bar{a}>\bar{e}$, or perhaps more likely to the effect of the following $r$, which preserved the new open $\vec{z}$. That the $r$ did not have a similar effect on the $E$ in perl, can be explained by the different nature of this $e$ (= closed $\bar{e}$ ). In the same way we find (meer) and (seer) in 33, for more and sore, not (mi'r) and (si'r); cf. §57. We might explain the mod. Sc. $\bar{E}$ in words of Engl. origin, e. g. arm, sharp, \&c., in the same way, ONthmb. arm (see Sievers, § 158)> e rm, \&c.; but perhaps in some words a different explanation is necessary, and we must set the first appearance of an $e$-vowel at a very early date, and conclude that this $e$ was, or soon became, short and remained so till a comparatively late date; for the beginnings of the change to $e$ are found in the $0 \mathrm{Nthmb}$. dial., cf. Sievers, $\S 150,(3)$ and Hilmer, pp. 9 and 23, fracture $e a$ was there often represented by $a e, e$ or $e o$. Only in one word, beard, is an found in mod. Sc. diall., which would represent a MSc. $e$. Is this to be explained from the influence of rec. sp. or in some other way? Cf. Bruce, berdlass, 11. 217.

$\S 311$. Murray's silence with regard to D. 34 seems to imply that it agrees with D. 33 in the pronunc. of these words, and Ellis, in EEP. $P^{t} 5$, interprets the silence in this way; his lists give us very little information respecting the words in question. But my friend Mr. David Anderson, M.A., L.I. B., Advocate, of Edinburgh, has very kindly taken the trouble to get the Edinburgh pronunc. as nearly as possible, and I find there is some difference, especially in the first set of words, in which er has become aer in 33. In the first list he sent me, Mr. Anderson gave me $e$ instead of $a$ in heart, smart, starve, farm, start, and stern for star, also an $e$ in err; but left the remaining words of the first set with $a$ unaltered. He further gave an $\bar{e}$-vowel in farce, barrel, warrant, and $\bar{E}$ in bargain, and also in the following words not included above, Mark, march, March, parch, barge, marsh, tart. The words which in D. 33 have er for early ME. ar, (see $\$ 307$, yard, \&c.), he gave with er also in the Edinb. dial., and in addition mark and spark, which in 33 have $a$.

It was evident from this that the ar-pronunc. is even less extensive in Edinb. than in D. 33; and thinking that perhaps some of the words, in which Mr. Anderson had allowed $a$ to stand, might have been influenced by rec. sp. or some other Sc. dial., I requested him to test the pronunc. once more, which he did "from the mouth of a man who has spent most of his life in Edinb." As result, his revised list gives an e-pronunc. (i. e. pare $e$, not the a of rec. sp.) also in far, hearth, dark, certain, mercy, nerve, concern, serpent, divert, serve, warm (about warm and hearth he seemed doubtful and gave both pronunciations). He still gave only ar in carve and prefer, and (AA), = rec. sp. au, in hard. The words with $i$ ' in D. 33 are pronounced according to him in the same way in Edinb. 
We find, then, that this dialect corresponds much more closely with those further North than with Dr. Murray's dial.

$\S 312$. For the remaining diall. Ellis's lists are very meagre in respect of these words. In the following I take D. 37 and 38 as example, because Ellis gives us some material from these, and I fortunately have the advantage of the oral information kindly given me by my friend $\mathrm{Mr}$. J. Webster Low, B. A., whose home is in Forfarshire, just about the border line between 37 and 38 ; his rendering of the pronunc. agrees with Ellis's, where the latter gives any, and on the whole seems to belong to D. 35; but in the pronunc. of these words the two diall. go together.

$\S 313$. First, er-words, i. e. with early ME. or Fr. er; here the regular development seems to be only $\mathbf{e}$; so in heart, smart, starve, hearth, farm, start, certain, mercy, nerve, concern, serpent, err, divert, serve, clerk, firm, clergy, herb, perch, sergeant, (not with az as in rec. sp., but with $e$ ). But Mr. Low gives $i$ ' in some words in which D. 33 has $i$; so in pearl, hearse, search, desert, but the $i$ is very short. It is difficult to say whether this is a regular development (the $i$ is given by Mr. Low only in four French words, against $e$ in fifte $\mathrm{en}$ ), also whether the $i$ ' is to be explained in the same way as for $\mathrm{D}$. 33 . The following contain an $a$, which is probably to be explained from surrounding consonants ( $k$ seems to favour a) or from Norse influence: - work (with $a$ in all Sc. diall.), far (ON. fjarr?), star (ON. stjarna).

$\$ 314$. Second, ar-words (Fr. ar, OE. ear, \&c.); here there is on the whole perfect agreement with Marray's D. 33, in most of the words we have $e$, (but it seems here to be always long, sometimes particularly so, the result of MSc. $\bar{a} r$ ), and in a few $a$, just as in D. 33 , see above; also $a$ in mark and Mark, but $e$ in march, March, parch, marsh, tart.

$\$ 315$. As far as Ellis's materials go, all the other diall. agree with this, the vowel $a$ is only given in work, far, star, bargain, which everywhere have an $a$ vowel, and once in starve in 42 (but $e$ in 35. 36. 38. 39) and once in part in 35 (but also $\bar{e}$ in 35. 38. 39). The other words as heart, farm, serve, certain, \&c., are only given with $e$.

\$ 316. Now the question comes, whether we are to suppose that in these diall., in the er-words, the modern $\mathrm{er}$ is the direct continuation of MSc. er, i. e. that there has been no change since the MSc. period, or whether here as elsewhere $e r$ first became ar, ar, in MSc., and then between MSc. and NSc. there has been a refronting of the vowel, a return to $e r$. Both are possible. On the one hand, ar has certainly become $e r$ in such words as part, \&c., and may have gone hand in hand with an ar from earlier er; on the other hand, there may have been a tendency in these diall. both to retain $e r$ and to change $a r$ to $e r$, except where some other influence was at work. This is much simpler, and quite in accordance with what Dr. Murray has observed, viz. that the diall. of Central Scotl. represent an older stage of the language than those of the S., which have undergone a much further development, in the same way as the English of New Eugland and also of Ireland is in many respects more antiquated than Engl. rec. sp. He says, p. 82, this "evidence thus agrees 
with the historical fact that the Lowland tongue has been longer established South of the Forth than elsewhere in the North-east and West of Scotl. It is a curious though well substantiated philological law, that the transplantation of a language into a new region gives a check to its growth, and interrupts for a time its normal rate of development; so that while the same dial. in its original home continues to grow and change, in its new position it remains for a longer or shorter period stationary at the stage at which it was transplanted. .... There are two tendencies observable in the case of a transplanted language. One is that produced by contact with the language which it supersedes, and which always gives something of itself to the new comer; the other is the conservative tendency produced by reaction against the contact which strives to fix and crystallise, as it were, the new tongue in its actual state."

$\S 317$. Taking this view of the matter we may draw the following scheme of development for the diall. in question (all but 33): -

$$
16^{\text {th }} \text { cent. } \quad 19^{\text {th }} \text { cent. }
$$

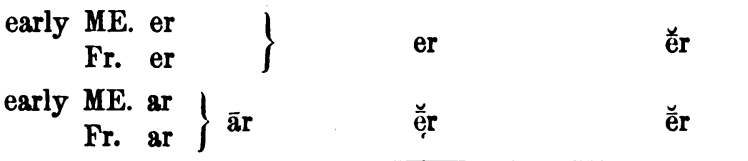

\section{Compare}

early MSc. $\overline{\mathbf{a}}$

$\overline{\mathrm{e}}$

$\overline{\mathbf{e}}, \mathbf{i}$

$\overline{\mathbf{e}}$

$\overline{\mathbf{i}}$

$\overline{\mathbf{i}}$

For D. 33 we can represent as follows: -

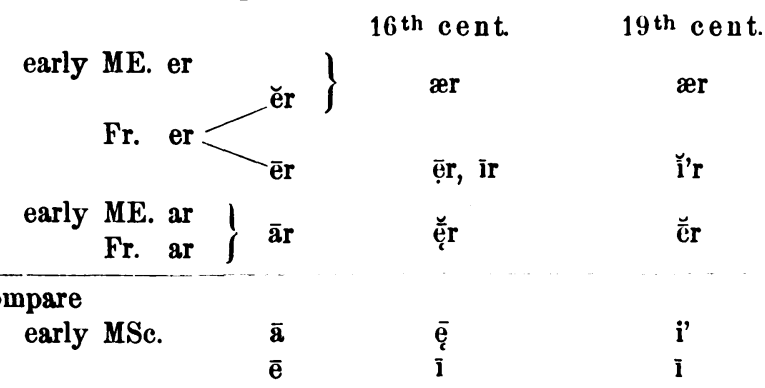

The above is suggested with all diffidence; there are difficulties in the way, however we try to explain. To decide with certainty we require mure exact chronological knowledge than we have at present of the dialects of Middle Scotch.

$\S 318$. At any rate the rimes give us here another proof that the author's dial. was not that of D. 33 ; heart and part cannot rime there at the present day and they did not do so in the 16 th cent.; for having originally contained different sounds and being different to day, it is impossible that they can have coincided at any intermediate period. And this being so, the rimes must be interpreted in accordance with some dial. other than that of $\mathrm{D}$. 33, and therefore it is possible that the rimes between 
older $e$ and $a$ prove rather that $a$ has become $e$ than vice vers $\hat{a}$, except perhaps in the word wark (which may have had already its general mod. pronunc.) and sarke, and, if so, then also mark, cf. the rimes, warke : sarke, sarke : marke; but this must remain doubtful, the author may have used two pronunciations; wark was, however, the regular MSc. form, just as in mod. Sc.; cf. Sc. Leg. warke 5/14, Satir. P. work : stark 5. 113, vark : dark : mark : vark, 44.16, bat clerk : werk 42. 234, 972. The spelling with $a$, hart, smart, start, must then be attributed to a scribe who must have been either from the $N$. of Engl. or the S. of Scotl.

$\S 319$. The rimes in (f) are particularly interesting; to the eye they are almost altogether imperfect. According to our supposition the vowel is $e$, probably long, in all the words; it would be so to a man from $D$. 34 or 38 , for instance (hêrt : pērt for heart : part would be a perfect rime to-day in 34 or 38 ), but to a man from D. 33 the sound would be $a r$ or ar in hart and $\overrightarrow{e r}$ in dairt, pairt, depairt, and the spelling in the latter words is quite in accordance with this, for there is no doubt that ai means, in the $16^{\text {th }}$ cent., the $\bar{e}$ which arose out of earlier $\bar{a}$ which was written $a i$. This is plain not only from rimes with undoubted $\bar{e}$, but also from the occasional interchange of $a i$ and $e$, and some rimes between $\bar{e}$ and $\breve{e}$, written $a i$ and $e$. A few examples will suffice, e. g. D unb. waist : haist, 32. 30, in another MS. spelt west : hest, Satir. P. traist, adj. : raist (= rest), 10.138 , cf. trest, $\mathrm{vb}$. : rest 17.183 , gaist (= guest) : manifest 34.75 ; in Montg. we find blait (= bleat, OE. blettan), implaidging (= pledging), where there is no question of $a i$ possibly meaning $\bar{a}$; it must have meant $\bar{e}$ or $\breve{e}$. We have similar indications in the MS. of Clar., e.g. dewaist (= divest) : rest 2.850 , gaist (= guest) : possest 4.500 , and ay, which means the same as $a i$, is always written in the word livaray, levaray, where Fr. $e$ cannot have become $\bar{a}$.

$\S 320$. It is then certain that $a i$ meant $\bar{e}$ in the $16^{\text {th }}$ cent. and aiv must have meant $\bar{e} r$; and the spelling with $a i$ and $e$, and rimes with $e$, give us an interesting proof of the establishment of the $\ddot{e}$-pronunc., which is found in the mod. diall., in the words which had previously contained $\breve{a}$. It is very probable that this was so even earlier then the $16^{\text {th }}$ cent.; cf. Bruce, herd, adj. 12.530, 14. 26, 19.642, herd, adv. 18. 482, sterkar (= stronger) 15. 491, Sc. Leg. gerris (= makes, usually spelt gars) 3/10, gert $\mathbf{6} / 85$, Early Sc. Law s (end of $14^{\text {th }}$ cent., in vernacular translation) pert (= part), mercat (= market) (see DSS. p. 32), Sc. Acts of Parlt (AD. 1424, 1436) mercat, merchande (see DSS. p. 39). For the $16^{\text {th }}$ cent. the following examples can be given in addition to Clar. - Gol. merk, D n nb. (see Kaufmann, p. 51), ern, sperkis, berd, scherp, stervit, Dougl. schairpe, 1. 28.12, rewarde : lairde 1.86.24, barn : dern 4. 23.12, expert: dart 4. 67. 28, smert 4. 70. 16, sterve : deserve 4. 75. 2. Lyndes. Sat. rewairds : lairds 1547, Laird : spaird 2592, bairds (= bards) : Lairds 2608, spaird : wairde, vb. 4489, Sa tir. P. gaird : rewaird : Laird 7. 219, regaird : spaird (= spare) : rewaird 14. 86 , pairt : divertt 27.40, pairt : desert 27. 128, hairme 35, 59, schairpe 35. 64 (\&c.), hairt 36. 1 (\&c.), lairge 36. 59, gaird : prepaird, 35. 18, expert : hairt : mairt : pairt 36.119 , foirwairnd 41. 62, foruairns 45, 5, baird : rewarde 45. 917, Berge (= barge) : chairge

Anglia. N. F. V. 
46. 3, cairdit (= carded) 48. 41, harme : werme 48.95, bergane (= bargain) 17. 77, mercat (= unarket) 20. 22, merkis 45. 223, perciall (= partial) 47. 1, onmerkit 47. 32, Montg. harte : advert : darte, MP. 47. 16, heart : convert MM. 22. The following examples show what confusion there was in the use of $e r$ and $a r$ in the words peril, quarrel, Sc. Leg. parele 5/6, Gol. beryell (= beryl) : quarrell : pereill 1088, Satir. P. perell : querrell 27. 43, parrell 31.119, parrell : quarrell 38. 88, parel : quarel 39.176, perrell : querrell 43. 200. Hame in his 0rthographie \&c., AD. 1617, (EETs. 5) gives us later testimony for the sound $\bar{e}$ in part; on p. 10, $\S 2$, he proposes $a e$ to be written for the sound $\bar{E}$ in shour of hael, and in $\S 4$ he writes paert.

$\S 321$. The orthoepists of the $16^{\text {th }}$ cent. give double forms for Eng-

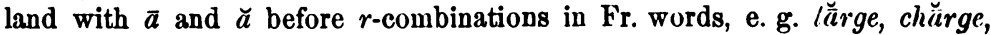
\&c., and in the native words b̆arn, wărn, see Kluge, PG. 1. 876, so that the forms lęrge, chẹrge, bẹrn, wę̧rn, were perhaps also possible in England, (as Kluge says, $\bar{a}$ was of a very palatal nature all through the $10^{\text {th }}$ cent. in Engl.), unless the authorities referred to were only quoting Sc. forms when they gave the long vowel.

$\S 322$. It is pretty clear, since $a i$ meant $\bar{e}$ for one at least of the scribes, that he pronounced perrt (= part), \&c., and, like the author probably, also knew nothing of an $a$-pronunc. in the Fr. \& Lat. words in $\$ 302$ (e) which are spelt with an $e$. The difference in spelling in pairt and expert is quite intelligible; it is the result of traditional spelling and perhaps of the learning of the scribe; pairt had formerly had an $\bar{a}$, but expert had always had $e$ and there was the existence of the Fr. word to keep him from writing $a i$; perhaps, too, a difference of quantity, pairt with $\vec{c}$ and expert with $\breve{q}$. Perhaps in heart the author had a double pronunc. $\stackrel{\breve{e}}{,}$, hence the riming with both sets $\S 302$ (e) and (f).

The rimes in (a), (b), (c), (d) all admit of the saue interpretation, that the vowel is $e$; although those in (b), (c), (f), might of themselves imply the very reverse, that $e r$ has become ar, yet the evidence of the mod. diall. and the orthugraphical irregularities together point the other way. Still it is here also uncertain how far the author may have adopted an Engl. pronunc.

§ 323. Kluge, in PG. 1. 875, explains the double forms mark: merk, barn : bęrn from doubleness of origin, OE. mearc : ON. merke, ON. barn : OE. bearn. The foregoing paragraphs show that this is unnecessary; if barn were only due to Norse influence we should expect to find this form especially in the $N$., and the case is just the reverse, the $\bar{e}$-forms are the prevalent Sc. forms, and are independent of the character of the cons. following the $r$, so that it is not necessary to assume that OE. ear produces ar before a voiceless cons. and $\bar{e} r$ before a voiced cons., as we must do with the above explanation of Kluge's.

$\S 324$. It will be noticed that heart is almost always spelt with $e a$, which appears occasionally in other words of this class, e.g. deart, pearte (= part) 4. 2579, search, \&c. This is most likely English orthography, and means probably $\bar{q}$; but why it should be particularly used in this 
word is not clear; $e a$ is written nearly, if not quite, without exception in Earl, and sea has invariably $e a$; otherwise it is not very much used, the

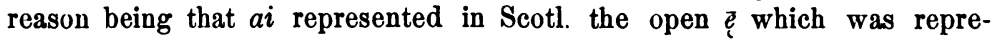
sented in Engl. by ea. But there seems to have been altogether an Anglicising tendency on the part of one of the scribes; we notice it in the substitution of - ght for -cht, zoung for zing, maiden for may, (the latter even to the destruction of the rime). So with $e a$; where used, it must generally have meant $\bar{e}$. In the following words it can only have meant the earlier $\bar{a}$ or the later $\bar{e}:-$ heast, leave (= remainder, : save, gave, \&c.), heave (= have : saue), bease-dance, beace (: space), recleame (: fame), \&c.; and in the following it can only have meant the earlier $\bar{e}$ ( $\bar{e}$ in Engl.) or the later $\bar{\tau} .:-$ leave (= permission), beames, heade, speache, meane, vb., leave, vb., leaves (of tree), streames, \&c. Therefore the general value was $\vec{e}$, and the alternate spellings prove the same, e. g. haist, heast, receave, resaue, speach, speech, meane, meinit, peal-̌eoun, pailzeoun, leaves, leives, (in two consecutive lines, 5. 286, 287). In one case ea represents an older pronunciation for the younger $e i$, i. e. an English or Anglicising scribe had the older pronunc. $\bar{e}$ in words in which the Sc. diall. already had $i$, represented by the alternative spelling $e i$, and in the other a younger pronunc. for the older $a, a i(=\bar{a})$, i. e the pronunc. of the scribe agrees with that of the author, $\vec{e}$, but he expresses it by an Engl. orthography, ea, instead of Sc. ai. When least can be written for lest, readie by the side of reddie, traist by the side of trest, the value of the $e a$ can only be an $e$-sound. Thus we see that the orthography is altogether very confused, but we conclude that $e a$ before $r+$ cons. means $e$, and is only the Engl. equivalent of the Sc. $a i$, which is also sometimes replaced by $e$.

$\S 325$. If the author used the dial. of D. 38 or 34 or of a corresponding district, probably he only knew the sound er in all the words we are discussing; but in the text we find no less than five different spellings: - the Sc. ai in pairt, depairt, rewaird, airlie, baimis, lairg (= large), lairt, waird (= weird, fate), wairn, \&c.; the Engl. ea in heart, hearpe, 2. 446, pearte (= part) 4.2579, search, pearle, fearce, rehearse (: verse), dearte, heard (= herd), peart (= apert) : desert 3. 1004, beard; $e$ in herp (= harp) 2. 352, hertfullie, perke (= park) 4. 1739, merchald (=- marshalled) 4. 2436, smert, enermit (= unarmed) 1.118, mervell, persoun, dwerff (= dwarf) 1.478, and in many more words from Fr. in which rec. sp. has $e r$ (being of such rare occurrence, these $e r$ forms are perhaps forms written by the author and left unaltered by the scribe); $a$ in hard (= heard, prt.), armeine (= ermine), start, staris (= stars), farder, hart, marmaid, wnarmit, harberie, wark, smart, \&c., (here, of course, a is meant, which points to a scribe from the S. of Scotl. or some part of Engl.; the change from Fr. er to $a r$ is found in almost all mod. Engl. diall); and once $e i$ in peirt (= pert : desert) 3.2166 . This last is one solitary example which can point to the $i^{\prime} r$ of D. 33 , for $e i$ meant $i$ in the $16^{\text {th }}$ cent., including the chief scribe of our MS., see $\S 12 i$. 'There are no more traces of this pronnuc. for the scribe, and no rimes at all to prove it for the author, in words of Fr. origin. 
§ 326. eard, OE. eorpe, rimes with OE. eo and Angl. $\bar{e}=$ WS. $\overrightarrow{\imath e}$. eard : raird (OE. reord, for *reard, Goth. razda) 1. 734.

: steird (prt. of Angl. steran) 3. 366.

This is not included above as the development is here different from that of the other words containing OE. eor; the second rime plainly shows that the vowel is $\bar{i}$ from previons $\bar{e}$. In $0 \mathrm{E}$. the eo was lengthened before $r p$, hence a ME. $\bar{e}$. In Sc. this $\bar{e}$ remained, but in Engl. it became $\vec{e}$ on acconnt of the $r$, just as in the words learn, earnest, earl, heard, hence the spelling with $e a$ in rec. sp., cf. Kluge, PG. 1. 880. In Engl. the vowel was also shortened. In MSc. texts we often find eird, e.g. Henryson, eird : effeird : appeired, Dougl. eird : weird : Feird (= $4^{\text {th })}$ : vnleird (= unlearned) 1. 81. 5, Roll. C. V. eird : leird, Prol. 78, Montg. eird : appeird, C. 108: weird MP. 46. 32 ; cf. also the spelling of the rimeword steird. But the last scribes seem to have pronounced it with open $\vec{e}$, for which they used the Engl. symbol $e a$ (it is generally eard in the text, but sometimes also erd, 1. 497, 503, \&c.); but in the other rime-word raird, for the same sound, one of the scribes has used the Sc. ai, though elsewhere we find rearde, 4. 1039, reard, 5. 2030, reardit (prt. = resounded) 4.1660, 5. 2322. This latter word generally has $\underline{e}$ or $\bar{q}$ in MSc. and is often spelt with $e i$, so Gol. reirdit, Montg. reird, vb, S. 12, "Can thunder reird the higher for a horne?"; Orm has also rệrd. The rimes must be altered to eird : reird : steird, cf. Dunb. reird : eird, 27. 85. The above rimes are also proof of the change from $r p$ to $r d$, which is so frequent in Sc. texts.

The mod. diall. agree generally with the form used by the author of Clar. rather than with that used by the scribes and represented in other texts by erd; they nearly all have (Jerd), commencing with a consonantal $i$ or $y$, the development being probably thus, MSc. ẹrd $>\operatorname{ird}>$ $i$ 'rd $>$ ierd $>$ ierd, with shifting of the accent from the $i$ to the following parasitic $e$, which thus became the bearer of the syll., while $i$ was changed from sonant to consonant. This form or a similar one is given by Ellis in $35,38,39$, and, with the same initial sound, but th at the end, in 33 and 36. In D. 35, 36, 39, ěrth is also found, and in 42 ert.

§ 327. starne : decerne 2. 902, star : Lucifer 2. 1398.

Starne and star owe their spelling with $a$ certainly to the scribes, the vowel was in both cases $e$ for the author. Cf. for the first form the sterrne of $0 \mathrm{rm}$ (Brate, p. 58, derives it from the unfractured form of $0 \mathrm{~N}$. stjarna); and further in Brace, stern 4.12i, sternis 4. 711, D u n b., sternis 2.3, stern 1. 52, Dougl. leidsterne : eterne 2. 17. 26 : decerne 2. 64. 26, Ga u, sterne 67. 8, W is d. Sol. sternis 812 , Hamp. P. C. sterne, Destr. Troy, sterne 1057, 1498. We find the same spelling starne in the text in 5. 2076, cf. Montg. starnis : harnis (= brains) C. 227.

The form (starn, stærn) is given by Ellis only in D. 33, (for which ar instead of er is characteristic) and in 42, (which shows irregularities in many ways); we find (stAAr) in 35, and (star) in 38 and 39 but there is no trace of ster or stern. Is the $a$ in far and star, starn, due to a later second Norse influence after the $e$ was fractured to $j a$, or merely to be explained from rec. sp.? The text shows elsewhere staris 4.1104, lodstar 
4. 1202, star 1. 22, but we have sterre, sterres in K. Q. st. 1 and 99, and in Dunb. ster : desuper 10. 3 .

$\$ 328$. schorte rimes only with words containing Fr. o -

schort : report 1.1556 : disport 2.568 (\&c.) : sport 2.630, 5. 1506 : support 3. 50 : sorte 3. 1044, schorte : report 3.1232.

The $e$ in OE. sceort merely marked the palatal nature of the $c$, hence $s c e>s c h$, and the $o$ remains and rimes perfectly regularly.

$\S 329$. 2. Before $1+$ cons. - rimes with

OE. $\mathrm{i}$-. silke : ilke 3.960

silc is found in OE. already as well as seolc, cf. Koch, Ztsfdph. 5. 38, and at the same time $0 \mathrm{~N}$. silki may have been of influence in fixing the $i$, cf. t. Br. p. 36 ; the adj. silcen may also have helped.

The word is not given by Ellis in his lists, but the similar word milk is found with an $e$-vowel in $33,35,36,38,39,42$, probably a recent development of $i$ on account of the following $l$.

\section{EO'}

$\S 330 .=(1)$ Gmc. eu, (2) contraction from $\breve{e}, \breve{i}, \breve{y}$, with following $a$ or $u$, through dropping of intermediate $h$ or $j$. Both kinds of $\bar{e} \bar{u}$ are treated alike.

\section{Not followed by $\mathbf{w}, \mathrm{g}$ or h. - rimes with}

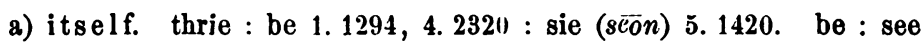
1. 1016, 1544 : se $2.378,3.604:$ sie 3.1786 (\&c.) : kne $3.148:$ glie 5.804 . knie : sie (seon) 5. 1072 : se 4. 40, kne : se 3. 2242 . scho, (pron.) : be 4. 828 (\&c.) : sie 5. 1726 : knie 5. 1438, schoe : see 4. 2068 : be 5. 1450 . betweine : beine (inf.) 4. 2230, 5. 1236 : beine, ptc., 4. 2234, 5. 1064 : seine, inf. 4. 2390, betwine : seine, inf., 3. 1916. - b) OE. $\overline{\text { eO }}+$ gntt, see $\$ 346$ (a). - c) General OE. or $O N$. $\overline{\mathrm{e}}$, see $\S 192$ (d). - d) $\mathrm{OE}$. $\overline{\mathrm{e}}=$ Angl. $\overline{\boldsymbol{\Phi}}$, mut. of $\overline{0}$, see $\S 185$ (c). - e) Angl. $\bar{e}=$ WS. $\overline{\mathrm{e}}$, see $\S 190$ (d). - f) OE. $\overline{\text {, }}$, mut. of $\overline{\mathrm{a}}$, see $\$ \$ 226(\mathrm{~g}), 241(\mathrm{~d})$. $-\mathrm{g})$ Angl. $\overline{\mathrm{e}}=\mathrm{WS}$. $\overline{\mathrm{e}}$, see $\$ 212(\mathrm{e})$. - h) Angl. $\bar{e}+$ gutt. = WS. $\overline{e a}+$ gutt., see $\$ \S 217$ (a), 223 (a), 225. i) OE $\overline{\mathrm{a}}$. scho, (prou.) : wo 3. 2264. - k) OE. $\overline{\mathbf{o}}$. scho : do (inf.) 3.826 : to 3. 1018. - 1) OE. or ON. ѐ. quheill (hwềl <*hweohol) : weill (sb. wela) 3. 524, see $\$ 132$. beheld (prt.) : feild 1. 216 (\&c.), see $\$ 172$. - fell, prt. : tell 3. 564 (\&c.) : dwell 3. 2284. - m) ON. jū. seik (adj. séoc) : meike 3.1542. - n) ON. $\varnothing \mathbf{y}$, see $\$ 499(\mathrm{~b})$. - o) ON. ig. be : womanlie 5. 504. - p) Fr. e. thre : degree $1.364:$ mellie 1.502 : contrie 2.2 , thrie : dignitee 4. 2518. deir(e) : cleire 1.24 (\&c) : altare (OFr. alter, see Behrens Franz. St. 5. 83, not from OE. altar) 4. 2410 : spheire 5. 2230. zeid : proceid 2. 80. scho (pron.) : pitie 3.836 : adversitie 3. 2058 : degrie 4.2556 : countrie 5. 566. kne : humilitie 1. 1536. see, se, sie : cuntrie 1.116 (\&c.), contrie 1.862 : weritie 4.404 : bewtie 3.772 : destanie 4.2092, and many more. be : pitie 3.136 (\&c.) and many more. - q) Fr. ie, later e. betwine : cuntine 2. 554. siene (inf.) : contine 5. 2062. beine, inf. : conteine 3. 2434 : perteine 5.1002 , beine, ptc. : susteine 3.2106 . beine, ind. sg. : conteine 2. 1510, beine, ind. pl. : susteine 1. 438. fleice (flēos) : Greice 5. 74. 
deir (e), adj. : inquire 1.1454 : coller 1.1564 : colleir 4.2010 : maneir (e) 1. 138 (\&c.) : cheir $1.1366,3.614$ : inteir 4.2650 : require 2.1684 : requyre 4. 2080 : cleire 4. 1992, 2738 . deir (sb. deor) : cheire 5.1194. - r) Fr. ei. thrie : monie 4. 492. se, sie : munie 4.1334, 5. 2496. - s) Fr. ien. be ; perdie 5. 16, 1504. - t) Fr. i. be : supplie, suplie, 3. 1370, 120.

$\S 331$. This belongs to t. Br.'s $\gamma$-class of $e$-vowels, which produced è everywhere in ME.; in our text it has, like every other earlier $\bar{e}$, the value $i$, ef. the rimes with $O N$. $i g$ and $F r . i$ in (o) and (t), see $\S \S 125,126$. We have $\gamma: \gamma$ rimes in (a), (b), (c), (d), (e), (m), (n), (p), (q), (s), $\beta: \gamma$ rimes in (f) and (g). Those in (h) can be reckoned $\alpha: \gamma$ rimes, cf. $\$ 220$; in (l), quheill : weill, we have certainly an $\alpha: \gamma$ rime; those in (r) are only apparently so, for we find mone (: the) as early as the $14^{\text {th }}$ cent., which Behrens, PG. 1.822, explains by exchange or assimilation of suffix. $\bar{e} 0$ before $r$ is treated in the same way as in other positions, ef. the word deir above.

$\S 332$. The words knie, trie, glie, are, of course, derived from the OE. nominatives $c n \overline{e O}$, tr $\bar{e} \overrightarrow{0}, g l \bar{e} \bar{c}$, or Nthmb. $\operatorname{tr} \bar{e}$, \&c. (cf. Sievers, $\S 250,2$ and 247 , note 3 ); the $w$ of the inflected forms (gen. trēeoses, cnēowes, glēwes) has left no trace here, as, for example, in Roll. C. V.glew (= glee) : vntrew, Prol. 31 : blew (= blue) : trew : hew (= hue, sb.) 1.90 : persew : new : rew 1.243 : few : trew : persew 3. 97, Lyndes. glew : knew, Sq. M. 1040. This form for glee is also found in Engl. texts, e. g. Rob. Br., Gen. Ex., Hav., Metr. Hom., Map.; Dougl. has the verb glew (to make merry): trew : hew : rew 1. 106. 4, but gleis (sb. pl.) : greis : treis : seis : tapestries 1. 2. 3. The mod. diall. show $i$ in these words almost uniformly throughout, (except in D. 33, where (ei) is generally found for final $t$ of the remaining diall.).

$\S 333$. The shortened form of $\bar{e} \theta$ is found in rime in the prt. fell, see above in (l) and in fled, see (f) and (g) (although the rime-word is spelt adreid, the vowel is short, cf. $\$ 213)$, and even in fred see $\$ 226(\mathrm{~g})$, where in rec.sp. we have the long vowel $\tau<\dot{e}$; perhaps the latter is a new formation, for shortening should be the rule, and free and flee ought to be treated alike.

The case of fred for freed, shows that the form fled can be explained as a weak prt. of flee, just as well as from a conjectared OE. *fedan, to flow; cf. Zupitza, Litt. Bl. 1885, 610. Is not the difference of meaning alone a rather formidable difficulty for the latter derivation? Just as fred stands over against the frēede of La $z$, so fled against *fleode or *flède.

In beheld the vowel is not shortened, as is shown by the rime with $f e i ! d$, cf. $\$ 172$, or else the rime is imperfect; it was so apparently to the scribe; cf. biheeld, Langl.

$\S 334$. greit. In 3. 112, "bristing out of greit", there may be an error, of for to; cf. 3.166 , "brist out to greit", or it may be a lawful construction, for which analuga can be found, where of apparently precedes the infin. and where in mod. Engl. we should use to, e.g. More, Utopia (p. 124, Arber's edit.) we find, "yf any thing ..... should chance of offend and myslyke them". Or greit may be a noun, ef. grête in C. M. 189 (from 
ON. gräti, according to Bradley) and A u nt. Arth. XXV, and Mir. Pl. 150. This is unlikely if Bradley's etymol. is correct, for $0 \mathrm{~N}$. $a$ generally produces an open $\bar{e}$ in Sc., which never becomes $\bar{\tau}$, cf. $\$ 245$. But we can compare Goth. grêts, sb. = weeping; the corresponding Angl. form for this, if there was one, would contain $\bar{e}$, which would produce MSc. $\vec{e}$ and $x$.

$\$ 335$. The verb is very common in MSc. and is still found in dial., being quite common in the $\mathrm{N}$. of Engl. and in Scotl. Gregor gives greet, (pronounce grit), grat, grutten, as the conjugational forms of the vb. in his Banffshire Glossary. It is also found in Spenser, Shep. Cal. April, 1. 1. greete : sweete. The form of the pres. could be derived from $0 \mathrm{E}$. groetan, grètan or grêtan, (the latter alune is given by Sievers, Ags. Gram.). The cognate languages show corresponding forms only to the former; Goth. grêtan, 0N. gräta, MHG. gräzan. But the other forms, grat, grutten, in mod. diall., which are confirmed by MSc. forms (quotations are given by J a m. Dict. s. v. greit, e. g. we find grat : sat, \&c., cf. § 285), especially the ptc. form, are rather to be derived from the other form OE. grētan, of the $2^{\text {nd }}$ Ablantsreihe. In either case the pret. would be irregular, both grêt and greät would produce MSc. grẹt, NSc. grit and thus coincide with the pres., but we have shown above how $a$ has arisen in the preterites of other verbs of the 2 nd Ablautsreihe, and the $u$ of the ptc. grutten is more easily explained from this class than from the redupl. form grätan. For this reason the word is included here under $\overline{e o}$, contrary to the etymol. usually given to it. BT. gives grōtan, grētan, prt. grēt, grëton, ptc. grīten, grēten, with 9 references to passages in which it is used, and greotan, greāt, gruton, groten, with only 2 references; but it would seem either that the latter was the more usual form in the $\mathrm{N}$., or that it eventually gained the upper hand, or else it is a case of complete transfer into another class. The same dial. (Banffshire) conjugates in a similar way loup (= leap, OE. hleapan or ON. hlaupa?), lap, luppen; this is a clear case of transfer; D u n b. has lap, prt., and Dougl. lap : gap : hap 1.63. 28. 'The form greotan would be Goth. *griutan; OSax. griotan is found. The verb is not found at all in the $S$. of Engl. (Bülbring, p. 108).

$\$ 336$. scho. In our MS. only scho or schoe is written, although the majority of the rimes prove the form sche; there are only three rimes to prove an 0 -pronunc, one of these being with $u o$, which contains a Southeru $\bar{o}$ for Sc. $\bar{a}$, see $\$ 330$, (i) and (k). This scho is the regular N. Engl. and Sc. form for Midl. she, and it seems that the anthor here with three exceptions entirely gave up his native pronunc. while the scribes always substituted the Northern scho for the author's sche or she. 'The consistency of the spelling scho is a remarkable cuntrast to the variety which is found in other words.

$\S 337$. The form has always been a puzzle to those attempting an explanation. Morsbach, p. 121, says $8 \bar{e} 0$ in stressed position gives $s \bar{e}$ in ME. and in unstressed position sho, and through contamination of the two forms arose the she of rec. sp. But if this be correct, why do we not find the form $s \bar{e}$ in ME. texts? and why in Northern texts often only scho in both stressed and unstressed position? Kluge, PG. 1. 902, suggests 
the possibility of Norse influence, OIcel. $8 j \pi$; bat where is the Northern Engl. and Sc. form with $\bar{a}$ which would be the correct representative of $s j \pi$ ? It is better to derive from $s \overline{e o}$ with stress-shifting, (which we are also compelled to accept in other cases), and explain as Morsbach does his "unstressed form" and Sweet the zho $<$ heo, viz. thus séo $>$ seó $>$ sjo, written scho.

§ 338. But why this development should be confined to the $\mathrm{N}$. is difficult of explanation. Perhaps Murray's assumption (DSS. p. 126) of Celtic influence ( $s>s h$ before $e$ ) is hardly necessary, it does not account for the loss of $e$ and also requires the acceptance of stress-shifting, and with the latter alone the sh would arise without any help at all from Celtic influence. The difficulty seems increased by the fact that in nearly all the mod. diall. of Sc. as represented in Ellis's lists, we find shi as in rec. sp. (ei of course in D. 33); in D. 36 a closed $\bar{\varphi}$ is found by the side of $\tau$, of which it is merely a variation; we find $\tau$ in 34. 35. 36. 38. 39. 40. But we do find the correct representative of MSc. sho, viz. (shəə), in D. 41 and 42 , where 0 E. and MSc. $\bar{o}$ has become (әә) generally. Of these diall. (the Orkneys and Shetland Isles), Ellis says, p. 788, "the present language is English, taught by Lowlanders, chiefly from the N. Lowland districts, to Norwegians. It is therefore an acquired tongue, and has not lasted long enough to be a true dialect". But it can give us older forms which have become obsolete on the mainland, and perhaps it is not altogether obsolete there, for the shi of D. 39 and 40 can also represent MSc. $8 c h \bar{o}$, since in this dial. earlier $\bar{o}$ has generally become $\tau$, e. g. $r i f$, stil, brim = rec. sp. roof, stool, broom (cf. $\S 462$ ).

$\S 339$. But the question arises, what has become of the $s h \bar{\delta}$-form in the remaining diall.? for in none of the others further S. than D. 39 and 40 has $\bar{o}$ regularly become $\bar{i}$, and yet she always appears with $\bar{\tau}$. In Engl. we find forms equivalent to ME. sho, with $u$ or $o$, only in S. Yorks., Lancs. and Derbyshire, D. 22, 24, 26, and part of 31. In other diall. we find $i$ or $e i$. But sho was the regular MSc. furm, also of the Central Counties, and of the $N$. of Eugl. as well, as will be seen from the material given below, collected from various texts. The only explanation seems to be in the Anglicising influence, which, probably proceeding from the capital, Edinburgh, introduced the Southern form she or shi. and drove out the proper native form as far as the extreme $N$. of Scotl., where it survives in D. 39. 40, 41, 42, and a considerable distance southwards into England, where it enjoys a still more limited existence in the districts mentioned. 'This Anglicising influence is evident in many MSc. texts, as is naturally to be expected, and would seem, from the evidence of the mod. diall., not to have been confined to the literary language, unless the disappearance of sho is only of more recent date. Many MSc. texts show both forms scho and sche, but there are few which have such a preference for the $\bar{e}$-form as Clar. and in none is the 0 -form altogether absent except $K$. Q. The fact that the scribes often write 0 where the authors must have written $e$, shows that the new pronunciation proceeded from the higher classes, poets, courtiers, \&c. 
$\S 340$. Bruce has always scho (with one exception, sche, 13. 635), once proved by rime, scho : to 4 . 760 . In Sc. Leg. scho is always written, as yet $I$ have noticed no case of it in rime. $\mathrm{K}$. Q. has only sche (not in rime); Wall., always scho (not in rime); Gol., not found, according to Noltemeier; Lanc. scho once in 1.1169 , but usually sche or she, in rime sche : see 2798, shee : free 2390 , sche : fre 2298; D unb. scho, rarely sche (Kautmann, p. 81), both forms in rime, $8 c h o:$ do: to, p. 161, sche: degre p. 218, in the Freiris of B. (attrib. to Dunb.) scho: to, 1. 434; Dougl. scho and sche both in text and rime, but sche predominating in both, scho : ado 2. 13. 12 : ado: lo 1. 70. 20 : se : bewtie : ee 1. 19. 5, sche : kne 2. 40. 2 : Phenicie 2. 41. $10:$ be 2. 43. $8:$ hie (= high) 2.50.6: se (= sea) 2. 57. 22, \&c.; Compl. Sc., sche and scho (author probably from the Southern Counties - Marray, Introd.); Lyndes. mostly scho, sho in text, but sche : Heresie, Kittie's Conf. 20 ; Roll. C. V., scho always written (not in rime); Satir P. only sho, scho, : ado : to 12.142 : Cro : to : do 24,71 : to 30.96; Winzet sche and scho; Montg. scho: to C. 174, 294, sho: do MP. 30. 33 .

$\S 341$. Northern England - Sir Tr., only sche, once in rime, : fre : me : be : se 237 (hye, 101, is another form altogether due to the Southern scribe, Kölbing, p. 78); this appearance of sche in such an early text is further support for the suggestion of the southern portion of $\mathrm{N}$. Engl. as the home of the anthor; Kölbing, p. 77, excludes Yorks. Horn Ch. scho : do (Caro, p. 22). - Thom. of Castelf. always scho, : do : unto, (Perrin, p. 23). - York Pl., sho, she, scho, sche, (Kamann, p. 45). - H a m p. sco, sho. - Octav. (Northn version) scho in Linc. MS., sche, she in Camb. Ms. (not in rime); the Sonthu version has sche: cyte: be : pre, 509. - Sir Egl. generally sche, four times scho (Zielke, p. 44). Thom. Erc. scho in T, she in other Mss. - Sir Perc. scho.

$\$ 342$. It seems, then, that sche, she, came into use in Sc. poctry in the course of the $15^{\text {th }}$ cent., but only in those writers who are in other respects not free from Engl. influence. In writers of pure Sc. it is unknown even to the end of the Sc. literary period, e.g. Montg. Bat since that time it has naturalised itself in must of the diall. The author of Clar. is in this respect almost as anglicised as James I and the author of Ian c. In Northern Engl. Sir. 'Tr. stands alone in having she at such an early date. 'This form is found, however, in many texts of the $14^{\text {th }}$ cent., but rimes of proof are still wanting for this cent. and also the next.

$\$ 343$. OE. $\bar{e}$ de only appears with $i<i$, not with $o$, cf. Dougl. zoid : woid (= mad) 2.113.18, but zeid (not in rime), 2. 93. 21 .

$\S 344$. breist, 0 E. breust, has not shortened its vowel as in rec. sp.; the mod. Sc. diall. have all brist or bryst (in D. 33 Ellis gives brèst as well), and the MSc. Mss. have generally $e i(=\imath)$, e. g. Lyndes. breistis : preists, Sat. 1063, breist : neist : preist Sat. 538, and so nearly everywhere. Chauc. has both long and short vowel, brẹst and brěst.

$\$ 34$. seik, rec. sp. sick, has a long vowel, as usual in Msc., see $\$ 330(\mathrm{~m})$; the mod. diall., however, have $r$ according to Ellis; the shortening has taken place since the $16^{\text {th }}$ cent. Wc also find seik in the text, 4.62. 
$\S$ 346. 2. $\overline{\mathrm{eOg}}, \overline{\mathrm{eo}} \mathrm{h}$ - rimes with

a) OE. $\overline{\text { eo }}$ (without gutt.). drie (drēogan) : see, inf. 1. 1482 . theis (pl. of peōh) : treis (arbores) 3. 1070. - b) 0E. $\bar{\epsilon}$. thie (peoh) : he, (pron.) 1. 1000.

$\S 347$. These words contain $\tau$ from $e$, as usual in Sc., where the gutt. disappeared altogether, and the vowel $\bar{e}$ (it was $\bar{e}$ already in the OE. period in Angl.) remained unaffected by it, hence no diphthong in these and similar words, nor a lung $i$ (i. e. in early MSc.) as in Midl. and Southn ME. (Cf. Brandl, Th. Erc., pp. 59, 60, Buss p. 497); ég $>\bar{e} g>\overline{\mathrm{e}}>\overline{1}$ (late MSc.), in just the same way as ea + gutt. produced MSc. $\ddot{e}$ and then $\tau$. In the case of peolh, the $h$ was lost in OE. already in the inflected forms, ef. fioh, feos, hence we find in ME., even in Southern texts, thee, \&c., without a trace of the gutt., e.g. 0 wl \& N., peo: beo, Rob. Br. pe : be, see Sweet, p. 359 .

Such forms are frequent in Sc. texts. The mod. diall. show perfect agreement, we find the forms thi (=thigh), fli $(=\mathrm{fly}), l_{\mathrm{i}}(=\mathrm{lie})$ in all diall.; thigh is given by Ellis once with $a i$, in D. 39; this is, of course, not pure dial.

Clar. betrays here no anglicising influence.

$\$$ 348. To Buss's examples we can add - Dougl. dre : adversitie 2. 57. 16, theis (= thighs) : kneis 2.157.2, hie (= higb) : see 2. 40. 32 : thrie 2. 27. 4 : sey (= sea) : eye : me 1.42.3, de:ee 2.27.16, ee : bewtie : se : scho, 1.19.11, leis (3 sg. lēogan) : fleis, 3 sg. : seis (maria) : seis (videt), \&c. - Lyndes. eine (= eyes) : meine Sat. 492, theis : kneis, Suppl. 83 and Sq. M. 1348, \&c. - Roll. C. V., hie : destinie : mollifie : sle (= sly) 2. 401, \&c. - Montg. sie (seah) : trie, C. 319, ee : thrie, S. 41, ee : 8ee : dee : be, S. 591, \&c. - Rosw. hie : be, A. 130, hie : me 528, 602.

$\S 34 !$. 3. $\overline{\mathbf{e O}} \mathbf{w}=\mathrm{Gmc}$. inj, iw, - rimes with

a) itself - new : hew (hềw) 1. 17ı) (\&c.) : schew, (prt. *scëow, see $\S 35 i)$ 2. 516 : knew (cneow) 4. 1398. treuth : rewth 5. 1096. rew (hreowan) : knew 3. 2026. hew : knew 2. 710, 4.996 : schew, prt., 3. 1470 : trew, (adj. treowe) 3. $228,4.230$. drew (OE. was $d r \bar{g} g$, but of. $§ 355$ ) : threw 2. 1526 : flew (OE. was flea $h$, but of. $\S 35 \overline{5}$ ), 3. 856. - b) OE. $\overline{\mathbf{u}}$. zow (pron.) : how 3.830. - c) OE. $\overline{\mathbf{u}}+\mathbf{w}$. jow : trow (trüwian) 2. 552. d) OE. $\bar{x}+$ w. trewth : slewth (OE. slöw $p$, NE. sloth) 4. 1098, sleuth 4. 2342. - e) Fr. u. zow : avow 4. $\$ 20$. zouris : collouris (= colours) 4. 2016 : honouris 5. 2422 : amouris 4. 1508. - f) Fr. i. schew, prt. : wertew 3. 298 : salew (saluer) 2. 532. trew, adj. : wertew (MS. wertew \& bewtie for bewtie \& wertew) 3.1424. knew : vertwe 1. 1150. - g) Fr. en, ieu. new : persew 2. 1010 : blew, adj. 4.1178 (\&c). trew, adj. : persew 4. 488, 5. 1260. knew : persew 1.910, 3. 1078: adew (a dieu) 1.926: blew, adj. 2. 1438. hew, sb. : blew 4. 1004 (\&c.) : pursew 1. 36. schew, prt. : persew 4.1142 (\&c.). drew (for OE. drög, see below) : Pardew 5. 2396. - h) ? schew, prt. : eschew 1. 550 , see $\$ 357$.

$\S 350$. The regular development of $0 \mathrm{E}$. euw is eow $>$ ẹw $>$ ẹy $>$ iu, which later became iu; we have iu or iú (prob. the former) in the above words, not only in new, hew, schew, knew, flew, but also in trew, 
treuth, rew, threw, drewv; for though it will be seen below that after $r$ the $i u$ only remains to-day in D. 33, while in the other diall. we find $\bar{u}$ as in rec. sp., $d r \bar{u}$ (= drew), \&c., so that we might imagine perhaps the spelling $e w$ to be only due to the copyist, still we do not know when the $i$ disappeared in the central diall., and on the analogy of the orthography in other words, we should expect ow to appear occasionally in the MS., if the author had used it, as he would have done, had he pronounced with $u$ instead of $i u$; so that it is perhaps safer to suppose that $i u$ still existed after $r$ in his pronunc. Although we might be allowed to accept $i \bar{u}: \bar{u}$ rimes, yet as all the rime-words contain certainly $i u$, we must accept $i u$ in the above mentioned words as well. Cf. Montg. MP. 17, where all of the following words rime with perseu - sleu, greu, bleu, aneu (= enough), deu (= dne), reu, kneu, fleu, dreu, threu, sheu, (prt.).

§ 3.51. There is another possible development of eow, viz. to $\breve{\partial} u$, which remained $o u$ in medial and became $\bar{u}$ in final position, according to t. Br., p. 39. Our rimes only show this in zou, see (b) and (e), and, with transference of the $u$-final by analogy into the medial position, in zouris, see (e), as explained by t. Br. l. c. In zow the $i$ of $i u$ has become conson. and the $u$ alone is bearer of the syll., hence the rime with $\bar{u}$ not $i u$.

$\S 352$. In accordance with this, the verb trow, generally derived from OE. trēowian, is, on account of its riming with OE. $\bar{u}$, to be derived, in this form, from OE. trüwian, and will be found below under $\bar{u}$ in $\$ 535$. As remarked in the preceding paragraph, we cannot here assume that triu has become $\operatorname{tr} \bar{u}$, witness the adj. trew, only spelt with $e w$ (not $o w$ ) and riming with $i u$ not $u$. The spelling ow may mean $\bar{u}$ as well as ou, and must mean $\bar{u}$ alone for our author, if he wrote it. Skeat accepts $\bar{u}$ as the value of $o w$ and $e w$ even as early as Barbour's Bruce (EETS. 29, p. 638), also Buss, p. 499, for Sc. Leg., and the words now, how, have still the long vowel $\bar{u}$ (not diphthong) in most of the Sc. diall. Sir Tr. has trowe now : Peticru : ynouz: how; if ow here meant the diphthong ou, the change from $\bar{u}$ to ou in how, now is to be dated very early indeed. Similar rimes are in Lyndes., trow : now : zow, Sat. 471, : how 734 : now 852, Satir. P. trow : how : pow (= pull) : now 16. 1.

The pronunc., then, of the vb. trow was tri.

$\$ 353$. The scribe as well as the author observed a difference between the vb., which he writes trow, and the adj., written trew. Similarly in Satir. P. trow, vb. (cf. $\$ 352$ ) but trew : jew 16. $24:$ grew : rew, vb.: anew (= afresh) 16. 29 : anew (= enough) 16. 66. To-day triu is spoken for the adj. in D. 33, but tri in all the other diall. except 41 , where a solitary instance of triu is given by Ellis. If trow contained the diphthong ou for the scribe, probably the rime-word now did too, which would point to D. 33 or the N. of Engl. where you, how, now are all pronounced with a diphthong, while in all other diall. of Scotl. they have $\pi$.

$z$ zow and zouris, which had $\ddot{u}$ in the pronunc. of the anthor, may possibly have had $o u$ in that of the scribe, as at the present day in D. 33 \&c. For different explanations of these forms see t. Br. p. 39, note 2, Sweet $\$ 655$, Morsbach p. 74 . 
$\S$ 354. The following is the only material given by Ellis for the mod. diall. - you has (au) in 33 , (uu) in all the other diall., also (au) in 32 (Northumbld.), but (ó) in some of the diall. of N. Engl.; true, (inu) in 33 and 41 , also in 32 and nearly all diall. of the N. and N. Midl., (uu) in all other diall. of Sc.; truth is very varied in pronunc., (ou) in $33,(\delta \mathrm{u})$ in 39 , ( $\mathrm{a} u$ ) in $40,(\mathrm{y})$ or $(\mathrm{yy})$ in $34,35,(\theta)$ or $(\partial \theta)$ in $35,36,42$, (iuu) in 33 , 41, also in 32 and most of the diall. of N. Engl. and N. Midl., (u) or (uu) in 38 and part of 32 ; trow is only once given, with (ou), in 33 ; brew has (iuu) in $33,(\mathrm{uu})$ in $35,38,39,42$, also (ii) in 39 ; rue (ou) in 33 ; chero (ou) in 33,39 , (au) in $35,36,38,42$, also (AA) and (as) in 39 ; four (bu) in 33, $39,41,(\dot{a} u)$ in $35,38,(00)$ in 33 ; forty only (o) or (oo).

Here again the evidence, as far as it goes, tends to show that the dial. of the author was not that of D. 33 .

$\S 355$. drew and flew are included here, for, althongh the $0 \mathrm{E}$. forms were $d r \bar{g} g$ and $f \bar{e} a g$, the forms which arose regularly from these were replaced by others formed on the analogy of threw, blew, \&c., cf. Builbring, pp. 92 and 99. The vowel-sound is (iu), cf. Montg. flew : anew (= enough) C. 800, drea : flea : persea, \&c., MP. 17. 1.

$\S 356$. eschew, see (h), has had different etymologies given to it. Skeat in his Princ. gives Fr. eschuer, in his Dict. and his edit. of Lanc. Fr. eschever; Bradley in his edit. of Stratmann and Skeat in his edit. of Brace give Fr. eschiver. Perhaps there was here a mixture of two Fr. forms, and possibly further also of a native word, the ME. 8cheowen = avoid, see Stratm. - Bradl, cognate with M. L. G. schiwen, which is connected with OE. scēo $h$, adj. and NE. skew (by Skeat derived direct from MDu.). At any rate there are two forms in MSc., sometimes both used in one and the same text, one with $i u$ the other with $\check{e} v$ or $i v$; cf. Brace, escheve 18. 532, eschevit 20. 454, eschewe 12. 473, 15. 349, eschewit 11. 535, 16. 207; Sc. Leg. eschewe : leife (= permission) 29/1022, eschew : nov (= now) 68/428, eschewe : leyfe 96/322; W all. eschew : inew 9. 812; Lanc. eschef : beleif 2732 : pref (= prove) 3475 ; Rat. Rav. enschew (for eschew according to Lumby) : wertew 1147; Craft of Deyng, eschef 153, eschewyng 18; D un b. eschewit : bespewit 27. 80, eschew (construed with fra): slew : new 33. 9, escheve : greve : leve (sb. = departure) 81. 42; Dongl. escheuit : releuit : engreuit : brewit (= bricted, written) 1. 31.16, escheuet (= escaped, departed) : aggreuit \&c. 1. 79.4; Satir. P. eschew : persew : slew : brew 5. 68; M on tg. eschew : trew, C. 1298, esheud : breud (= brewed) : outspeud : indeud (= indued) S. 24.

$\S$ 357. schew, prt., a new-formed pret. on the analogy of knew, \&c.; the verb was originally weak, as in NE. showed. We find the same form in other Sc. texts, e.g. W all. schew : drew 11.92; D nn b. schew 3. 252; M ontg. shewe : trew, C. 1016, sheu : perseu MP. 17. 55, sheu : heu : blẹ 35.57, furthsheu : kneu : sleu : ouirthreu : treu : hen : feu : adeu, 27.5.

The passage referred to in $\S 349(\mathrm{~h})$, is not quite correctly rendered in the MS.; "His father is displeasit, and in schew Dangeris pairin quhilk he micht nocht eschew", but a slight emendation (change in to him) renders it intelligible. 


\section{ON. JU'}

§ 358. rimes with

a) OE. $\overline{\mathrm{eo}}$. meike (ON. $m j \bar{u} k)$ : seik $(\overline{s e c})$ 3. 1542. - b) OE. $\overline{\mathrm{e}}$, mut. of $\overline{0}$. meike : seike, vb. 4. 612. - c) Angl. $\overline{\mathrm{e}}=$ WS. $\overline{\mathrm{e}} \mathrm{a}$ before a gutt. meike : eik(e) 2.1552 (\&c.).

In ME. mẹke, there was a substitution of $\ddot{e}$, the representative of $\mathrm{OE}$. $\overline{e o}$, for the corresponding $0 \mathrm{~N} . j \bar{u}$, which, of course, then rimed with $\underline{i}$ from all other sources. Cf. Zupitza, AnzfdA. 2, 7.

\section{$\mathbf{I}$}

$\S 359$. Short $\gamma$ is usually represented by $i$, sometimes, but only seldom, by $y$, e. g. ryssine 1. 1177, sympleness 1. 223. In ME. texts it was often the custom to use $y$ for $\tau$ immediately before or after $m$ or $n$ for the sake of distinctness, (see t. Br., $\S 9$ ), but in Clar. this is quite exceptional; instead of it we sometimes meet with $j$, which serves the same purpose, especially in the suffix -jng; and at the beginning of a word we sometimes find a capital $I$ when $m$ or $n$ follows, e. g. Innis. The absence of $y$ in this use is due to the fact that it is almost exclusively used, at any rate in medial position, for earlier long $\bar{\imath}$, which has become the diphthong $e i$, $\partial i$, see below $\S \S 432 \mathrm{ff}$. There is no example of $u$ for OE. $i$, and only a few of $e$, mekill (also mikill), wemen \&c.

\section{I -}

$\S 360$. 1. Not followed by e or $g$ (for which see $\$ \$ 410,411)$ rimes with

a) itself. leiue (= live) : giue 4. 154, 2632 : geine 4. 2356. b) $\mathrm{OE}$. $\overline{\mathrm{ed}}$. geiue : leave (OE. leâf $=$ permission) 4.146 , giue : leane 3 . 1014. - c) OE. e, WS. ie after palatal. wite (witan, vb.) : zit (= yet, OE. get, giet) 1.1348. - d) OFr. ie, AFr. e. leive : grive, vb. 1. 306.

$\S 361$. (The two vowels $i$ and $u$ are so similar in their treatment, and the history of the one throws so much light on that of the other, that we shall find it advisable to discuss them together, hence $u$ - is treated in advance with $i$ - in the following $\S \S)$. It is generally stated that the vowels $i$ - and $u$ - are not "subject to new-lengthening in ME.", Sweet $\$ \$ 623,647$, ef. Kluge in P. ( $\mathrm{x} .$, Morsbach, p. 21, 1\$1, \&c. But this has raised doubts in the minds of some who, like $t$. Br., have been unable to see why these two vowels should be exceptions to the general rule of ME. lengthening in open syll. Morsb., p. 21, seeks an explanation in the fact that in the pronunc. of these vowels the angle of the jaw is smaller than in the case of the other vowels; but it is difficult to see why this should be any hindrance to the lengthening. ten Brink in ZtsfdA. 19, N. F. 7, 212, Angl. 1. 512, \&c. and Chauc. $\$ \S 3,35,36,37$, finds refuge in a "schwebender vokal", which he assumes, in order to explain the occasional rimes with lung vowels in Chauc. This expression, however, has met with much disfavour, and although the existence of such a vowelquantity, situated mid-way between long and short, is by no means impossible, (we possess such a one at the present day in words in which 
the vowel is followed by a liquid or voiced cons., e. g. live, bill, where the vowel quantity is not quite the same as in sit, sip, and according to Ellis every so-called short vowel in Scotch is half-lonir in comparison with Engl.), still the expression in this sense as nsed by $\mathrm{t}$. $\mathrm{Br}$. is perhaps not to be defended.

$\S 362$. The custom of an anthor such as Chauc. sometimes riming a word with a long vowel, sometimes with a short, is to be taken rather as evidence of a two-fold pronunc., both long and short; in fact, that he here, as often in respect to the quality of vowels, had also two strings to his bow with regard to the quantity, and that these two ditferent forms came from different diall., not resulted from his own normal pronunc. intermediate between short and long; in this sense we can defend the term "schwebender vokal".

$\S 363$. The whole difficulty seems to lie in the fact that up to the present two important matters have been somewhat overlooked in the discussion of this question, (1) the exact nature of the OE. $\zeta$ and $\breve{u}$, and (2) the difference of development in different diall.

$\S 3$ 3i4. OE. $i$ was not $=(i)$, high-front-narrow, but $=(i)$, high-frontwide, a sound approaching $e$ in character; cf. Ellis, p. 105, "the Engl. sound ( $i$ ) lies between (i) and (e)", (the latter = mid-front-wide), i. e. it approaches $(e)$ in so far, that boing a wide vowel, the size of the soundpassage was larger than for (i) and nearer that for $(e)$; and just as $Y$ rimes with $\breve{e}$ in closed syllable, see below, so we should expect that this sound lengthened would rime with $\bar{e}$, (from which it would not much differ), instead of with $\bar{i}$, and it actually does so in Clar. and many other Sc. texts, ef. (b) and (d) above. Ct. Ellis, EEP. 1. 271, 272, who compares similar pronunciations of the present day and mistakes arising therefrom; see also Ellis, p. 106, "the true long sound of $(i)$ is not an acknowledged sound in our langaage, though in frequent use among such singers as refuse to say happee, steel, eel, when they have to lengthen happy, still, ill".

For this value $(\imath)$ and its rimes in closed and open syll. cf. further Morsb. p. 33, Wackerzapp, p. 30, \&c., Buss, p. 504, Schleich, Angl. 4. 308, Zupitza, Guy, p. XIV, Brandl, p. 60, and AnzfdA. 13. 97 ff., Ullmann, p. 13, Zielke, p. 15, Sarrazin, Octav., p. 173, Külbing, Ipom., p. 173, Dannenberg, p. 14, Noltemeier, p. 14, Fick, p. 14, Zietsch, p. 75, Lloyd, pp. 166, 183 \&c.

$\S 365$. Similarly OE. $u$ was not pare (u), high-back-narrowround, but $(u)$, high-back-wide-round, a sound approaching (o), nid-back-wide-r., in character, cf. Ellis, V. p. 823 , so that we can say of this $(u)$ that it lies between (u) and (o); from it the mod. Engl. (u) in but is more easily explained than from pure (u). It is sometimes represented by $u$, just as $(i)$ is represented often by $j$. We are naturally led to expect that this sound, when lengthened, should, on the parallel of $\dot{j}$, rime with $\tilde{\varphi}$ (from which it would not much differ), instead of with $\bar{u}$, and it actually does so in Clar. and many other Sc. texts, cf. $\$ \S 377,500$. The true loug sound of $(u)$ or $\xi$ is frequently used in singing foot or pull to a long note, (fuut, puul); we then distinctly hear the difference from 
(fuut, puul). It is often also found before $r$, where it is particularly liable to become (oo); an Englishman's pronunc. of the German word Uhr generally sounds like $\mathrm{Ohr}$ to a German ear, and is really (oor), and the common pronunc. of poor as pore, (poor) instead of (pnur), is well known.

It should be noticed that Sweet in his HoES. assigns the pure values (i) and (u) to OE. $i$ and $u$.

$\S 366$. The lengthened sound of $(i)$, or $j$, changed, then, as we consider, from (ii), $\bar{z}$ to $(e e), \vec{c}$, or in accordance with the tendency of long vowels to narrowing; noticed by Sweet, $\$ 53$, became (ee), $\bar{e}$, after which it followed the same fortunes as ordinary $\ddot{e}$, producing $\mathrm{NE} . \bar{\imath}$, not the diphthong (əi) or (ai), which are the modern representatives of ME. $\bar{i}$. Similarly, the lengthened sound of $(u), y$, changed from $(u u), \bar{u}$ to $(0 o), \bar{o}$, or, with narrowing, (oo), $\bar{o}$, and then followed the same fortunes as ordinary $\bar{\varphi}$, which produces, where undisturbed by other influences, NE. $\bar{u}$, (uii) and NSc. (әz) or (yy), not (an), or (əu) the representatives of ME. $\bar{u}$ in rec. sp., nor (uu), the mod. Sc. equivalent of MSc. (uu). It is this fact, that the lengthened forms were not ME. $i$ and $\vec{u}$, coupled with the rarity of examples in which the long vowel is still found in rec. sp. (various external canses having tended to prevent it) that has misled people to assert that $i$ and $u$ were not liable to lengthening in open syllable.

$\S 367$. First let us consider the development of $i$ - in rec. sp. If we examine the word-list in Sweet's HoES., we find that in many cases the lengthening has been prevented by an $l, n, r$ or $y$ in the following syll. (Sweet's "back - shortening"), e. g. in fiddle, flicker, withy, risen, or by syncope, e.g. church, cir(i)ce. In some, the short $y$ may be due to inflected forms in which the $i$ was not in open syll., as shin, sinew; in others Sweet might have given another $\mathrm{OE}$. form, as tillan instead of tilian (he does give swillan as a by-form of swi'ian). In others, again, a form with vowel length exists in dial.; for instance, sieve has a long vowel, 1 , in D. 31, 32, 33, 34, i. e in the N. of Engl. and South and Mid Lowland, in which districts the short vowel, $s\lceil v$, is altogether absent, and once Ellis gives $s \bar{v} v$ in the S. of Engl. in D. 4. By the side of wit we have weet, an archaic form frequently used in the time of Elizabeth and James I, e.g. Spenser, F. Q. : feet, 1. 3.6. In other words, again, analogy or differentiation may have been at work. But in five words, mod. rec. sp. has $i$, the representative of $\mathrm{ME}$. $\bar{e}$, viz. weevil, beetle (unless this is to be derived from OE. bitl, see B-T.) beaker, these, week. In the first three mentioned we might perhaps have rather expected a short vowel, on account of the following $l$ and $r$, but we have similar cases of the absence of back-shortening, e.g. cradel, navel, which have a loug vowel in rec. sp. (ef. however the dialect forms $b r t l$, navl, for instance, in Somersethire, see Elworthy).

$\S 368$. The dialectal forms, as $s i v$, and the forms in rec. sp. weevil, beetle, beaker, these, week, are due, then, to ME. forms with $\bar{l}$ or $e$, and this long vowel was possible in all words containing $\mathrm{OE}$. $i$-, at any rate in sume diall. of ME., but in rec. sp. either there has been a return to $r$ in all but the five words mentioned, or else the lengthening in the ME. dial. of rec. sp. was limited to these five, or they are merely forms which 
have crept into rec. sp. from an outside dial. (northern?). (In the words live and give the vowel can have been shortened through the influence of the forms lived, given, \&c., in which the short vowel is quite in order). That this lengthening existed in ME. is confirmed by a number of rimes in which words that now have $\gamma$ in rec. sp., must then have had a long vowel in the respective diall. in which the rimes are found, and the mod. dialectal forms are a further support.

§ 369. Completer lists than Ellis's would probably contain many more dialectal forms with $\mathfrak{i}$; (the Somersetshire dial., Elworthy, p. 4i, has liv for live, but this is not an example on which much weight can be laid, for there is a tendency in this dial. to turn every $r$ to $\bar{i}$, in closed as well as open syll.). Ellis's general list unfortunately only includes (besides those words in which $g$ or $w$ follows the $i$ ), week, sieve, ivy, her, these, get. . Of these get is of Norse origin (git, also due to northern influence on account of the initial $g$, instead of $y$, is much commoner in dial., get is found chiefly in the N.); these, sieve, week have already been mentioned above; her shows no irregularity in the treatment of $i$ before $r$ when short, it is found, however, riming with long $\bar{e}$ in some ME. texts, e. g. Chauc., here : swere, which proves a long vowel, and, what is more, even an open $\underset{e}{,}$, on account of the following $r$; and $i v y$ does not properly belong here, for it is $0 \mathrm{E}$. ifig, or ifig (see Morsbach, p. 181, Mayhew $\$ 811$ ), it has the diphthong $a i$, $\partial i$ or $o i$ in all the mod. diall., except in the Midland, where, on account of the following $y$, it has been regularly shortened to (ivi).

The form $g \mathfrak{i}$ for give, common to almost all diall., Engl. and Scotch, is also more easily explained from a form $g i v$, i. e. early NE., the ME. would be $g \bar{e} v$; but a complete chronology of the word would make this clear; if our explanation is correct, we should, of course, not expect to find $g i$ before $\bar{c}$ became $\bar{i}$. Still this is not absolutely necessary, for we can derive gis from gifis, 3. sg., just as lüs comes from lufis, loves, and then from $g$ is, by analogy, $g$ i. Ellis gives the forms $g$ in in D. 34 and 39, and (gjiiyn) = giving, in 39; also (leevin) = living, in 39; Murray, DSS., p. 140, gives leeves = (liivz), as the mod. pronunc. of lives in 33.

8 3io. Now for the ME. and MSc. rimes in evidence. In Clar. we have rimes with $0 \mathrm{E}$. $\bar{e} a$ and $\mathrm{Fr}$. ie. The rime-words leave and grieve rime otherwise in Clar. only with words containing a long vowel, viz. previons $\ddot{e}$, and have kept their vowel-length till the present day in rec. sp. and all diall.; thercfore we must conclude that live and give were pronounced by the author of Clar. with a long word, viz. $i$. The orthography with $e i$, leive, geiue, implies of itself an $i$ for the scribe. Fick, who also notices this tendency to lengthening in the Pearl, ("OE. $i$ has become long $\bar{e}$ in a few cases") gives an ill-chosen example, forgete : grete (0E. éa) : retrete, for in forget we have Norse influence again; the original vowel was $e$, not $i$. He says "OE. $i$ had in common with every OE short vowel the tendency to lengthening in open syll.", and then apparently gives it the value $\tau$, (i. e. ME. $i=\mathrm{NE}$. $\partial i, a i$ ), which is certainly wrong. He brings forward examples of rimes with long $i$, e. g. per-ine : lȳne (0E. i) : vyne (OE. $\bar{z})$, but his explanation of this rime seems very questionable. 
Such rimes we must consider, in spite of their comparative frequency, imperfect in quality, rather than suppose that $\gamma$ has become $i$, for which we find no trace in the mod. diall.; the apparent exception (sâi) and (sáil) for sieve in D. 21 and 22, Lancs. and Derby, may perhaps be a different word; Ellis gives (sâi) as being ased in a special sense, = a sieve for milk.

Menze, too, p. 36, speaks of "a tendency to lengthening in open syll., even if the rimes give us no certain proof". t. Br., Chauc, p. 25, gives as examples of his schwebender vokal in open syll. from Gen. Ex. liuen, inf. : bilewen (bi-lōefan), dede, prt. : stede, sb. : childhede, deden : steden, \&c. Brate, AnzfdA. 13.97, gives among his list of $i: e$ rimes some in which $i$ in open syll. rimes with $\bar{e}$; these seem to be confined to the $\mathrm{N}$. and $\mathrm{N}$. Midl.

§ 371. Here follow a few more examples from Sc. and N. Engl. W all., geyff : leyff (sb. = departure) 1. 448, gyff : myscheyff : leiff, sb. : preiff (prove) 2. 206, giff : scheyff (= escheve, escape) 3.263, weite (?= witan, to know, or ask?) : heit (= heat) 5. 346, leyff (= live) : preffe (= prove) 5. 630, leiff (= live) : raleiff 10.724; Gol. geif : encheif $(=$ achieve) 1063, leif (= live) : cheif (vb. "for chance pat may cheif") 1193; Lanc. lewis (= lives, 3. sg.) : prewis (= proves) 1210, geif : leiv (= departure) 1718, if (= give) : relief, $\nabla b ., 1740$, lewyt (= lived) : prewit (= proved) 2174 , lef : eschef (= achieve) 2514 : rapref (= reprove) 3230 ; Dunb. leif (= live) : mischeif 69. 19; Dougl. speitis (= spits, sb.) 2. 229. 19. L yndes. forgeue : leue, sb., Sq. M. 337 , geif : leif (= permission) Sat. 460; David s on (Irving, p. 402) leuis, 3. sg. : neuis (= fists); M a it land (Irving, p. 410) geif : sleif (sleeve) : neif (fist); Satir P. geif : leif : mischeif : preif (= prove) 40.135, leuis : neuis (= fists) 42. 428, geif : greif, vb., 42.834, give : neife 45. 450, leivis, 3. sg. : theivis, teill (vb. OE. tilian) : Commonweill 33. 372, speit.(sb. OE. spitu) : sweit : meit, adj., 33. 3!8; Montg. leiv : bereiv MP. 21. 1, leive: grieve MP. 14. 16, give: prieve : relieve : deiv (= deafen) MP. 33. 42, givis : bereivis 35. 80. - H \&mp. (Ullmann, p. 13) zeue : greue, lyue : greue, gyfe : belyefe, \&c.; Sege Mel. weite (witan) : mete, vb. : grete, vb. : mete, adj., 120. Many more such conld be given, cf. Heuser p. 17, Carstens, p. 12, \&c. Give and live are of most frequent occurrence; a long $e$ is found even in the $S$. in sive, numerons examples of which are given by Bülbring, Gesch. des Abl., who derives from a non-WS. form.

$\$ 372$. For further examples of $\Varangle: \bar{\imath}$ rimes, ef. Bruce, tharin : vyne (win) 15. 93, within : tyne 1.107, Sc. Leg. begyne : lentrine 144/121), Ine : virgine 150,(651, (cf. vergine : lyne, 2/5i); Troj. W. vith-Ine : tyne 2. 235 , vitht-Inne : syne 2. 647. - Sir Tr. inne : sinne : pine : mine (pron.) 2liti9; Sir Egl. (Zielke, p. 15) wete (witan) : tyte; Th. Erc. blyn : syen (stppan) 8; Mass Book, dryue, ptc. : beliue, 84. 28. - Gen. Ex. hire, (pron.) : kive (cȳre) 1694 : shive (vb. subj. pres.) 2036, writen, ptc. : wliten $(O \mathrm{E}$. vlite); this word wliten rimes also with eten, inf., 2290; Launfal (Münster, p. 19) peryn : uyn (win), here (prou.) : sere (Fr. sire); Lyric P. (Schliiter, p. 19) ywis : his : unwis (0E. wis) : ys (= is), is : rys (0E. hrīs) : uys (wis) : pris : bys : his, yn : wyn (win); Partenay (Hatten-

Anglia. $N$ F. $v$. 
dorf, p. 23) therin : Melusine, yn : fyne. Menze, p. 65, gives a number of such rimes from the EMidl. dial.

$\S 373$. Contrary to the observations made ahove as to modern dialectal $i$ for rec. sp. $\zeta$, in one word just the very reverse is to observed, viz. week; here the form wrk, with short vowel, preponderates in all the diall.; $w i k$ is found occasionally in the S., and a little more frequently in the $\mathrm{N}$.

$\S$ 374. There is a Sc. form gleit for rec. sp. glitter, which perhaps belongs here, if we derive from ON. glita. It appears only in rime with $\bar{e}$; in Cla r. when balmie liquore dois on leavis gleit: sweit, 5. Prol. 2.; Do ugl. gletis : streitis, 2. 88. 16, gleit : spreit (= spirit) : sweit : fleit, vb., 1. 33. 18; Montg. all is not gold that gleits : freits (= superstitions, omens) C. 1288, : weitis (nor water all that weitis) MP. 5. 42.

$\S 375$. Now let us look at $\mathrm{OE}$. $u$ - (exclusive of $u+g$, which had a development of its own). Here again back-shortening has sometimes taken place, e. g. in honey, thunder, butter, ruddy, slumber, numb, summer, cuttle, = OE. hunig, punor, butere, rudig, ME. slumeren, OE. genumen, sumor, cudele; in the latter there was also the external influence of Du. kuttelvisch. Or there has been syncope, as in monk, wont $=0 \mathrm{E}$. munuc, gewunod. Perhaps inflected forms have given the decision in crumb, shun, stun, = OE. cruma, scunian, stunian. In the remaining instances, with the exception of nut, $\mathrm{OE}$. linutu, the spelling in rec. sp. points to a possibility of ME. $\bar{o}$, door, love, above, son, come, wood, and the mod. pronun. is perfectly compatible with it too, for with these words we can compare floor, glove, done, gum, good, which are exactly similar in pronunc. to the above in mod. Engl. and all have an $\bar{o}$ in OE., flör, glöf, gedōn, göma, $g \bar{o} d$, which in some of them becomes a short vowel in mod. rec. sp.

$\S 376$. And further, as in the case of $i$, the diall. often show forms with a long vowel, and this generally corresponds to the vowel which represents $\mathrm{OE} . \bar{v}$ in the several diall. But here the $\mathrm{N}$. dues not give the preponderance of evidence, for the short rowel of rec. sp. is extensively found there, and the $S$. offers some examples of long vowel.

One word, above, is found almost everywhere with long vowel, in the forms (abəan, abuun, abiikn, abiun); although the vowel-length might in this case be explained by the loss of intervocal $f$, still it is noticeable that the resulting long vowel is in every instance the same as that resulting from OE. $\bar{o}$, and, moreover, we find the long vowel in forms in which the $f$ has not disappeared, e. g. (abuuv) in D. 18, (aboov) and (abuuv) in 19. The forms with $n$ are not confined to the N. (although they are the only ones found in Sc. and the N. of Engl.), we find (abuun) in D. 5, 20, 22, 24 , and (8bee) in 10, (Bbyy) in 11, without any final cons.; here again with the vowel corresponding to $O E$. $\bar{o}$. love has in Sc. nearly always a short vowel (a) or (o), but (0o) is found in $41,\left(y_{1}\right)$ in 42 , and pret. (luud) in 41; in Engl. we find (luuv) in 20 and 24 , and, what is particularly interesting, (liigv) in 30, where there is no doubt of the origin of the (iiø) being a former $\delta$, cf. below, $\S 463$. The word door it is not necessary 
to derive from OE. dor; it agrees with floor in rec. sp. and in very many of the diall. we find forms with (uu) or (uure, ûs) or similar sounds, in most cases agreeing with floor, which has the same sounds; where $\vec{o}$ is represented by (iir) or (iu), D. 30) and 31, there door appears with (iir) or (iu); the $\delta$ of rec. sp. and some of the diall. is, of course, the effect of the following $r$, and this is the form asaally found in Sc. diall., but D. 33 has (dar), which is probably a development from early MSc $d \bar{o} r$, late MSc. dör. come and son generally have (a) in Sc., but son has also (o) in 38, (ə) and (eé) in 39, (i) in 40 and 41 , some of which sonnds may be from MSc. $\delta<\delta$, and we have traces of $\delta$ in 32, with (oh); come has also (oh) in D. 5, and (nu) in 1,12, 20. wood is only given by Ellis with short vowel in Sc., but this short vowel is $(y)$ in 39 , and (i) in 42 , otherwise (a); in Engl. we generally find $(u)$ as in rec. sp., but D. 5 has (uud), and D. $10\left(\partial_{1} d\right)$, corresponding to $\left(\right.$ st $\left.\partial_{1} d\right)=$ stood. This authorises us to agree with Kölbing and Wuilcker with regard to the rime rode : wode, in WL, VIII. 13, Lyric Songs in MS. Harl. 2253, who quite correctly consider rode as $=0 \mathrm{E}$. $r \bar{o} d$; Böddeker and Schlïter object to this on account of the rime and derive from OE. rudu (see Schlïter, p. 21 and note).

We see, then, that the diall. give decided proof of $\mathrm{ME} . \bar{\sigma}$ in some cases and strong traces of it in others.

$\S 377$. But we have not only the mod. diall. to depend apon; ME. and MSc. rimes give us a valuable confirmation of the lengthening of $u$ in open syll. Those in Clar. will be found below in $\S 500$; we find rimes with OE. $\bar{o}$, Fr. $i \ddot{\text { and }} o$. The spelling, too, with $u i$ is evidence of vowel-length $(=\bar{\delta})$ in the pronunc. of the scribes. The following may be added as a few examples from Sc. and N. Engl. texts: - Bruce, schonand = shunning, 5. 201, aboue, aboun, abovin, abovyn, abowyne, sone (= son) : wone (= wont); no rime of proof, but the orthography, as will be seen below, is of some value as evidence; the verb come appears as com, come, cum, cume. - Sc. Leg. wone (= dwell) : mowne (= moon) 12/578, sone (sunu) : alsone (sōna) 23/618, abone : done 168/556. - W ynt. cum : Rwme 6. 3. 7i. - Wall. abuff : ramuff, remuif (= remove) 1.68, nome (ptc. genumen) : come, prt., 1.124, abuffe : luff : pruff (= prove) : behuff 2. 224, luff : applruff, lufe : apprufe 3. 346. dur (door) : cur (Fr. cure) 4. 234, off buffe, abufe : pruff 5. 230, luffe : pruff 5. 636, luff : ramuff 5. 716 , dur : flur 5. 1112, luff : pruff : abuff : ruff $(=$ rest $)$ 6. 60. (NB. u is generally the representative of $0 \mathrm{E} . \bar{o}$ in Wall.). - Gol dure (dur $u)$ : sture (stōr) 110, gome (OE. guma) 525 (\&c.). - Dunb. abone : redoun : toun (= tune) $81.20:$ done: Scone : vndone 2. $276:$ sone 30. 8. - Du ugl. aboue : remoue : Loue : behuif 1.101.7. Roll. C. V. abufe : vnrufe (= unrest) 2. 446. - Satir. P. luit : muif 26.11, abone : sone 31. 53, abone yame : tone yame 31.134, sone (sunu) : done 33.64, abone: done : sone (söna) : none (= noon) 39. 63, abone : tone : sone : done 39. 313, \&c., \&c. Montg. abune : tune C. 100, (but aboue: Loue, C. 105), abone : tone : sone : mone : done MP. 3.14: tone (= tune, vb.) S. 44.14 (cf. tune : sune $=$ OE. söna, 44.1) : soon MP. 48. 95, luve : commuve : abuve : ruve (vb. = rest) MP. $52.14:$ pruve C. 1593 , love : prove : remove : rove : above : behove : glove MP. 6. 7 \&c. - Surt. Ps. come : dome 24. 9. - Curs. M. 
come : dom 23055. - M etr. Hom. cum : dom 25.5 : kingdom 96. 3, com : gone 95.17 : gom 127. 12. - Horstm. Leg. (N. Engl.) com : dom 28. 106. - Ham p. come : wysdom(e) PC. 144, 149 : dom 263, loues : proues $4^{\mathrm{b}} 42$, loue : behoue $5^{\mathrm{b}} 6$ : reproue $21^{\mathrm{a}} 29$, dore : flore $24^{\mathrm{b}} 1$. $-\mathrm{Sege}$ Mel. sone (sunu) : done : mone : konne 303, gones (gumas) : stones 1288. - Bened. cum : dom 519, 1311 : dome 1899. - Sir Egl. sone (sunu) : done 1265. Sir P erc. wonne: sonne (sunu) : donne 165, wonne : sonne : bygone 349 , wonne : sonne : donne : none 580, wodde (wudu) : stode : fode 180, wodde : zode : gude 193, mone (OE. mune, opt.) : sone : done 567. - Sir Torr. dore (duru) : before 367 , son : Aragon 765, com : kyngdome 1762, sonne (sunu) : done 1801.

Such examples could easily be multiplied; more will be found given by Fick, pp. 16, 17, and Menze, p. 40, who, with some others who have written on Northern and Midl. diall., have noticed this lengthening and recognised the $o$-quality of the lengthened vowel; most of the above quotations (with the exception of the Sc.) are collected from their treatises, from Wackerzapp and the following: Wende, p. 17, Ullmann, p. 14, Dannenberg, p. 17, Zielke, p. 17, Ellinger, p. 11, Adam, p. 12, Schlïter, p. 21, Hattendorf, p. 25. We see from these that the lengthening is not confined to the $\mathrm{N}$., but also appears in Midl. texts.

$\S 378$. Further evidence is given by the orthography and also by the grammarians of the 16 th and following centuries. From Sweet, HoES., I collect the following : - dore, Lay., North. (i. e. Northern Engl.), Wicl. and Chauc., pron. with (oo, uu) Gill, (door) Lediard, Buch., Sher.; loov Cheke, (ua) Smith; son with (o) Bullokar; honey with (o) Buch.; thoner, Ps., Townl. M.; sonien (= scunian) Lay., schones Ps.; stonien (= stunian); wont with (o) Buch., (cf. the usual pronunc. in rec. sp.); nhote (OE. hnutu) Ay., o Prompt.; wo(o)de, Chauc., woode, Tindal.

$\S 37 \%$. In the course of the preceding $\S \S$ we have occasionally hinted at the second consideration, the neglect of which has led to erroneous statements. The long vowel is not found to the same extent in all diall.; as far as our present materials go, it would seem that it is of far more frequent occurrence in the $N$. than in the $S$., but the question requires further investigation before this can be settled; fuller examination of the mud. diall. would probably make this more clear. At any rate the lengthening is certainly to be accepted for the N., both of $i$ - and $u$-.

$\S 380$. In the face of the above evidence it is impossible to agree with Morsbach (p. 181). His first statement against t. Br.'s theory is "that OE. $i$ and $u$ in open accented syll. appear neither in ME. nor in NE. as a lengthened vowel or diphthong". It is true, as shown above, that there is no trace of a diphthongal pronunc., but the vowels are lengthened both in ME. and in NE., and more in dial. than in rec sp. The number of words in rec. sp. with long vowel is but small (the number of words with OE. $i$ - and $u$ - in which there is no disturbing influence is altogether small), five with OE. $i$-, or six if we include weet, and perhaps unly one, viz. door, with OE. $u$. Of the former, three have a $w$ before the vowel; 
if these were the only examples, it would be tempting to seek an explanation in the $w$, as Morsb. does; but would not its influence tend rather to produce $w u$ instead of we? (the forms wuke, wouk, \&c., are found). And M. himself says it is only in open syll. that this $e$ is found (p. 64); wi remains $w i$ in closed syll. And there still remain the words beaker, these and perhaps beetle to be explained, and the dialect forms with $\bar{\imath}$, as $s i v$. Morsbach's by-forms weke, wevel, wete, are quite in keeping with what has been said above, the $e$ represents that vowel $j$ lengthened, nearly, if not quite, = lengthened $e$, as he says, and hence the NE. form instead of $a i$, as he correctly observes.

§ 3₹1. M.'s second argament, (p. 18\%), from the use of $o$ for $u$ is just as much a support for the long vowel as it is against $\mathrm{t}$. $\mathrm{Br}$ 's theory. He shows that $o$ represents a changed $u$-sound, (i. e. the development from $\mathrm{OE} . u,(u)$, which was not very different from $o$ ), in closed syll. as well as open, and in proximity to all kinds of consonants. But because there is no difference in the representation it does not follow that the vowel must be in all cases short; it does away with t. Br.'s argument in his $§ 37$, the 0 cannot be taken as a mark of a "schwebender vokal", but it may be either short or long, not exclusively the one or the other. M. shows clearly that the origin of the $o$ for $u$ is not to be sought in orthographical but in phonetical considerations; it was not originally used for the sake of distinction from accompanying conss., but in order to express the changed sound-value of older $u ; u$ is often written in proximity to $m, n$, \&c., and M. shows in another place (p. 35) that there was no necessity for using $o$ instead of $u$ in proximity to $w$, and in many cases there is no question at all of the surrounding conss. being confused with an $u$. Still, because $u$ in open syll. is only found before $n, m, v$ (according to Morsb., who rejects the word door from this class and seems to have forgotten wood), he allows the preference for $o$ here to be due to this striving after clearness in writing. But, even supposing this were the reason for $o$ being preferred to $u$, what grounds are there for not supposing that in each case the $o$ may have represented that lengthened $\bar{u}$ sound, which was not very different from $\bar{o}$, just as it certainly did in rode? Perhaps it may have been different in different diall., and the later return to $u$ in the orthography and the pronunc. of mod. rec. sp. may be due to some dial. which did not lengthen; or there may have been actually a return to vowel-shortness in one and the same dial. Differences of dial. must be borne in mind in investigating this question.

$\$ 382$. M.'s third argument, from the rimes in Chauc., seems very wide of the mark. Rimes between $\zeta_{-}, \bar{u}$ - and $\tau, \bar{u}$ are, as we have shown, not the ones to be at all expected, and where they appear (examples of $\tau: \tau$ rimes have been given in $\S 372$ ), they are to be considered as imperfect either in quantity or in quality. The rime site (sittan) : wite (witan) is no difficulty; it merely shows that $i$ in open syll. may rime as a short vorvel as well as long; in Clar. we have one example of the short vowel, wite : $z^{i t}$, see $\$ 360$ (c), cf. Wall. wit : sit, 7. 1160; or we might even explain site in the same way as we do live, from inflected forms, sitest, 
siter; in this case the two words sititele and wite are exsctly similar and the rime proves nothing.

$\S 383$. The rarity of rimes in 1 CChauc. to prove a long vowel is due, as we think, to the position of his didiabl. Had he written in a more northern dial., they would have been as nummaerous as they are in northern texts. M. makes mention of the frequent ririnimes in the $\mathrm{N}$. between $\mathrm{OE}$. $\breve{u}$ on the one hand and OE. $\bar{o}$ and Fr. $\bar{\sigma}$ on the other, but prefers to consider them incorrect in quantity and approximatateiely good in quality. Considering the frequency with which they appear, ; ththis is too much to assume, and we must undoubtedly consider them gowood both in quality and in quantily.

$\S$ 384. Another argument of MM.I.'s against vowel-length is "the circumstance that ME. Mss. have no ininsstances of reduplicated vowels as a sign of length". But Clar. and otheheer Sc. texts have, if not reduplicated vowels, the spelling with $e i$, and $u i$, 1 wwhich amounts to the same thing, and in later ME. texts a final $e$ is found $l$ a as a sign of length.

$\S 385$. The single occurrence oof $\mathrm{f}$ an accent on the $u$ in lifian in the marginal notes to the Nthmb. Gospelsls,; (see Bouterwek, p. 258, l. 1) is perhaps not altogether without meaningg; and may be evidence of the early date of the lengthening.

$\S 386$. As result, we have, theienn, the following parallel development of OE. $i$ and $u$ in open syll., as far $:$ ass they are regularly developed:-

$$
\begin{aligned}
& \text { OE. } \mathrm{i}=(i)>\text { ME. } \bar{l}, \overline{\mathrm{e}} \\
& a=(u)>\quad \bar{u}, \overline{0} \\
& >\text { NE. I - e.g. these. }
\end{aligned}
$$

for Scotl. as follows: -

OE. $i$

$$
>\text { early MSc. } \bar{\oplus} \text {, latete : MSc. } \underline{1}>\text { NSc. } \mathbf{i}
$$

u $>\quad \overline{0} \quad->\quad(2)$, \&c., see $\$ 462$.

Before $r$ probably $\ddot{q}$ and $\ddot{e}$ becasanme $\bar{q}$ and $\bar{c}$, cf. door and here : swere in Chauc.

It may be, however, that in sommne Engl. diall. the lengthening never took place at all.

\section{IL ::}

$\S 387$. 1. Not followed by 1 nad, ht, $g$, c - rimes with

a) itself. thing : bring 1. 10992,?, 3. $174:$ sing 1.1186 . I-wis : thus (for this) 1.218, 2.1920: blis(e) 2.133778, 5.988: this 3.1190. will : still 1. 334 (\&c.). wine $(\mathrm{vb} .=$ win) : bberegyne 3. 790 , win : begine 5. 2926. is : blis, bliss 4. 2596, 2860. gift : schiniftft (0E. scift, = trick) 5.2168 - and numberless others, esp. between singg, , bring, thing, \&c. and verbal nouns and partic. forms in -ing. - b) OE.i. I y (later i), see $\$ \$ 540$ (a), 544 (b). - c) OE. e. still : fell 1. 980. flflyynt : hint (OE. hentan) 2. 1138. d) ON. e. will, vb. : dwell 3. 2440. ‥ e) $0 \mathrm{~N}$. $\overline{\mathbf{y}}$ (shortened) see $\$ 550$ (c). - f) Fr. or. Lat. i. thing : bening 1. : 2210 (\&c.) : resing (= resign) 4. 1480. bring : being (for bening) 1.162 : cooususingne 2.1704 : bening (MS. bricht) 2. 1832. sing : bening 2. 1880 . it : : ppromit (sb., influenced by Lat. promitto) 5. 188. wist : resist 3. 294. thhriring : cousigne 3. 388. will : volateill 
5. 2244. - g) Fr. el. bring : ringe ( (rregnare) 4. 2384 . ring is the usual Se. form of this word. - h) Fr. u. t ththis (?) : Clariodus. thus (= this) : Clariodus 3. 1674. - i) Fr. -ble. thainirtrtill : Constabill 5. 2002. (This rime might be included among the imperfecectet, but such rimes are very common with poor versifiers, when a final sysylfll., usually unaccented, to suit the emergency acquires the accent.)

$\S 388$. The rimes in (c) and (d)d) ) are instances of the quite common assuciation of $i$ and $e$ in ME. texts. '] They are not to be considered altogether imperfect, for the $i$ and the : $e e$ were not pure (i) and (e), but, as stated above, $i$ represented a more opjpeen suund than strict (i), approaching to $e$ (in fact, it had in $0 \mathrm{E}$. the same e i value, see EEP. V, 523, II, 510, 525, 573 , and where it has not suffered leleengthening it has remained the same sound ( $i$ ) from $\mathrm{OE}$. times down to ththe present day), and $e$ was often in ME. a more closed sound than strictet t $e$, approaching to $i$. So the rimes might be perfect with a sound intermmoediate between $i$ and $e$, which $\mathrm{t}$. Br., $\S 7$, and others represent by the symmbbols $i, j, i e, \& c .,=$ Ellis's $(i)$, cf. above $\S 364$, where references to otheheser treatises are given. This $i$ is also common to the Northern and Sc. didiahll, as it is to all others, as Brandl has already shown, and the $i$ : $e$ rimmees cannot be explained away by the assumption of different original formsns, $\rightarrow$, as Buss attempts to do with those occurring in the Sc. Leg. In still ll: : fell we can find no authority for stell instead of still, nor for fill instetexad of fell. They are either imperfect rimes, which in the abundance $e$ of examples in all diall. would be very remarkable, or to be considerecedd as perfect with the pronunc. $j$, or perhaps as Brandl, AnzfdA. 13. 102, , ddesignates them, "half-pure".

$\S 389$. The mod. Sc. diall. do 0 i not throw much light on the matter. On the une hand OE. $i$ has become $e e$ e in closed syll. in (med'l) $=$ middle, $($ geld $)=$ to gild, $($ steqk $)=$ stink, $($ s $($ swweqk $)=$ swink, $($ ren $)=$ run, (thres'l)

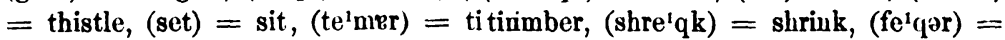
finger, (en) $=$ in, (theq) $=$ thing, (hhaem) $=$ him, (le $\left.{ }^{1} p\right)=$ lip, (kwek) $=$ quick, $($ tel $)=$ till, $\left(\mathrm{fe}^{1} \mathrm{lk}\right)=$ which $, \mathrm{l},($ wel $)=$ will, $\left(\right.$ ge $\left.^{1} \mathrm{f}\right)=$ if,$\left.\left(\mathrm{e}^{1} \mathrm{z}\right) \mathrm{d}\right)=$ is it, (shep) $=$ ship, (kest) $=$ chest; $t$; (in many of the foregoing the $i$-form exists by the side of the $e$-form). ( $00 \mathrm{n}$ the other hand, $\mathrm{OE}$. $e$ has become $i$ or $i$ in (strik) = stretch, $($ biz'm)n $))=$ besom, $($ binsh, bintj) $=$ bench, $($ drintj $)=$ drench, $($ wint $j)=$ wench,,$\quad($ (linth) $=$ length, $($ strinth $)=$ strength, (rist) $=$ rest, (twinty) $=$ twenty; ( (hihere, too, there are often two forms given by Ellis, $i$ and $e$, by the sididee of each other). It will be noticed that the two sounds interchange chibiestly before $n, m$ and $l$.

$\S 390$. Zielke, p. 15, says $e$ b boecomes $i$ in proximity to palatals and dentals in all ME. diall., and that thihivis is very extensive in the mod. diall. of the Midl. and S.; cf. Franz, Engl 5 l. . Stud. 12. 210, and, for the $16^{\text {th }}$ Cent., Panning, Dialektisches Englisch in Elïlivizabethanischen Dramen, p. 32. Brandl, AnzfdA., 13. 102, says $i$ is lowered do $e$ especially before $s, n, r, l$, followed by a conson., and in somewwhhat less degree before single dentals, $n, r$ and $v$. It seems, then, that thdeere were two tendencies, one by which $i$ could become $e$, and another by ? "which $e$ could become $i$, so that both were liable to become $\dot{j}$, the half-wavayy sound between them, thas rendering 
rimes between them possible, and that this sound might then become $e$ in mod. diall. or remain $j$. The laws, if any, by which this was settled, have yet to be found out; at any rate a following palatal was, as the above examples show, decisive for the $i$-sound.

§ 391. zeing, zing. This is not from WS. geong, but from the ONthmb. form ging which existed by the side of the regular giung, gung (see Sievers $\S 157$, Sweet $\S 430$, Hilmer p. 18), just as gind stood for WS. geond. The rime words contain

a) 0 E. 1 , zoung : thing 2.1542 : abasing 1.54 : fighting 1.82 : biding 4. 350 : commoning 4. 1700 : sojorning 5. 2854,

zing : king 1.806 (\&c.) : distelling, ptc. 4.1792 : commoning 5. 526 : beholding 5. 1814,

zeing : king 2. 1626 (\&c.) : luging (= lodging) 3. 410 : clothing 4.965 : sing 3.1252 (\&c.) : thing 3.1264.

b) Fr. 1, zoung : bening 1. 180.

zing, or zeing, is the usual MSc. form, bat it has disappeared in the mod. diall., all of which have the same pronunc. as in rec. sp. with (aq). The scribe in many instances has substituted the other form (English) zoung, but not so often in rime as in the text; there was here some attempt at retaining good eye-rimes, notwithstanding that to the ear of the scribe they were imperfect.

$\S 392$. kist must be derived from $\mathrm{ON}$. kista and not from Angl. cest $=$ WS. ciest, as is shown by the $k$ in place of $c h$; the vowel, too, is then explained directly, without a raising from $e$ to $i$. Murray's dial., D. 33, still has kist for chest, see DSS., pp. 121, 122.

$\S 393$. ges $=$ NE. guess, is generally derived from one of the cognates, MLG. gissen, MDu. ghissen, Dan. gisse, Swed. gissa (see Stratm.Bradl.), but it is strange that in all dialects the vowel is $e$; the word must come from some form (OE. or other dial.?) with $e$-vowel. Clar. has ges : riches 3.804 : doutles 3.2406.

$\S 394$. this and thus are often interchanged in the MS., ef. $\$ 387(\mathrm{~h})$, where this rimes with Clariodus. In other texts we find the same confusion between the two words; e. g. this is written for thus in Sc. Leg. 26/853, D un b. 42. 82., Roll. C. V. 2. 562.

\section{$\S 395$. 2. Before nd - rimes only with}

itself.

fynd : behind 2.1062, finde : binde 3. 1668 .

lynde (OE. lind, lime-tree) : behinde 4. 1772.

$\S 396$. These rimes alone give us no positive evidence as to the quantity of the vowel, but the negative evidence is very important; for whereas there are otherwise rimes in abundance between $0 \mathrm{E}$. $i$ and $y$, before all kinds of consonant-groups, it is before nd alone that the two vowels are kept distinct, which points to a difference of development in this position. This is further supported and confirmed by the evidence of the orthography and of the mod. disll. The occasional spelling with 
$y$ might imply length, ef. $\S 359$; but the $y$ is very rare, in the above six examples it occurs only twice, and in the middle of the verse we generally find $i$, blindit 3.237 , windo 2 . 1309, to-blindit 3. 1796, windis 3.1957 , wind 3. 1965, \&c. On the other hand $0 \mathrm{E}$. $y$ before $n d$ is always represented in Clar. by $y$, inside the verse we always find mynd, never mind.

$\$ 397$. The mod. Sc. diall. show the same difference, as will be seen from the following, summarised from EEP. 5: - OE. blind appears as (blend) 33 (i), (ble $\left.{ }^{1} n^{\prime} d\right) 33$ (ii), (blin) 35, (bli $i_{11}$ nd) 38, (ble $\left.e^{1} n\right) 39 ; 0 E$. rind as (rain' d) 33 (ii), (rand) 38 ; 0E. wind as (wand) 33 (i), 36, (wan) 33 (ii), (wi $i_{1}$ nd) 38 , (we $e^{1} \mathrm{n}$, win, wyn) 39, (wind) 42 ; OE. bindan as (bend) 33 (i), (be'n' d) 33 (ii), (bin) 35, (bi $i_{11}$ nd) 38, (be ${ }^{1}$ n) 39 : 0E. findan as (fend) 33 (i), 37, (fe $\left.{ }^{1}{ }^{\prime} d\right) 33$ (ii), (find) $34,37,42$, (fən) 35 , (fin) 35,36 , (fi $i_{11} n d$ ) 38 , (fe ${ }^{1} n$, fen) 39 , (fin') 42; OE. grindan as (grend) 33 (i), (gre ${ }^{1}$ 'd) 33 (ii), (gran) 35, (gri ${ }_{11}$ nd) 38 , (gre ${ }^{1} n$ ) 39, (grind) 42 ; OE. windan as (wan'd) 33 (ii), (wan, win, wáind) 35 , (wéind) 38, (win) 39, (wind) 42; OE. hind as (hent) 33 (i), (hidmsst, hinmest) 42; OE. behindan as (a-hént) 33 (i), (rhent) 41 . But OE. gecynd appears as (kÉin'd) 33 (ii), (kin) 35, (kéind) 36, 38, (kjain) 39, (kálind) 41 , kindness $=$ (kennys) 34 ; and OE. mynd as (mÉin'd) 33 (ii), (méin, main) 35, (méind) 36, 38, (máin, móind, móin) 39, (má1ind) 41. That is, for OE. $i$ we have a short vowel, but for OE. $y$ the diphthong which regularly represents ME. $\tau$. The few discrepancies in the above must be due to false information on the part of Ellis's authorities, or to the diall. having been subject to disturbing influences.

$\S 398$. Further, it will be seen below that $\mathrm{OE}$. $y$ before nd rimes with $i$ in words of Fr. origin, in which the vowel certainly was long, and which at the present day contain the diphthong $a i, e i, \& c$, in the mod. Sc. diall. So that we may look upon it as certain that the dial. of our author had a short vowel in find, bind, lind, bchind, but a long vowel or diphthong (probably the latter) in mind and kind, and that the dial. of the chief scribe was in this respect exactly similar.

$\$ 399$. It will be noticed from $\$ 397$ that in the Mid and North Lowland diall. more often than not the $d$ is dropped after $n$. This is also reflected in Clar. in the rimes of $\mathrm{OE}$. $y$ with Fr. $i$, ef. $\$ 5.12$ (b). For -ind there is no evidence in this particular, but we shall probably not be wrong in allowing the mod. diall. here to lead us to the assumption that the words find, bind, had also lost, or were losing, their $d$ in the author's dial. 'This is, in fact, one of the special characteristics of the Middle Period of Lowl. Sc., when the Mid Lowl. variety of the Edinburgh division had the upper hand as the language of the court and the literary world; it is, according to Murray (DSS. 28, 53, 121) due to Celtic influence, and has its analogy in the dial. of Barony Forth in Ireland, where loane stands for /and, \&c.; also in SW. Engl., ef. Elworthy, Dial. of W. Sumerset. Some of the rimes which have been reckoned among the assonances, such as $\mathrm{n}: \mathrm{nd}, \mathrm{ng}: \mathrm{nd}$, are rather to be considered as correct in Sc. texts, (final $-n g$ was also liable to drop its $g$ ). Perhaps this throws some light on an obscure passage in K. Q. st. 107, in which we obtain a better sense by taking bynd and as written, and mynes as = myndes, and translate -.. 
with others to bind and to discern their minds (i. e. to tell whether your lady is favourably disposed towards you), that belongs not to me to perform alone (independent of other deities).

$\$ 400$. The other MSc. writers, with the exception of those who are undoubtedly affected by Southern influence, observe on the whole the same difference between $\mathrm{OE}$. ind and $y$ d. It is striking how seldom the words in question appear in rime in some anthors; this is probably due to this very difference in pronunc., which made the Sc. poet's range of rimes much more limited than of a writer in a Southern dial. Bruce has no rimes at all with these words, which is very strange considering the length of the work, over 13,500 lines. In the Sc. Leg. they are rare, but generally regular; an examination of over 17,000 lines (Prologue and Nos. 1 to 26, vol. 1 of Horstmann's edit.), gave as result seven rimes with $i: i$, viz. $23 / 626,70 / 552,77 / 366,85 / 22,171 / i 8,173 / 192,195 / 236$ (eleven if we count four assonances, fynd : mornynge 164/266, bynd : kinge 165/384, bynde : thrynde = thrynge, according to Horstmann, 6/86, fynd : lowynge 170/656), one with $i: e$, viz. fynd : kend 191/984, three with $y: y$, viz. $110 / 220,148 / 470,152 / 822$, on e assonance with OE. ig : Fr. $i$, nynte: Ynde 86/4, only one rime with $i: y$, fynd : kynd 153/890, and one with $y: e$, mynd : wend 128,276. The Troj. War fragments have four $i: y$ rimes, tynde : kynde 1.78,514, 564, wynde : kynde 1.458, one with $i: i$, and one with $y: y$. Can the fact of these rimes occurring at all in the Sc. Leg. and ' 'Troj. W. be used as a further piece of evidence in support of Buss's arguments against the authorship of Barbour?

In $\mathrm{W}$ all. these rimes are also scarce, but perfectly regular, $y: y$ five times and $i: i$ only once, although the poem has no less than 11,853 lines. Gol. has bynde : wynd 440, and kynde : fynd : lynd : bynd 125. Lanc. (3486 lines) has $n$ in e rimes with $i: y, 11.19,197,503,363,1244$, $1426,1910,1984,2008$, one with $i: i, 1606$, and one with $y: y, 1864$. Rat. Rav. (2750 lines) has four rimes with $i: i$, seven with $y: y$, one with $i: y$, fynd : kynd, 1.1780, and five in which the word friend rimes with OE. $y$, kinde 2. 332, vnkind 2. 388, 3. 128, mankynd 3. 54, vnkend (for vnkind) 3. 216. It must be remembered that in this word friend the short vowel is only of recent date; formerly it had, like fiend, a long vowel and in the mod. Sc. diall. we still find frind, frin, but not with diphthong fraind, the comes from a MSc. $e$ (not $i$ ), and it is from ME. frẹnd that the mod. Engl. frend is to be explained. So the last mentioned rimes are impure in quality unless the OE. plur. friend, frȳnd produced ME. or MSc. frind; at any rate they do not break the rule that $\mathrm{OE}$. ynd has a long vowel in MSc.

Du n b. is perfectly regular, only the word Ynd (proper name = India) always rimes with long vowel, with mynd, kynd, strynd. With regard to this word we must remember that proper names are often irregular. Perhaps the length of vowel is due to the nature of the French vowel? Ynde appears in many other texts with a long vowel. Dougl. has $i: i$ 28 times, $y$ : $y 33$ times, OE. $i$ : Fr. $i$ once, wind : Ind 3. 64. 6, OE. $y$ : Fr. $i$ times, mynd $:$ fynd $=$ refined 3. 60. 20, kynd : Inde 3. 201. 24, 
mynd : defynd 2. 252.12, and $i: y$ only three times, rynd: kynd 3.78. 18, myndis : wyndis, 3. sg., 3. 262. 32, mynd : rynd 4. 52. 8. Lyndes. (altogether over 18000 lines) has $i: i 12$ times, $y: y 8$ times, $y:$ Fr. $i 5$ times, (mynde : Ynde 3 times, kynde : Ynde, and mynde : inclynde), OE. $y$ : OE. $z$ once, mynd : pynd, ptc., and twice we find the triple rime kyndis : Hyndis : strandis, Mon. 5022, Dreme 824; here there is evidently laxity of rime in strandis and perhaps also in the other two words. Roll. C. V. (3982 lines) has $y: y 3$ times, $i: i$ once, no rimes with $i: y$. The Satir P. give an interesting confirmation of the difference between OE. ind and ynd in pure Sc. These poems are of a late date (1565-1584), and from their nature, being intended for the people at large and not for an educated class of readers, were likely to be more popular in language and preserve local peculiarities of pronunc. Some of them have very poor rimes, being full of assonances, but the vowels rime for the most part correctly and it is striking that the two classes of words, with one exception (p. 170, unkynde, mynde, strynde, rynde) never rime with each other in those poems which are of Sc. origin, but in three of them, Nos. 1, 9 and 34, which the editor in his preface, p. XII, says are undoubtedly of Engl. origin, such rimes are found, e. g. finde: mynde 1. 28, wynde : mynde 1. 40, 100, blinde : assynde : mynde 1.350, myndes : finde 1.608, mind : find 9.34, kynd : find 34.25, mynd : find 34.67. In the others, genuine Scotch, we meet with such rimes and assonances as the following:cryme : kynde : mynde : Ingyne p. 34, mynde : pynde p. 86, minds : pynis p. 133, mynd : strynd p. 162, kynd : treind p. 231, kynd: Inclynde p. 245, kynd : Inclynd : mynd : defynd p. 256, find : sin : win : burne (for brin) p. 35, and many others with $i: i$ or $y: y$, but only the one single instance mentioned above of $i: y$. With Montg., one of the latest poets of the Sc. literary period, it is only to be expected that Southern influence should be shown to some extent, and in addition to this with his elaborate system of riming, not only at the end of the lines, bat often three times in the middle of the line, it was but natural that he was sometimes at a luss for a suitable rime-word, and often strained a point or two to bring in words which did not make the best of rimes. So we find the rimes: - kynd : fynd p. 31 , behind : pind (= tortured) p. 85 , strynd : kynd: hynd (= deer) : mynd p. 155, Hyndis : kyndis : tyndis (= horns) p. 193. Otherwise we find 13 rimes with $i: i$, a with $y: y$, and the folluwing in which $\mathrm{OE} . y$ rimes with $0 \mathrm{E} . i$ or Fr. $i:-$ kind $: \operatorname{mind}:$ pinde (= tortured) : inginde p.64, Ind : mynd : kynd : pynd p. 119, pynit : unkind : mind p. 133, myiul : pynd p. 147, mynd : defynd : kynd p. 169, mynd: enclynd : pynd: kynd p. 203, inc'ynd : kynd : mynd : pynd p. 218.

It is noticeable that amongst the exceptions the words rind, and hind appear oftenest with the unexpected long vowel, of. also Tayis Bank (Irving. p. 206) mynd : kynd : rynd : hynd, but (p. 207) wynd : wodbynd : lynd : fynd; and these words are given by Ellis 1.291, as having the same sound in NSc. as mind and kind, viz. the diphthung ei or $ə i$.

$\$ 401$. In N. Engl. we do not find this difference observed. Sir'Tr. has kinde : finde 141, 1364, kinde : tinde : finde : linde 511 , kinde : finde: binde : Ynde 2594 ; in the first 10,000 lines of Curs. M. we find $i: i 14$ 
times, $y: y$ twice, $i: y 13$ times and, of these latter, four are only found in the Trin. MS. C.; in the first 6,000 lines of the Northn Leg. we find $i$ : $i$ three times, $y: y 8$ times, $i: y 4$ times $(12 / 90,74 / 690,77 / 16,85 / 400)$ and Ynde rimes with kynde and fynde once each, 20/20, 21/108; Y w. G aw. has find : kynde $957,1035,1051$; Mass B. has also $i: y$ rimes in MS. C. (Northern dial.); Relig. P. mynde: strynde : kynde : fynde p. 85, kynde: mynde : blynde : fynde p. 87.

N. W. Midl. - Sir Gaw. wynde : kynde p. 11, St. Werburge (Chester) has $y: y 14$ times, $y: i 19$ times.

NEMidl. Desp. Body and S.: kinde : minde : binde : blinde 361, A m. kinde : Ynde : finde 760, minde : bihinde : finde 2193, Ipom. mankynde : fynde 503.

$\S$ 402. It appears, then, that in Scotl. the distinction between -ind and $-y n d$ is always observed except in the poems which bear strong evidence of Southern influence, (from the end of the 16 th cent. on very little really pure Scotch poetry is to be found), while in the $\mathrm{N}$. and Midl. the rule is not so strictly observed, and further South there is no distinction at all. Such rimes, then, as the above may perhaps be used, with restrictions, as a test for localising the dial. of Northern ME. texts. At any rate, in all future investigations attention must be paid to these rimes; up to the present all dissertations have simply taken for granted that lengthening has taken place before $-n d$, without separating words with $0 \mathrm{E}$. -ind from those with OE. -ynd.

$\S$ 403. Fick's reasoning, p. 20, requires some modification in the light of the above facts. He assumes for the $\mathrm{N}$. W. Midl. district that in the ME. period there was lengthening before $-n d$, and that in the NE. period there has been a return to the short vowel, for, as he observes, the diall. there show no lengthening of $i$ in ind as a rule. ('The Engl. diall. of the $\mathrm{N}$. all show the same difference between $0 \mathrm{E}$. -ind and -ynd, as the Scotch; brud, frud, \&c., are found with short vowel as far S. as Linculnshire on the East Side, and as S. Lancs. on the West, but mind and kind have everywhere a diphthong). But Fick's only example contains $0 \mathrm{E} . y$, not $i$, kynde : schynde, and the mod. diall. do show lengthening for ynd; so that his theory falls to the ground and the truth probably is, that -ind was ind in the $\mathrm{N}$. W. as well as in Scotl. right through the ME. period, and has never been altered in pure dial., while $\mathrm{OE}$. ynd became -ind there as everywhere else, for which Fick's rime is satisfactory evidence. But, as shown by the examples given above, the ME. texts of the $\mathrm{N}$. and N. Midl. diall. did not always correctly reflect pure dial., or else the treatment of these words gives us a criterion for localising the texts more exactly, -Ind being proof of a more Northern locality.

$\S$ 404. Kluge, PG. 1. 866, sets bindan, blīnd, findan, grindan, wīnd, gecȳnd, as general $0 \mathrm{E}$., with long vowel, and says this lengthening must have been completed at the latest by the $10^{\text {th }}$ cent.; but he also says, "the chronology of these lengthenings (before certain conson.-groups) is very complicated", and again, "not all vowels are to the same degree 
liable to lengthening" and " $n d, n g$ lengthen, as it seems, "only in a few diall'." He brings forward as evidence of the lengthening the frequent use of accents in OE. texts, such as the Blickling Homilies, \&c.; and stress is also laid upon the importance of these accents by Sievers $\S 124$, and Sweet, § 395. The latter says, "the accuracy of the mss. differs greatly", $\S 379$. Sievers says, "the different texts vary very considerably in the matter of the lengthenings, but there are the rule in Lind. and Rushw.".

$\S 405$. Matters would be very simple for us, if we could show that there was no lengthening of $\tau$ before $n d$ in $0 \mathrm{Nthmb}$. But this seems difficult to decide until the whole question of the meaning of the accents in $0 \mathrm{E}$. mss. has been satisfactorily cleared up, although the evidence we have at present leads us to assume that there was lengthening of $i$ as well as of other vowels before $n d$. In the ONthmb. glosses of the Gospels, (Skeat's edition), there are instances in which an accent is placed over the $i$ in ind, viz. uinde (vento) Matt. 11. 7, gebinde 12. 29, wind (ventus) 14. 30; blind Joh. 9. 24, ofblindade (excaecavit) 12. 40; wudu binde Mk. 1. 6, blind 10, 46; blind Lake 18. 35 .

$\S 406$ How are these accents to be interpreted? The accents are, it is true, not used with much regularity; in some chapters they are hardly found at all; in others it seems to have occurred to the scribe to pay particular attention to them and he pats them in very profusely; and in others he seems to have been careful only to mark certain particular words, as ric, tid, éc, which appear very frequently with an accent. Sometimes a word is accented once and appears again in close proximity without an accent; in Joh.12, where we find blind once, there are twelve cases of blind or its inflected forms or compounds without accent in the same chapter. But on the whole the accents appear on vowels which must have been long, as we learn from comparative grammar and the later development of the words in English; where they appear on vowels that can only have been short, Sweet, $\S 381$, explains them partly as "the result of pare carelessness", and it is in many cases possible that "the accent was meant for the preceding syllable" or the following one. In the case of ind it might be considered that the accent was used to distinguish the stroke of the $i$ from those of the following $n$. This would appear more probable if we could find examples of an $i$ similarly accented in words in which the vowel could only have been short. These failing, and an accent being found on other vowels before $n d$, e.g. infaind, Matt. 12. 44, ge-ónduorde 12. 45, hónd 12. 49, énde 13.40, \&c., \&c., in which such an explanation would not apply, we must probably accept vowel-length in ind as well as in ând, énd, ind, und.

$\S 407$. We must not forget the possibility that the accents in the Nthmb. Guspels may be due to a Midl. or Southern revising scribe. If they are not, and if it should finally be proved that there was lengthening before $n d$ in $O N$ thmb., we then have the further questions, when did the shortening take place in the $N$. of Engl., why only in the $N$. and why only in the case of certain vowels? A possible solution may be found in Norse influence, viz. the adoption in place of the vernacular find, blind, 
\&c., of the very similar Norse forms frnd, blthd, \&c., just as yive and toryit were replaced by give and forget. Cf. Klnge, PG. 1.791, "Im allgemeinen scheint sich der mischungsprozess so vollzogen zu haben, dass skand. worte neben den urverwandten engl. platz nehmen und diese dann schliesslich ganz verdrängen.".

Brate, p. 8, prefers other causes than Scand. influence to explain the absence of lengthening in certain words in $0 \mathrm{rm}$.; but none of these, though evidently correct for $0 \mathrm{rm}$., give a satisfactory explanation of these Sc. forms, which do not appear in isolated instances, for, as shown above, all words with original -ind, whether the syll. be unstressed, followed by shortening syll., liable to influence by analogy, or not, show vowelshortness.

§ 408. Ellis, in EEP. 1. $276 \mathrm{ff}$. and 290, misses the point altogether, for he does not separate original -ind from -ynd, but simply classes them together (as has generally been done by all others) and thereby introduces matter which is no support to his arguments. From the fact that bind, blind, find, \&c., still have a short $Y$ in the $N$. of Engl. we cannot argue that in Chanc.'s language they had a short $r$ too, and that therefore the words which rime with them in Chauc, as mind, kind, could not possibly contain a diphthong; they probably did not, but the words bind, \&c., give no argument to prove this; the dial. of Cumb. cannot prove anything for Chauc.'s dial. (Although Ellis does not use these words directly as arguments, he does so indirectly, speaking of thein as "analogies" with mind, kind, Ind). Again, on p. 276, he argues similarly, that kind was pronounced with a short $i$, from rimes with Ind. But, as we have seen above, this word seems generally to have had a long vowel, and, as Ellis says; still has to-day in poetry. He looks upon this as an irregularity due to eye-rimes, and says that, as India has a short vowel, Ind must too. But this is not convincing; Ind and India can stand in the same relation to one another as child and children. That "the nasal pronunc. in French is not indicafed in the numerous words beginning with in-" is also no proof; in most of them the in - is a mere prefix which did not originally bear the stress; and beyond these there is no instance of Fr. ind or in before a voiced conson. which would make lengthening possible, so that analogous cases are wanting. In one word we have int, viz. pint, and here the $i$ has been lengthened and diphthonged even before a voiceless cons. We may probably, therefore, look upon (oind) as the regular pronunc. of Ind, which, either through the rare use of the form or through the influence of India, has been gradually lost, except where it survives in poetry, and this form is regularly developed from the ME. form with $i$. Whether this is to be explained from the nasality of the French vowel, or is due to some other cause, the fact that it did not coincide with the sound in bind, find, \&c., at any rate points to a difference in quality of Fr. -ind from native -ind. The correct interpretation of the rimes given by Ellis, p. 276, as appearing in Chauc., such as kynde: Inde, fynde : kynde : mynde : Inde : bynde : lind, is rather that the vowel in find, bind, lind was lengthened in Chauc.'s dial. and could thus rime with that in kind, mind, Ind, which was long in all diall. 
$\S 409$. In Ellis's D. 1., the dial. of the Baronies of Forth and Bargy, in which, at the time the materials were collected frow which Ellis's lists were made, ME. was still kept pure and not diphthonged to $a i$, we also find $i$ in the words kind, wind, \&c., i. e. both OE. ind and ynd had the long vowel.

\section{$\S 410$. 3. $\mathrm{i}+\mathrm{c}$}

In the prononn 1 pers., the $i$ was originally short, $\Upsilon_{c}$, but it appears already in $\mathrm{OE}$. as $\bar{i} c$, with long $i$, cf. Sievers, $\S 332$, and after this $\bar{i}$, the $c$ became vocalised and absorbed, producing ME. $\bar{\imath}$, without gnttural. The rime words contain

a) $0 \mathrm{E}$. or $\mathrm{ON}$. $\mathrm{i}+\mathrm{g}$. I : ly (vb.) 1. 1086 : ladie 2. 25?, 4. 1746: worthy 4.1354, and many adverbs in $-l y$, $-l i e$, cf. $\$ 413$. - b) $0 \mathrm{E} . \mathrm{e}+\mathrm{g}$. see $\S 164$ (I : say). - c) Fr. i. I : victorie 1.198: melancholie 1. 1030: adulterie 2. 302 : cry 4.1466 : genealogie 2. 308 : companie 2. 964 : chevalrie 4. 1434.

For the pronunc. of this Fr. $i$ in unstressed syll. ef. $\S 415$.

$\S$ 411. 4. $\mathbf{i}+\mathrm{g}$ - rimes with

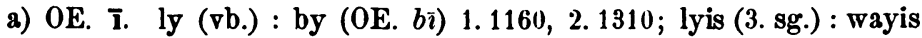
(for wise, cf. $\$ 441$ ) 3: 434, 4. 652 : syis (sipas) 2. 370. - b) OE. i + c, see $\S 410$ (a). - c) Fr. i. nyne (nigon) : defyne 5. 102 : cristallyne 5. 2184. ly (vb.) : companie 3. 1060 . - d) Fr. ei, see $\$ 164$ (by : perfay).

For $i g$ in unstressed syll. see $\S \S 413,414$.

$\S 412$. It is evident that here, as everywhere else, $0 \mathrm{E} . i+g$ has become $i$ through vocalisation of the gutt. and absorption in the preceding vowel, in the same way as $i+c$, see $\$ 410$. The mod. Sc. diall. show invariably the diphthong $a i$, ei or $\partial i$, with no trace of the gutt. and this diphthong had probably been formed already in the dial. of our author, cf. $\$ 432 \&$ c.; hence we read $e i$ or $a i$ in all of the above rimes.

$\S 413$. The adverbial ending -ly or -lie.

This is to be derived from ON. -ligr, -liga, ef. t. Br. \$53. The OE. -lice produced ME. -liche, -leche, which is abundantly found in Southern texts.

'The rime words contain (only a few of the numerous examples are given)

a) OE. 1. quhy : tenderlie :. 504, why : lustillie 4.1922. by : aluterly 2. 910 (\&c.). - b) $0 \mathrm{E}$. $\mathbf{i}+\mathrm{g}$. ly (licgan) : delyverly 1. 56. and numberless rimes with the ending $0 \mathrm{E}$. $-i y$, as worthie : glaidly 4. 52", ladie : greattumlie 2. 1622 (\&c.), \&c. - c) OE. $\check{\overline{1}}+$ c. I : perpetualy 1. 1118 (\&c.). ferlie (fürlic, Angl. fürlīc) : oppinlie 2.780. - d) OE. Ē,

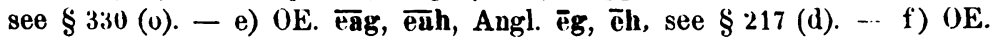
$\Re+\mathbf{g}$, see $\$ 164$. - g) OE. , see $\$ 226(q)$ - - h) Fr. i. cry : suddentlie 3.1662 (\&c.) : fellomilie 1.1256 : petiously $1.98,476$. allay (= ally) : truely 1.410 . victorie : only 1. 240 - and numberless others. - i) Fr. ei, see $\$ 164$. - k) Fr. e. bewtie : heartfullie 3.674 , pitie : cruellie 3.1514 , cuntrie : glaidlie 4. 390, degrie : fullie 5. 781). - 1)? Guy : worthilie 1. 10811.

$\S 414$. OE. ig in the adjectival ending - ie (usually unstressed) has exactly similar rimes, with Fr. $i$ and also with OE. eag, euh, \&c., Fr. $e$. 
$\S 415$. We have evidently to do with two pronanciations here. On the one hand we have rimes with $0 \mathrm{E}$. $\mathbf{i}, \overline{\mathbf{i}}$, which only produced a diphthong, $e i$ or $a i$, and on the other hand with $\overline{e a}, \bar{e}+$ gutt., $\overline{e o}$ and Fr. $e$, which produced an $\bar{t}$ ont of previous $\bar{e}$; these two sets of rimes are irreconcilable without the assumption of two different sounds; and further, we have rimes with Fr. $i$, which resembles $0 E$. $i g$ in likewise producing two pronnnciations, according as it appears in stressed or unstressed syll. Usually, in the words in question, the suffix - lie or -ie was, of course, unstressed and the vowel $i$ was consequently not subject to the diphthonging, hence the numerons rimes with previous $\bar{e}$, which prove for the latter that the change $\bar{e}>\bar{i}$ had already taken place. But when in rime, or for the sake of emphasis perhaps, they became stressed, then they underwent the usual diphthonging, cf. the mod. occasional pronunc. of sure-ly in dial., with (əi). Gill distinctly admitted the double pronunc. of the adverbial ending - ly, cf. Kluge PG. 1. 898, and below $\S 445$; and Murray, DSS., p. 136, shows that the same doubleness exists in the mod. diall., the adv. suffix $l y$, usually $=(l i)$, is "sometimes purposely accented and made (lai), trew-ly = (trau-lai)."

\section{$\S 416$. W ords in -ight, -icht, -yght, -ycht}

The vowel, spelt $i$ or $y$, has in these words various origins: -

1. OE. ie, $\mathbf{i}<\mathbf{e o}=$ Gmc. $\mathbf{i}$, $\ddot{\mathbf{e}} ;$ knight, right, bright, wight (sb. = person), sight, plight, fight, wight (= weight). - 2. OE. $\mathrm{i}<\mathrm{ea}$ (Nthmb. m); night, might (sb. and vb.). - 3. OE. $\mathbf{i}=$ Lat. $\mathrm{i}$; dight. -4 . OE. eo (with later palatisation) $=$ Gmc. $\mathbf{1}$; light (adj. and adv.). - 5. OE. $\mathbf{I}$; alight, vb. - 6. OE. $\overline{1 E}$, Angl. $\bar{e}$, mut. of $\overline{\mathbf{e O}}, \overline{\mathrm{ea}}$; light, (vb.), height. i. OE. $\overline{\mathrm{eo}}$ (with later palatisation) = Gmc. iu ; light, sb. - 8. OE. $\mathbf{y}$, mut. of $\mathbf{n}$; flight. - 9. ONthmb. $\theta$ in redupl. pret.; hight (= was called, heht). - 10. ON. $\bar{\alpha}$; sleight $(s l \bar{\alpha} g h)$. - 11. ON. $\overline{\mathbf{1}}$; wight (adj., 0N. vigt, nent. of $v i g r)$.

$\S$ 417. In Clar. these words rime promiscuously with one another, but with no others, except in the isolated case of plicht : quhyte (0E. $h w z t)$ 5. 910. 'This is clear evidence that the gutt. was pronounced, as is usual in all other MSc. works, and as it still is to the present day in all Sc. diall. There is now no trace of the gutt. in the S. of Engl., where it finally disappeared early in the $17^{\text {th }}$ cent. or at the close of the $16^{\text {th }}$, cf. Sweet, p. 260; its absence is first admitted by Butler (1633); for the evidence of the other early mod. Engl. phonetic authorities see Sweet, p. 259 ff., Ellis, EEP. Pt. 3, and Kluge, PG. 1. 849. It was certainly in existence in some parts of Engl. in the $16^{\text {th }}$ cent. and $\mathrm{t}$. Br., $\S 121$, is probably right in assuming it to exist in Chauc.'s pronunc. and not yet to have become silent as Morsbach p. 101 would have it. Traditional as opposed to phonetic spelling was hardly so far established at such an early date, and according to Morsbach's examples the gutt. was generally written. But in the $N$. it disappeared much later than in the $S$. and in Scotl. not at all; all the authorities have universally recognised it as a peculiarity of Northerners, the septentrionales (Wallis), and the rime 
plicht : quhyte is another instance of Southern influence, or is to be considered as a piece of careless riming or faulty copying of the scribe, as Sarrazin, 0ctav., p. 37, suggests for similar rimes, fy $y_{\bar{\varsigma}} t$ : smyte, and streyght (= OFr. estreit) : ryght : myght; Fick gives tyzt (0E. tiht) : quit (OE. hwit) : crysolyt. The word plight seems in other diall. to have been one of the first words to drop the gatt.; cf. t. Br. Chauc. $\S 121$ plit : appetīt, Hattendorf, p. 24 : disherite : dispite : cite : delite : white : write : site, Zielke, p. 38 tyzt : quit (hwit) : plyt : crysolite, plyzt : delyt; cf. also K. Q. plyte : a lyte 53, Dougl. plite : indite : write : site : quhite, 1. 36. 22, but on the other hand plycht : ficht : micht : vnrycht 1.94. 5.

$\S 418$. It is unnecessary to give a full list of the rimes in Clar. The word of most frequent occurrence is knicht, knight, which rimes with almost every one of the other words in the list in $\S 416$. It is perhaps worth noticing that in this and other words the spelling -ght seems to be preferred to -cht in the $4^{\text {th }}$ and $5^{\text {th }}$ Books; knicht appears 64 times in rime, in Bk. I 23 times, II 27, III 14, knight appears 54 times in rime, in Bk. I twice, Bk. II twice, III once, IV 27 times, V 22 times. With the words bright, wight, night, might it is exactly similar. The only word which decidedly prefers $c$ is dicht, $c 15$ times, $g$ twice. In Books IV and $\mathrm{V}$ knight is only written with $g$, and mostly with a capital $\mathrm{K}$, whereas in Bk. I it is usually written with small $k$; but in this respect II and III agree with IV and V. This probably shows that in a previous copy of the existing MS. (which is the work of one hand) two hands at least must have been at work.

As a rale there is a striving apparent here to make good eye-rimes, and we generally find -icht : -icht and -ight : -ight; bat there are exceptions to this, especially with particular words, e.g. height, which very seldom has $c$.

$\$ 419$. ycht and yght are very rare; ei only appears in height, heicht, weight and twice in leicht. This preponderance of $i$ points to vowelshortness, and the mod. Sc. diall. prove the same, they mostly have a short vowel, $\breve{e}$ or $\breve{q}$, and always the guttural, Ellis's (kjh).

$\$ 420$. Worthy of notice is the rime weight (pondus) : fight 4. 291), where the author must have written an $i$ or $y$ instead of the $e i$ in weight. Here we have the regular development of $\mathrm{OE}$. wiht, instead of the ueight of rec. sp. which is either due to the influence of the verb weigh, or to be derived from the Norse; in the mod. Sc. diall. the word generally has the same vowel as might, right, night, sight. It is strange that here, where we should expect Norse influence to be strongest, MSc. and NSc. show a regular development from the OE. form, and this may perhaps incline us to accept the influence of the verb weigh as the more likely explanation of the noun weight in rec. sp., as is also suggested by the similar spelling; cf. Sweet, p. 303, Morsbach, p. 69 .

$\S 421$. Other words which only appear once in rime are height, prt. $=$ was called (: wight, adj. 5. 1654) and slicht (: knigt, 3. 420). The latter rime gives us the unly instance of -gt for -ght or -cht.

Anglia. N. F. V. 
$\S$ 422. The verbal noun in -ing.

The suffix is found in the OE. period in the form -ing, as well as $-u n g$, therefore it is included here under $z$. The rime-words contain

a) OE. i. cunyng : thing 2.474 : bring 5.1116: ringe 4. 2600 . walkeing : sing 1.1400, and numberless others, also numerous self-rimes as ludging : cherising 4.1166. - b) OE. y - numerous rimes with king. c) Fr. i. feinzeing : benigne 1. 536. having : bening 2. 788. tydings : florings 2.1330. (The word tiding is of Norse origin, but appears in the late $\mathrm{OE}$. period already as tidung, Chro. F. 995, having adopted the Engl. suffix of the verbal noun, instead of the -inde of $0 \mathrm{~N}$. tidinde. The regular ME. form is therefore tiding, and the Sc. form tydand is due to Norse influence, with mere substitution of the Sc. suffix-and.) fainzeing : cousing 1. 1526. imbracing : bening 4. 398. cumjng : bening 4. 2200. loving : conding 5. 2140. crounjng : dinge (dignus) 4. 2406. - d) Fr. ei, only in the word reign which appears as rigne and ringne, for ring, the usual form in all Sc. works, and rimes with thinking 3. 222, cnmjng 3.1818.

$\S$ 423. The Present Participle in -ing - rimes with

a) Verbal noun in -ing (the following lists are complete) - zaiking : fighting 1.1066. ryding : meitting 2.200 : morning 3.2. sitting : tyding 2. 450. distelling : speiking 3. 230 : depairting 5. 2522. leving : regrating 3. 1986. desyring : weiping 3. 2062. inclyning : tyding 3. 2292. schyning : justing 5. 1974. advysing : justing 5. 2092. - b) OE. - ing in nominal stems. thing : asking 1.248 : pertinjng 1.1142 : dwelling $3.1426,4.1914$ : distelling 3.1490 : changing 3.1922 : inclyning 5.1244. bring : cunjng 2. 708 : lying 3.2004 . jing : distelling 4. 1972. king (OE. $y$, later $i$ ) : standing 2.1680 : haistining 3.458 : willing 3.2418 : tending 4.282.

$\S 424$. With the exception that there are no rimes with Fr. i, (probably mere chance), the above are exactly similar to the rimes of the verbal noun in $\S 422$. The form in -ing, instead of Sc. -and, is one of the Southernisms adopted by the author of Clar., and many other Sc. authors who were influenced by Chauc. and the Engl. poets. In Clar. it has to a large extent supplanted the genuine Sc. partic. in -and as will be seen from the following statistics : -

-ing appears in rime 25 times (Bk. I-3 times, II-4, III-11, IV-3, V-4), -and $" 14 n(n-1, n$ n $1, n 3, n 7, n$ 2), -ing appears in the text $508, n(n 84, n 111, n 101, n 121, n 91)$, -and $78 n(n 18 n, 23, n 16, n 14, n 7)$.

From the above are excluded comjing, which appears 11 times for cumin, perf. ptc., and vnwitting, which is written twice for vnwittin, perf. ptc., vnwitting of ony wight, vnwitting of the King Clariodus. In the phrase "with tearis distelling", I take distelling to be intrans., = dropping, flowing, and therefore look upon it as a ptc. and include it in the above. Also in "fra day being", 3. 1035, I take being to be a ptc.

$\$ 425$. Although the suffix -and is fairly on the way to be ousted by -ing (the scribes use it even much less than the author) still it is by no means lifeless; it is, in fact, sometimes used where we find in general 
Engl. and also in Sc. a form in -ing, e.g. tydandis 2.482, tydand : land 3. $6,4.10$, ct. $\$ 422$; there are also many words derived from French present participles in - ant which are spelt with - and. It may be that these latter forms are to be explained from a general tendency to change final $t$, after a vowel-like, to $d$, as in rugend 1.67, and the pret. ordand( $e$ ) (instead of ordanit) : land 1. 700 : stand 2. 1338 : Commande 4. 346 : Ingland 5. 46. Or it may be that the Fr. words were felt as pres. participles, as in most cases there was a corresponding verb also in use, and that then they acquired the ending - and, even in those cases where no corresponding verb existed in Engl., as valiand. We also find -and for Fr. - ain, e. g. chalmerlands 5. 1419; ef. also mundand = nundane 3. 115.

$\$$ 426. Perhaps these last imply that the $d$ in -and has disappeared in pronunc. and consequently often a meaningless $d$ was tacked on to a word ending in $n$. And so it is possible that cumand 4.2331 is also falsely written, like cuming, instead of cumin, the perf. ptc., MS. "day cumand was anone". -ing is used for Fr. -ine in femening : inclyne, 5. 340, evidently due only to the scribe, as the rime shows; -ing may have actually existed in the dialect of the latter, (cf. DSS. p. 135, and the nod. dialectal use of -ing, as in garding, curting, heaving = garden, curtain, heaven), or the $g$ may be meaningless, $n g$ having becume $-n$. Cf. D $\mathrm{n} \mathrm{nb}$. doctring (= doctrine) : spending, \&c., 41. 7 , garding $=$ garden, 3. 16, Montg. burding = burden, C. 329 .

$\$ 427$. The correct Sc. forms were -and for the pres. ptc. and -ing for the verbal noun. When Sc. poets copied Southernisms they, in this as well as in other respects, produced a confused mixture of forms which was qnite artificial and did not exist in any actual dial., as is shown by Skeat, introd. to K. Q. pp. 15 and 34. So here we find the -ing or - and of the pres. ptc., the -ing of the verbal noun, and the -in of the perf. ptc. all confused with each other: but there is no case of -ing being used for the Chaucerian -en of the plur. indic. as in K. Q. Perhaps it is used for the Southern -en of the infin. in telling : king 1.896, "quhen thay hard telling".

$\$$ 428. Here follows a list of the words which have - and for Fr. -ant (where the form is confirmed by rimes, the rime-words and references are given) : -

valiand ( 4 times), (: fand 4.1696 : hand 3.1222$)$, waliand ( 4 times), (: fand 2. 1022 : Northumberland 4. 2084), valzeand (1) (: wnderstand 3. 1226), vailzeand (2) (: Esturland 3. 1414), wailzeand (2), plesand (5), plcasand (4) (: hand 5. 1895), pleisand (2) (: command 5. 898 : land 5. 2414), plesandlie (3), servand (3) (: Ingland 4. 232), seruand (1), servandis (3), avenand (2) (: diamand 1.362 : diamant 5. 2447), aveinand (1) (: land 4. 1545), merchand (3), merchandis (2), marchandis (2), triumphand (3) (: band 4. 2762), triomphand (3) (: hand 5. 1572, 2178: land 5. 2696), trinmphandlie (1), Pursephand (1) (: fand 4.34), Livetenand (1) (: laud 5. 2856), Luiftenand (1) (: strand 5. 2868), cunand (= covenant) (1), briggandis? (1), thimpland? (1). Twice we find -ond in diamond. 
emerand 5.1788 is probably the result of exchange of suffix, ef. emerant, D un b. Gold. T. 39.

For similar appearances ef. Zupitza, Guy p.12, where many rimes between voice-conss. and breath-conss. are given. $Z$. infers from these that the poet was apt to pronounce final voice-conss. as breath-conss., bat the reverse is probably the case at any rate for these words in -ant, -and; the final disappearance of the cons. is in this way better explained.

$\S$ 429. Pres Partic. in -and

inclynand : band 1. 820 : Ingland 2. 436 : strand 3. 944, inclynande : handis (for hand) 4. 2412; dissaveand : hand 3. 1680, birnand : land 3.1442 : hand 4.1556, comonand : Ingland 4. 412, aboundand : fand 4. 748, desyrand : Ingland 4. 1916, abydand : fand 4. 2168, lyand : hand 5. 1302, livand : Irland 5. 2778, commonand : land 4. 744.

(To be concluded.) 